ENHANCING PROFESSIONAL DEVELOPMENT THROUGH CLASSROOM ACTION RESEARCH PROJECTS: A CASE STUDY OF SECONDARY ENGLISH TEACHERS IN PALU CITY, CENTRAL SULAWESI, INDONESIA

BY

Mukrim Thamrin

\begin{abstract}
A thesis
submitted to the Victoria University of Wellington in fulfilment of the requirements for the degree of Master of Education
\end{abstract}

Victoria University of Wellington 


\begin{abstract}
This study explored the experience of five senior secondary teachers in Palu city, Central Sulawesi, Indonesia who participated in a pilot of Classroom Action Research (CAR) project that held by the Provincial Education Office (locally termed as DIKJAR Provinsi) five years ago. These teachers attended a five-day CAR workshop in 2005 and went on to conduct a small-scale project of CAR in their own classroom working collaboratively with other teachers in their schools. The main purpose of this study was consider the benefits and barriers of doing CAR, to understand the nature of support from school principal, colleagues and supervisor that helped the teachers conduct a successful CAR project, to investigate factors that impact on the sustainability of the practice of CAR beyond one pilot over a longer timeframe, and to find out teachers' perception of how CAR as professional development (PD) programme should be effectively planned and implemented. This study adopted a qualitative case study approach. Purposive sampling was used to select the teachers who participated in the CAR pilot for the study. Data was collected through in-depth interviews, brief semi-structured interviews with a closed-response questionnaire, and the collection of policy documents. Interviews were also held with local DIKJAR staff and one of the workshop instructors who provided documents pertaining to the pilot. The thematic analysis of this data revealed that engaging with CAR impacted on
\end{abstract}


teachers' teaching practices, teachers' awareness and better understanding of students' learning problems, and their role as a teaching professional, and their personal and professional development. Some notable barriers that teachers experienced during their CAR project were insufficient knowledge of CAR concepts, lack of advice, lack of assistance from research project collaborators and a time constraint. The study found teachers were well supported by school principals with administrative help as well as recognition of effort. Colleagues provided support as mentors or giving advice. The study also found 3 of 5 teachers continued CAR approaches in their classroom after their first pilot experience, believing CAR is a path toward their own PD; while the other two gave limited knowledge of CAR as the main reason for the lack of motivation to carry on. This study also found for CAR to be a sustainable practice for teachers, such a PD programme should be designed to fit the teaching background and subject area of participants and provide internal (e.g. school principals, colleagues), and external support (e.g. mentors from teacher educators, teacher trainers, and master teachers) as well as the chance to get recognition of their work. The implication of the study for facilitating teachers to grow professionally through CAR is discussed. 


\section{Acknowledgement}

First and foremost, many thanks to the Almighty God "ALLAH SWT" for His mercify and compassionate. My sincere thanks to my supervisor, Barbara Craig, for her insightful supervision of this study, specifically for her valuable feedback during the completion of this study. I would also like to thank the NZAID - New Zealand's International Aid and Development Agency for full financial support of my study.

I address my special thanks to the five teachers of senior secondary schools in Palu City, Central Sulawesi, Indonesia, who willingly took part in this study. Many thanks also go to all the Indonesian students in Wellington, the Indonesian Muslim community in Wellington, and Indonesian Embassy staff in Wellington for their valuable support, prayers and words of encouragements during my stay and study in New Zealand.

I would like to thank my parents, brother, sister and all my family for their endless love, support, prayer and encouragement. Without it, I would not have been able to complete this thesis. Finally, my profound thanks goes to my beloved wife "Athink" and my cute daughter "Nissa" who accompanied me during my stay in Wellington and shared their joys and laughter when I found difficulties with my study, as well as supported me with their words of encouragement, patience, and prayer for the success of my study. For my loving family, I dedicate my work. 


\section{List of Figures}

Title

Page

Figure 1 The structure of Indonesia's Education System

Figure 2 Map of Central Sulawesi

32

Figure 3 Action Research Model of Kemmis and Taggart

\section{List of Table}

Table $1 \quad$ Curriculum difference of 1994 and 2004

18

Table 2 Research data-reference

92

Table 3 Workshop content and hours allocated 


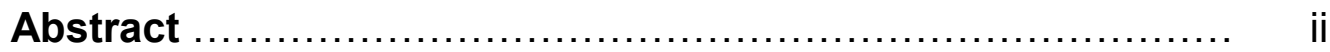

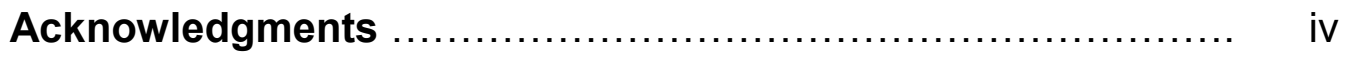

Abbreviations and Acronyms …............................. xiii

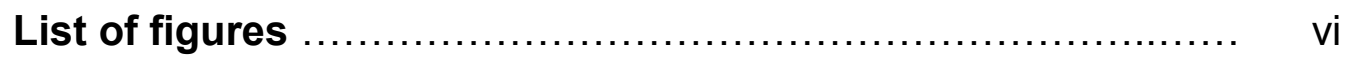

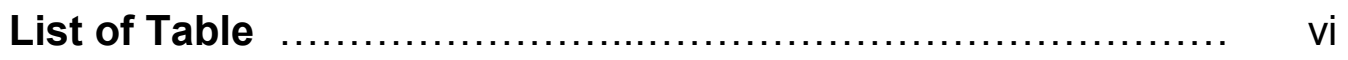

\section{Chapter 1: Introduction}

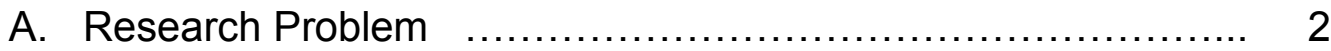

Teacher's professional development ...................... 2

Action Research as a PD tool for teachers .................... 3

Rationale of the study ........................................ 5

Action Research in Indonesian School ..................................... 7

Studies of CAR in Indonesia .................................. 8

Action Research in schools of Palu city ........................ 9

B. Context of the study: Education System and Teacher

Professional Development in Indonesia

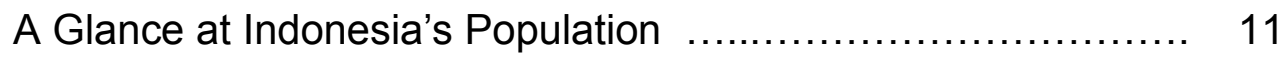

Education System of Indonesia .................................. 12

Reform in Education ...................................... 14

Teacher Status in Education Reform .......................... 21

Teacher Certification ........................................ 23

Teacher Competencies ..................................... 25

Continuous Teachers Professional Development ................ 25

CAR as a Teacher Professional Development tool: government policy ............................................................ 28

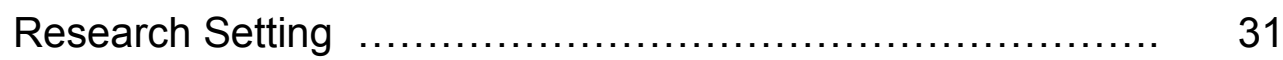

Education Profile of Palu City ................................. 33

Purpose of the Study ............................................. 34

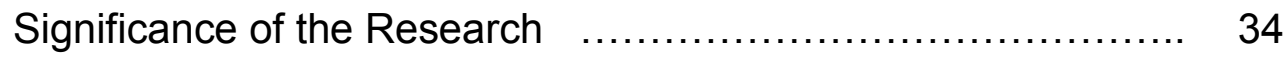




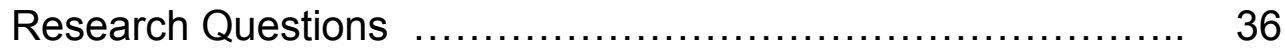

Brief Overview of the Research ............................... 37

Chapter Summary and Organisation of the Thesis ............. 38

\section{Chapter 2: Literature Review}

What is Action Research? .......................................................... 40

Action Research Applied to Education ............................... 43

Definition of Action Research Applied to Education ................... 45

Why Action Research is Important for Teachers? ................... 47

Classroom Action Research (CAR) ............................... 49

Criticisms of Action Research ....................................................... 53

ESOL (English for Speaker of Other Languages) Teachers'

Perception of Doing Action Research: Benefits and constraints ....... 54

CAR and the Reflective Practice: New professional development

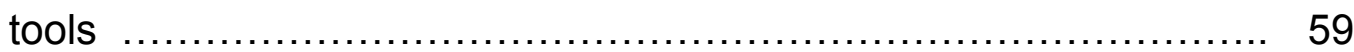

CAR as a means of PD .................................................. 59

Collaborative action research ................................... 61

Reflective practice and classroom action research ............... 63

Teachers Learn to Research: Some models from other countries ... 65

Facilitating and Sustaining Teachers to Do CAR .................... 68

\section{Chapter 3: Methodology}

Research Design .................................................. 73

Theoretical Framework …............................................. 74

Context and Setting: Brief overview ............................... 75

Negotiating Entry .................................................. 77

Consent from Teachers …...................................... 80

The Role of the Researcher and the Relationship with Participants .. 80

Research Sample ................................................... 81

Description of the Sample ............................................ 82

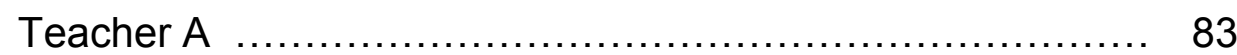

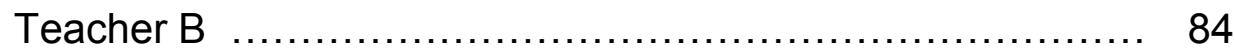


Teacher C ..................................................... 84

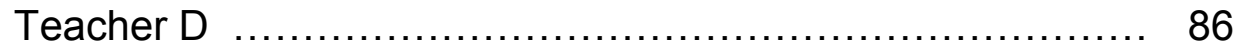

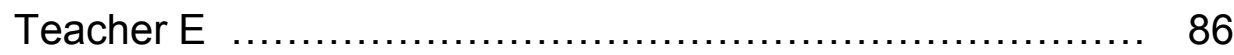

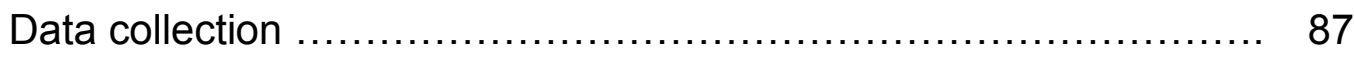

Questionnaire .................................................... 87

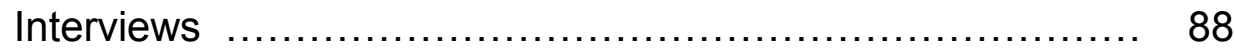

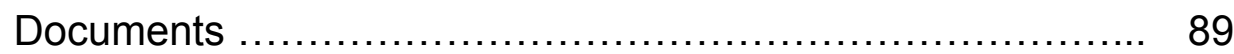

Gathering Data from Trainer and Education Officer .................. 90

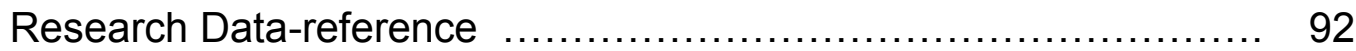

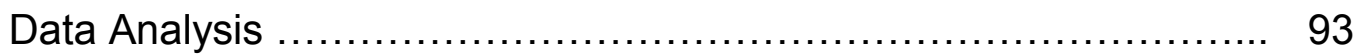

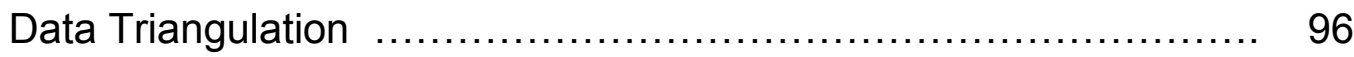

Validity, Reliability and Trustworthiness ............................. 97

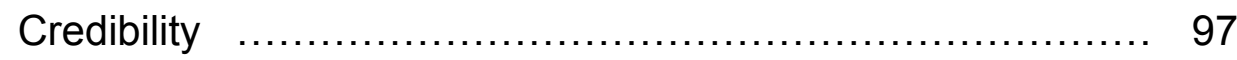

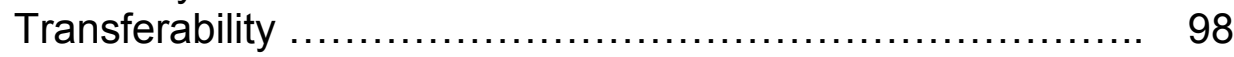

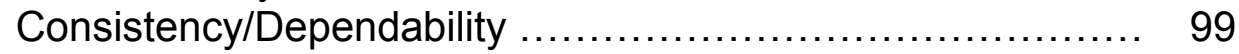

Research Ethics ................................................. 100

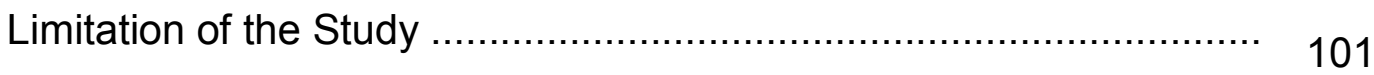

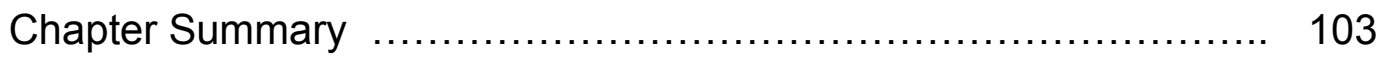

Chapter 4: The Classroom Action Research pilot case study

A. CAR Workshop .................................................... 104

The workshop key player …............................... 104

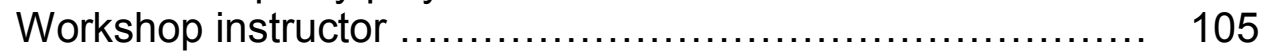

Rationale of the workshop ............................... 106

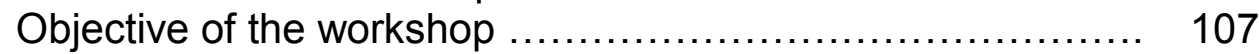

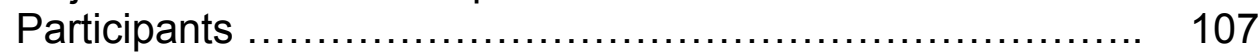

Location of workshop ........................................ 108

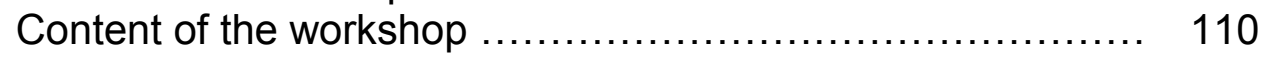

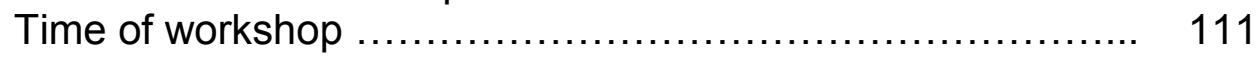

Workshop mode of learning ….............................. 112

B. Conducting CAR Project Following the Pilot ....................... 113

Objective of the pilot research project ......................... 113

CAR scope of study ........................................ 114

Expected outcomes of the pilot ................................ 114

The pilot process ............................................... 115

Collaboration in CAR ...................................... 116

CAR Proposal Phase ............................................ 117

Action Phase .......................................... 118 
Evaluation of workshop and pilot …........................ 119

Follow-up program after pilot ............................ 119

The CAR Pilot Project: Lessons Learned …..................... 121

5 CAR Reports: Teachers' topics ............................... 123

The CAR topics and their rationales ............................ 124

Teacher A ............................................ 125

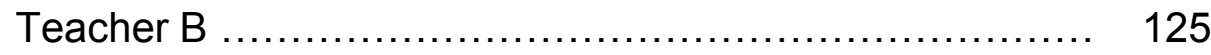

Teacher C ........................................... 125

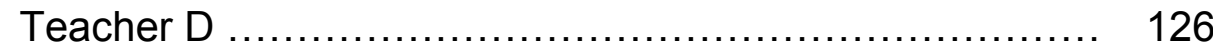

Teacher E .......................................... 126

Procedures of Doing CAR: How teachers did their action? ...... 123

Teacher A ............................................... 127

Teacher B,C, and D ..................................... 128

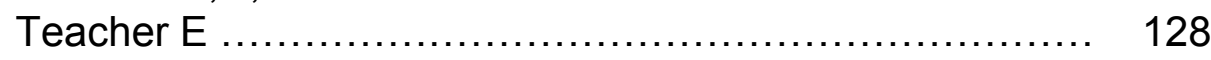

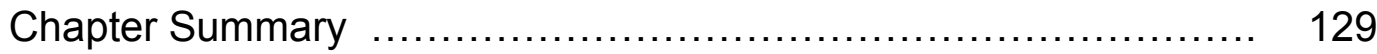

\section{Chapter 5: Findings and Discussion}

A. Teachers Experiences of Classroom Action Research .......... 131

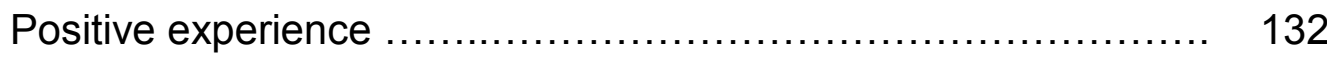

How CAR benefited to teachers' teaching practices?..... 132

CAR's impact on teachers' awareness .................... 136

CAR helped teachers to learn and to develop as professional teachers................................... 139

CAR as a Venue for Learning .................................. 140

CAR helped teachers to learn to grow personally....... 142

Teachers' negative experiences of doing CAR .................... 145

Insufficient knowledge of doing CAR .................... 145

Lack of advices from mentors ............................ 148

No assistance from collaborators ....................... 150

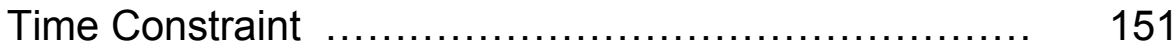

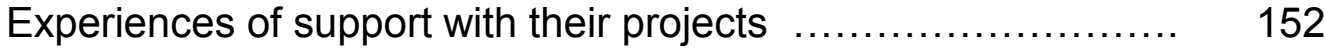

Support from Principals ................................... 153

Support from Colleagues .................................. 155

No Support from supervisors ........................... 156 
Discussion: CAR as a Tool of Professional Development.

Benefits of CAR for teachers

Challenges faced by teachers in doing CAR 157

The role of support for teachers ...................... 162

B. Factors Influencing Teachers' Decision to Continue with CAR

Teachers' motivation to do CAR projects ............... 168

CAR as professional growth $\ldots . . . . . . . . . . . . . . . . . . . . .169$

Support factors $\quad 169$

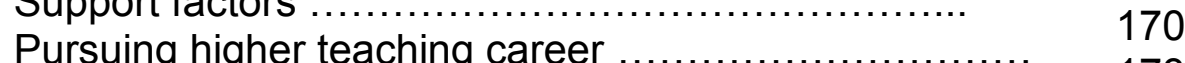

173

Why teachers decided not to do more CAR project: Stories of Teacher B and C.

Discussion: (1) Teachers Continue to Do CAR: What motivated and supported them?

CAR as a path to professionally ........................ 177

Supporting teachers to continue do the CAR ............ 178

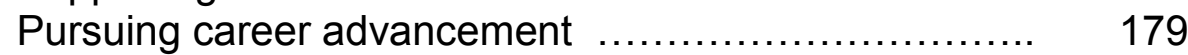

What Impeded Teachers not to Continue Doing CAR after their first Project?

C. Teachers' Recommendation about CAR as a PD programme ...

How should CAR workshop/training be designed?

CAR content designed for specific subject teachers

School-based workshop

Empowering MGMP (Teacher Network Group of Subject Teacher)

CAR Project Programme

Supervision

School community support

Funding and Reward

Discussion: Facilitating Teachers Learning CAR and Sustaining Doing CAR Project

Facilitating teacher learning CAR 


\section{Chapter 6: Conclusion and implications}

Conclusion of the Study ........................................ 201

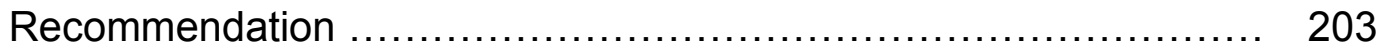

Implications of the study ........................................... 204

Issues for Further Research ..................................... 207

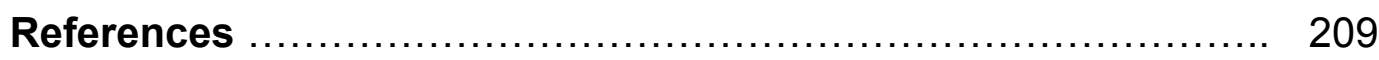

\section{Appendices}

Appendix 1: Interview Guide ............................................ 225

Appendix 2: Questionnaire .................................... 229

Appendix 3 : Quided Questions Informal Interview with the Education Officer

Appendix 4 : Quided Questions Informal Interview with the Instructor.

Appendix 5 : Participant Information Sheets for Teachers ............. 233

Appendix 6: Sample of Consent Form ................................ 236

Appendix 7: Consent form of Gaining Document .................. $\quad 238$

Appendix 8: Research Inform to School Principal .................. 239

Appendix 9: Letter of Information to the District Education Office ... 241

Appendix 10: Letter to Participate for Educational Officer ............. 243

Appendix 11: Invitation Letter to Participate for Workshop Instructor 245

Appendix 12: Informed Consent Form for Educational Officers and 247 Workshop Instructors

Appendix 13: Participant Information Sheets for Teachers (in 249 Indonesian)

Appendix 14: Consent Form for Participants (In Indonesian) .......... 252

Appendix 15: Information Letter for Principals (in Indonesian) ........ 254

Appendix 16: Information Letter for Palu city DIKJAR (in Indonesian) ......................................... 256

Appendix 17: Ethics approval letter ….......................... 258 


\section{ABBREVIATIONS AND ACRONYMS}

\begin{tabular}{|c|c|}
\hline AR & Action Research \\
\hline CAR & Classroom Action Research \\
\hline DIKJAR & $\begin{array}{l}\text { Pendidikan dan Pengajaran (Education office in } \\
\text { province and district area) }\end{array}$ \\
\hline MENPAN & Menteri Negara Pemberdayaan Aparatur Negara( \\
\hline LPMP & $\begin{array}{l}\text { Lembaga Penjaminan Mutu Pendidikan (Education } \\
\text { Quality Assurance council) }\end{array}$ \\
\hline MoNE & Minister of Education \\
\hline MoRA & Minister of Religious affair \\
\hline TL & Teacher Law \\
\hline MGMP & $\begin{array}{l}\text { Musyawarah Guru Mata Pelajaran (Secondary School } \\
\text { subjects teachers' working) }\end{array}$ \\
\hline PD & Professional Development \\
\hline INSET & In-service Training \\
\hline SMP & $\begin{array}{l}\text { Sekolah Menengah Pertama (Junior Secondary } \\
\text { School) }\end{array}$ \\
\hline BERMUTU & $\begin{array}{l}\text { The Better Education through Reformed Management } \\
\text { and Universal Teacher Upgrading }\end{array}$ \\
\hline SBM & School-based Management \\
\hline BPS & Biro Pusat Statistik (Central Statistic Bureau) \\
\hline CBC & Competency-based Management \\
\hline KTSP & $\begin{array}{l}\text { Kurikulum Tingkat Satuan Pendidikan (School-based } \\
\text { Curriculum) }\end{array}$ \\
\hline HDI & Human Development Index \\
\hline TIMSS & Trends in International Mathematic and Science \\
\hline
\end{tabular}




\begin{tabular}{|c|c|}
\hline PISA & Program for International Student Assessment \\
\hline NE & National Exam \\
\hline SBC & School-based Curriculum \\
\hline GDP & Gross Domestic Product \\
\hline LPTK & $\begin{array}{l}\text { Lembaga Pendidikan Tenaga Pendidikan (Teacher } \\
\text { Training Institution) }\end{array}$ \\
\hline$P P G$ & $\begin{array}{l}\text { Pendidikan Profesi Guru (professional teacher } \\
\text { education program) }\end{array}$ \\
\hline NUPTK & A unique teacher and education staff number \\
\hline KKG & $\begin{array}{l}\text { (Kelompok Kerja Guru), elementary teacher working } \\
\text { group }\end{array}$ \\
\hline BAPEDDA & $\begin{array}{l}\text { Badan Perencanaan Pembangunan Daerah (Regional } \\
\text { Development Planning Board) }\end{array}$ \\
\hline SMUN & $\begin{array}{l}\text { Sekolah menengah umum negeri (Public Senior } \\
\text { Secondary School) }\end{array}$ \\
\hline ESOL & English for Speaker of Other Languages \\
\hline PNS & Pegawai Negeri Sipil (Employed-State official) \\
\hline
\end{tabular}




\section{CHAPTER 1}

\section{Overview of the Research Problem and Indonesia Education System: Setting the Context}

This chapter provides a brief background to the research and describes its importance to both the researcher and to the field of education in Indonesia. The research problem is discussed and the research questions defined in relation to the problem. The theoretical framework that has guided the research project is described as is the motivation to conduct this project. This chapter also reviews the state of the current Indonesian education system. Several laws have been recently passed that are believed to improve Indonesian education management and quality such as the Regional Autonomy Law of $22 / 1999^{1}$, the Education Law No. $20 / 2003^{2}$ of National education system and the Teacher Law of 14/2005. It discusses the Indonesian education system and reforms in education in the areas of school management and curriculum. It also discusses the policy that the government has implemented in relation to upgrading teachers' competencies and professionalism, mandated by Teacher Law. In particular, teacher competencies, teacher certification and continuous professional development are presented. At the end of the chapter the outline of the

\footnotetext{
${ }^{1}$ The law issued in the reform era of the Indonesia government which gives more autonomy to provincial and district levels of government to manage public sector.

${ }^{2}$ Further explained on page 15.
} 
thesis is provided with a brief overview of the contents of the chapters that follow.

\section{A. Research Problem}

Teachers' professional development. Teachers need to upgrade their knowledge and teaching repertoire throughout their careers by enrolling in various professional development in-service training programmes. It is argued that by increasing and improving professional knowledge, skills, attitudes and capabilities in a defined area, they will be able to more effectively educate children (Bolam, 1982). In addition, preservice training cannot provide all the knowledge and skills required to succeed in the classroom given that the curriculum and approaches to teaching are constantly changing in response to new research and government policies (Richards \& Farrel, 2005).

Various in-service professional development (PD) programmes are offered to cater to the needs of teachers to enhance their professional development. These include options such as: attending workshops run by professionals outside of school, school-based workshops, taking part in teacher support groups, peer coaching and classroom action research (CAR) projects (Richards \& Farrel, 2005). The particular focus of this research is to investigate the potential of classroom action research as an in-service professional development tool. Johnson (2008) maintains that 
teachers grow professionally through participating in action research as it provides the opportunity for teachers to reflect on their practices and make changes. In addition, research does indicate that the more traditional inservices courses such as a "brief one-shot workshop without follow up", (Ponte, 2005, p. 274), do not provide enough time, activities, or content to develop teachers' knowledge or affect their practices (Birman, Desimone, Porter, \& Garret, 2000). The purpose of this study is to determine the extent and the kinds of changes in practice that teachers attribute to the reflective features of classroom action research.

Classroom Action Research as a PD tool for teachers. Hendricks (2009, p. 9) defines CAR as "A form of action research that is conducted by teachers in their classroom with the purpose of improving practice". Action research can be a tool for teachers' professional development (Burnaford, 1996; Johnson, 2008; Mertler, 2009; Zamorski \& Bulmer, 2002). Teachers who engage with action research can learn and grow from this process (Burnaford, 1996) and become more reflective (Mertler, 2009). However, the path to development through action research is not an easy one for teachers. Very often teachers experience challenges such as technical issues (e.g. time constraints) and personnel issues (e.g. group dynamic with collaborators (Cole and Knowles, 1993), or research skill and financial issues (McKernan, 1996) during their involvement with action research and as a result they do not continue to practice action research in their classroom after their first experience (Rayney; 2009; Volk, 
2009). In addition, the absence of support from their school administration, colleagues, and expert mentors becomes another issue that may impede teachers' willingness to engage in action research (Borg, 2006, 2010; Calhoun, 2002; Tinker Sachs, 2000).

Another issue related to teachers who do action research is the sustainability of the practice (Burton, 2000; Volk, 2009). In order for action research as a professional development tool to promote sustainable changes for teachers, there should be on-going support from school leaders, providers of PD, and local educational authorities, and long term and intensive PD programme (Burnaford, 1996; Calhoun, 2002; Lim, Pagram \& Nastiti, 2009). Moreover, to facilitate and sustain action research practice for teachers, it is essential to consider the conditions of the workplace, teacher, and the project itself (Borg, 2010).

This current study investigates teachers who participated in a CAR project which has been introduced to teachers in Indonesia since the year $2000^{3}$. It is believed this type of action research is relevant with day-to-day teachers' work where they are required to reflect on their practices and improve them, as well as being beneficial for teacher professional development (PD) and effective school reform (Hinchey, 2008; Manfra, 2009; Zeichner, 2009).

\footnotetext{
${ }^{3}$ Further explanation is on page 7 of this chapter.
} 


\section{Rationale of the Study}

My personal interest in exploring action research as a potential tool to enhance teachers' professional development was triggered by several reasons.

First, my interest has been driven from my own personal experience of engaging with a CAR project. Ten years ago, in the first year of my teaching career, I took part in a CAR project called the Junior Secondary Education Enhancement Quality. This project which was conducted by the Provincial Education Office (locally termed as DIKJAR or Dinas Pendidikan dan Pengajaran) of central Sulawesi of Indonesia in 2000 and funded by the Asian Development Bank (ADB), aimed at enhancing the quality of junior secondary teachers through various PD programmes such as CAR projects. I was at the time on the teaching staff in a Junior high school (known as SMP or sekolah menengah pertama) in Palu city. I attended a workshop for English teachers (around 70 participants) in Palu city that aimed to improve teaching practice and teach innovative strategies for solving classroom issues using the CAR approach. Following the workshop, I implemented the CAR concept into my classroom collaboratively with one of the teachers in my school who did not participate in the CAR workshop. We met to discuss and reflect upon our students' problems in learning English that we needed to improve. For instance, based on our reflection and data collection which revealed that 
students experienced difficulty in both speaking and writing English because of possessing insufficient of English vocabulary, one of our projects was to develop the students' English vocabulary. From this early reflection, we developed a strategy using various types of picture techniques to enhance students' vocabulary possession using a CAR approach. At the end of our project, we found students' vocabularies grew larger and they were able to use them in written and spoken tasks. From this experience, we found that CAR was effective to solve the teachers' teaching problem in the classroom as well as to help students to learn better. Moreover, I found personally that CAR helped me to grow as a teacher.

My interest has been further heightened by my postgraduate study. The positive benefits of CAR for teachers become clearer for me when I took some courses related to professional development when completing my Master of Education (M.Ed) studies in Victoria University in 2009. Most of the coursework I completed related to professional development and I learned that teachers should continuously be involved in reflection to develop their personal growth. One of the tools that potentially enhance this capacity is by engaging in classroom action research project.

The third reason for my interest in CAR arises from the current policy (Minister of Administrative Reform or MENPAN decree of 16/2009) of requiring CAR to be offered as a PD programme for teachers. As an 
Indonesian teacher, this policy, launched by the Indonesian government, related to the teachers' professional development is of great interest to me. Since the issue of Teacher Law (TL) $14 / 2005^{4}$, which aims at improving the quality of teachers in Indonesia, CAR is, in fact, required as a tool of teacher professional development. This policy is expected to lead to national support of teacher professional development through CAR practice in Indonesia. Therefore, it is a very important context to investigate the relevance of CAR as a tool for teachers in Indonesian PD today.

Action research in Indonesian schools. Action Research (AR) has currently become a major topic and learning objective both in preservice and in-service training of teachers in Indonesia, where CAR is the main research approach that teachers are taught in workshops and training courses, and which teachers are then expected to apply in the classroom. In Indonesia, the history of action research is relatively new. It was first introduced on a large scale to junior secondary education in 2000 in some provinces under the Junior Secondary Education Enhancement Quality project initiated by the Ministry of National Education (MoNE) and funded by the Asian Development Bank (ADB).

\footnotetext{
${ }^{4}$ Teacher law is issued by government to respond to the low quality of education in Indonesia through imposing various programmes that enhance the quality of teachers' performance as well as their welfare.
} 
In the context of in-service training, CAR is introduced mostly through a top-down mode in which policy makers (such as the provincial Education office and the Educational Quality Assurance Council (EQAC) locally named as $L P M P$ - Lembaga Penjamin Mutu Pendidikan) take the initiative to run training or workshops. During these short training courses teachers learn how to do CAR and most of the materials are presented by instructors from local universities or competent teacher trainers. Following the implementation of school-based management in 1999 as a new paradigm of education management, many schools, nowadays, take the initiative to run in-house training where CAR is the core subject of the training. Furthermore, currently, due to the assistance of international donors such as the World Bank and the Government of Netherlands, CAR is promoted intensively to the basic and junior secondary teachers under the BERMUTU (The Better Education through Reformed Management and Universal Teacher Upgrading) ${ }^{5}$ programme (Jalal, et al., 2009).

Studies of CAR in Indonesia. The study of teachers engaging with CAR is very limited in the Indonesian context. Moreover, most of the studies that do exist (e.g.,Burns \& Rochsantiningsih, 2006; Sukarni, Winarni \& Nirmayanti , 2009) took place in Java Island (normally termed as the western part of Indonesia) which, compared to areas outside Java Island, generally has more advanced and skilful teachers, more fully equipped schools, available experts advice, and easy access to education

\footnotetext{
${ }^{5}$ The BERMUTU programme is broadly explained in page 27 on this chapter.
} 
journals. This current study addresses this gap by exploring the experiences of teachers in the Sulawesi island context, specifically in Palu city, Central Sulawesi Indonesia, during the time they were engaged in a CAR project pilot in 2005-2006 and following the pilot. This study, therefore, adds to the limited number of studies of teachers involved in action research projects in their classrooms in the Indonesian context.

Action research in schools of Palu city. In the geographical context within which I conducted my study (specifically in Palu, Central Sulawesi, Indonesia), CAR was first introduced to junior secondary teachers (year 7-9 teachers) in 2000 under the Junior Secondary Education Enhancement Quality project which was funded by the Asian Development Bank (ADB) held by the provincial DIKJAR. During this time, CAR was taught in in-service teacher workshops and following these workshops, teachers were required to do classroom projects. Furthermore, in the pre-service context, teachers who were continuing their study, learned to do CAR in university and were required to conduct a CAR project. Their CAR project report then became a part of the requirement to obtain their bachelor degree. Currently, a similar practice is applied to teachers of English completing their master's programme (run by the state local university), whereby they must conduct a CAR project and defend their thesis as requirements for study completion (personal communication, master's student, November, 2010). 
However, at the senior secondary level (year 10-13), CAR was first introduced much later. The first CAR pilot was conducted by the provincial education office only in 2005-2006 (the participants of this pilot were the sample in my study) ${ }^{6}$. At that time, 150 senior secondary teachers participated in a CAR workshop to learn how to do a CAR project in their classroom. Following the workshop, DIKJAR offered grants for teachers who intended to do a collaborative project in their classroom for which they had to submit a research proposal. This grant was competitive and given only to 100 researcher teams (each collaborative team consisting of two or three teachers) whose eligibility was decided by the proposal examiner team. Those teachers who received the grants did the CAR projects at their own schools and in the end of their project they had to submit the CAR projects' report to the grant provider (in this case, the Provincial DIKJAR of Central Sulawesi).

Following that year, other institutions such as the education quality assurance council of Central Sulawesi (locally termed LPMP or Lembaga Penjamin Mutu Pendidikan) held other CAR in-service training workshops for secondary teachers in 2008-2009. However this CAR training was not followed by the requirement of participants to do CAR projects in their classrooms (personal communication, LPMP staff, October 2010). Hence, it was difficult to expect the participants to retain CAR knowledge without them being given any chances to experience it through action (Garet et al,

${ }^{6}$ Further background information about the CAR pilot is provided in Chapter 5. 
2001) as well as expecting teachers to grow professionally through CAR projects.

\section{B. Context of the study: Education System and Teacher Professional Development in Indonesia}

\section{A Glance at Indonesia's Population}

Indonesia is the world's largest archipelago country that consists of 13.500 islands which 6000 are inhabited. The largest islands are Java, Kalimantan, Sumatra, Sulawesi and Papua. The total population is 206.264.595 (BPS statistic Indonesia, 2000) which comprises more than 350 ethnic groups that speak more than 583 local languages and dialects. However, Bahasa Indonesia, declared as a national language in the 1928 Kongres Pemuda (Youth Congress) is the official language. The largest ethnic group is Javanese which make $39.4 \%$ of Indonesia population. Other ethics groups are Sundanese (15.8\%), Malay (12.1\%), Maduresse (4.5\%), Minang (2.4\%) as well as some smaller ethnic groups that together comprise $26 \%$ of the total population. Islam is the biggest religion and is practiced by $88 \%$ of Indonesians, followed by Protestantism (5\%), Catholicism (3\%), Hinduism (2\%), Buddhism (1\%) and others (1\%). Currently, there are 400 regencies (rural districts) and municipalities (autonomous cities), 33 provinces, and 350 ethic gr.ups in Indonesia. 


\section{Education System of Indonesia}

Indonesia education system is based on Pancasila ideology (five principals of national ideology which are: belief in the one and the only God; just and civilized humanity; the unity of Indonesia; democracy guided by the inner wisdom in the unanimity arising out of deliberations amongst representatives and social justice for all of the people of Indonesia) and the 1945 Constitution. The right of education for all citizens is stipulated in the 1945 Constitution of Indonesia, Article 31, Section (1), which states that each and every citizen shall have the fundamental right to education and further mandated in educational law, presidential and ministerial decree. In 1989, Indonesia's government launched the National Educational System Law which rules:

1. Articulation of rights of citizens to obtain education regardless of sex, religion, ethnicity, race, social status and level of capacity; and to be treated in accordance with her/his talents and interests;

2. The improvement of compulsory basic education from six to nine years;

3. Decentralization of curriculum with provision for local content and adjustment of national content to local situation, environment and needs; and

4. Establishment of the National Education Advisory Board (Yulaelawati, 2002). 
Moreover, the new Educational Law of 20/2003 of the national education system has improved the above Law by articulating that education shall be free from any charges; schools are given discretion in managing their own programs; community participation are encouraged; education finance shall be based on number of students instead of number of schools; and the obligation of government to assign at least 20 percent of the national budget to education.

The level of education in the school system of Indonesia consists of basic education, middle or secondary education, and higher education. Basic education consists of six years of Elementary School and three years of Junior Secondary School, which was declared as Nine-year Compulsory Education by the President of the Republic of Indonesia on May 2, 1994. Middle or secondary education consists of three years of schooling at General Senior Secondary School or Vocational Senior Secondary School. At the higher education level, non-degree programmes start from diploma 1 (one-year programme) to 4 (four-year programme); degree programmes consist of a bachelor programme (a four-year degree programme), a master degree (two-year post bachelor degree programme) and a doctoral program (three-year post masters degree program). Preschool education is also provided to prepare children to enter elementary school.

The school system in Indonesia recognises the secular stream schools (public or private) under the supervision of the Ministry of National 
Education (MoNE) and the Islamic schools (public or private) under the supervision of the Ministry of Religious Affairs (MoRA).

Below, the structure of Indonesia's education system is presented.

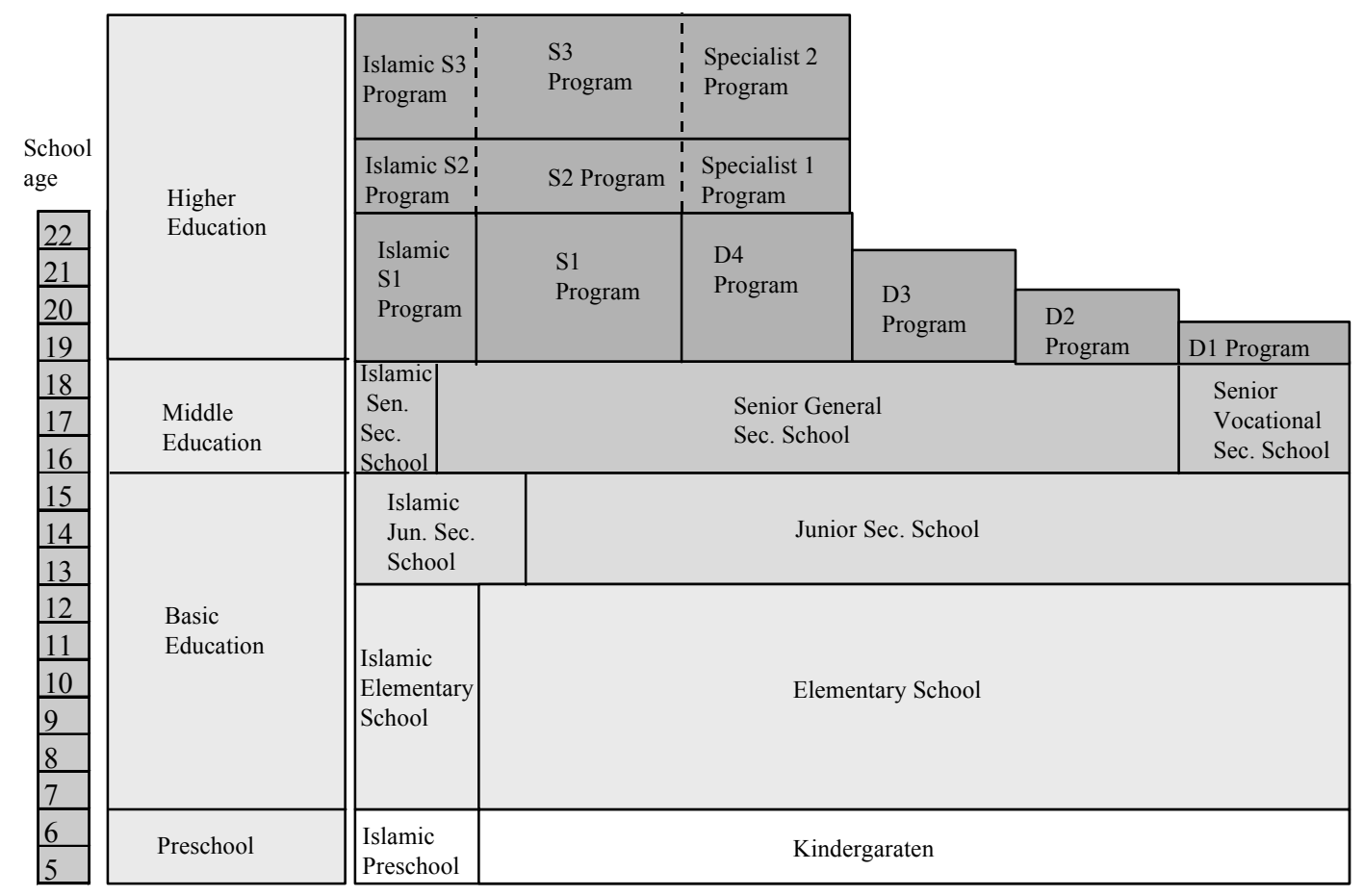

Figure 1: The structure of Indonesia's Education System (Source: Mohandas, 2004)

\section{Reform in Education}

Until the implementation of decentralized policy in 1999, following the declaration of freedom from Dutch colonial administration in 1945, Indonesia had operated under a centralized policy throughout the entire Sukarno administration (1945-1965). Following Sukarno, Suharto took the leadership for 32 years (1966-1998). During this era, the central government (based in Jakarta, the capital city) had powerful authority to 
manage its public sectors including the education sector. For instance, in the education sector, the Ministry of Education administered and decided all details of education matters such as appointing principals and teachers, managing in-service training for teachers, establishing curriculum, students' text books, budget allocation for school etc. (Sumintono, 2006). However, this era ended as marked by the stepping down of Suharto in 1998 following a wave of demonstrations by university students triggered by a monetary crisis in Asian countries and Indonesian in particular.

Following the resignation of Suharto in 1998, reforms in many sectors, including the education sector, have been imposed by the new government. During the Reform Era, post-Suharto administration, Indonesia has elected four presidents: B.J. Habibie (1998-1999), Abdurrahman Wahid (1999-2001), Megawati Sukarno Putri (2001-2004), and Susilo Bambang Yudoyono who won the office twice (2004-2009) and (2009-to the present day).

The prominent change during the first year of the Reform Era is the issue of Regional Autonomy Law 22/1999 which regulates the authority of the region. This new law emphasizes the decentralization of authority from central government to district governments in sectors such as "health, education and culture, agriculture, communication, public works, industry, trade, capital investment, environment, land, cooperatives, and manpower affairs" (Jalal \& Musthafa,2001, cited in Sumintono, 2006, p. 35). As a consequence, for the education sector in particular, central government no 
longer has full control of the education in the regions. The new government regulation, PP 25/2000, article 2, verse 10 (Government of Republic of Indonesia, 2000) stipulates that central government holds authority only in the following matters:

- setting standard for all age student achievement (i.e., competencies), setting the national curriculum and setting national examination/assessment system, as well as issuing instruction of these;

- specifying standards for learning materials;

- determining requirements for achievement and use of academic titles;

- determining a grade/set of standard for educational operational costs;

- determining requirements for admission, transfer, certification for students from all age of groups; and

- organizing and developing higher education, distance education and international schools.

(Cited in Sumintono, 2006, pp.35-36).

Moreover, in article 3, verse 10 of PP 25/2000, the provincial government holds broad authority to:

- determine policy on students' selection and acceptance with regards to equity issues. That is, policy regarding minority students, students from poor families and remotes areas;

- contribute to the provision of main study books/educational materials for kindergarten, primary, secondary and special education;

- assist in higher education management, except related to curriculum, accreditation and appointment of academic staff;

- consider the opening and closure of college; and

- manage "special schools" and training centres, including teacher training institution.

(cited in Sumintono, 2006, p. 36).

The decentralization policy in the level of governance has significantly

influenced the policy in education management and curriculum in 
Indonesia (Raihani, 2007). It was marked by introducing "Manajemen Berbasis Sekolah" or school-based management (SBM) in 1999 and "kurikulum berbasis kompetensi" or Competency-Based Curriculum (CBC) in 2004.

SBM was introduced to respond a World Bank report in 1998 which revealed that the education performance in Indonesia was poor and recommending that one of the strategies for school quality improvement was to give more autonomy to schools to manage themselves (Jalil \& Mustapha, 2001, cited in Sumintono, 2006). Furthermore, this report also asserted that education management was very centralistic in that the central education authority had control over virtually every aspect of schooling while subordinate authorities at provincial and district levels had to implement the policy from central (Raehani, 2007). In relation to SBM, Umaedi (2001, cited Raehani, 2007, p. 175) states that it gives the schools great responsibility in managing "learning and teaching process, school programme planning and evaluation, curriculum and development, staff management and recruitment, recourses and facility maintenance, finance management, students service, school community partnership, and school culture development". Given this broader authority management of school, principals and teachers are required to possess leadership, professionalism, initiative, and creativity (MoNE, 2003 cited in Raihani, 2007). 
Studies have reported that the implementation of SBM in Indonesia has improved the quality of education in the area of student achievement (Caldwell, 2005), improve teaching and learning English (Yuwono, 2005), and makes school better places for children (Bengeteku \& Haywardm, 2007, cited in Bandur, 2008).

CBC was introduced by the Indonesian Education Ministry in 2003 and implemented in 2004. This CBC is well-known as Kurikulum 2004 (the 2004 curriculum). Compared to previous curriculum which was "materialoriented, overloaded with content, and centralist in its development" (Jalal \& Supriadi, 2001, cited in Raihani, 2007, p. 177), the 2004 curriculum places emphasis on standardized competencies for students to achieve and provides large authority for school stakeholder to get involve in curriculum (MoNE, 2003 cited in Raihani, 2007). The following table shows clearly the differences between the 2004 curriculum and the previous one (the 1994 curriculum).

Table 1: Curriculum difference of 1994 and 2004

\begin{tabular}{|c|c|}
\hline 1994 curriculum & 2004 curriculum \\
\hline $\begin{array}{l}\text { - Centralist } \\
\text { - Contains no standardized } \\
\text { competencies } \\
\text { - No activities to familiarize } \\
\text { students to content and } \\
\text { concepts } \\
\text { - No ICT (information and } \\
\text { technology) } \\
\text { - Multiple choice assessment } \\
\text { - Thematic approach for grades }\end{array}$ & $\begin{array}{l}\text { - } \text { Decentralist } \\
\text { - } \text { Contain standardized } \\
\text { competencies } \\
\text { Integrated and programmed } \\
\text { activities to make students } \\
\text { familiar with content and } \\
\text { concepts } \\
\text { - Introduction of ICT } \\
\text { - Classroom-based assessment } \\
\text { Thematic approach for grades }\end{array}$ \\
\hline
\end{tabular}


$1 \& 2$ students of elementary school (recommended only)

- No continuity of competenciess

- No curriculum diversification

- Syllabus developed by the local education authority or school depending on needs
$1 \& 2$ students of elementary school (compulsory)

- Continuity competencies stratification from grades 1 to 12 (over school levels)

- Curriculum diversification: special and international curricula

- Giving opportunities to teacher, schools, and local authority for program elaboration and adaptation or analysis of materials.

Adapted from Raihani (2007, p.178)

To implement this curriculum, MoNE has provided guidelines for teachers to be successful in effective teaching and learning management. It is suggested that teachers need to be creative and posses great responsibility in implementing this competency-based approach. Furthermore, more recently the government has issued the Education Law No.20/2003 of the National education system which also emphasises the competency-based curriculum and autonomous education management. Following this act, the government issued the improvement of the 2004 curriculum called "Kurikulum Tingkat Satuan Pendidikan (KTSP) or schoolbased curriculum (SBC) in 2005 which gives more authority for each school to develop their curriculum based on characteristic of local region, source potency, local socio-cultural factors, and the characteristics and needs of learners (MoNE, 2007).

Zainurrahman (2009, p. 9) argues that "KTSP is designed to increase the quality of education and because the heterogeneity of the 
school, society, resources, students, teachers and so on". However, each school must develop curriculum or education should refer to the government policies in conjunction to the standard of content and standard of competency (MoNE, 2007). To implement the KTSP curriculum requires teachers to have a great deal of resources, teaching methodology, and competencies when dealing with students (Zainurrahman, 2009).

Although KTSP curriculum is regarded as the best option for empowering school stakeholder in order to achieve an improved quality of education, Toenlioe (2006) asserts that it also has dysfunction. He sees, for example, an inconsistency in KTSP whereby schools have the authority to expand or elaborate the core curriculum produced by the government; however the students' success is completely determined by national evaluation conducted by the government. He suggested that, ideally, the government should only set the general frame of education goal; competency content, strategies and evaluation, and the detailed development of ready-to-use curriculum is given fully to schools. Nowadays, the subject of national evaluation (or national exams-NE) has become a debate between Indonesian scholars and government about whether NE should be decentralized to school levels or centralized in which the students' success is determined by central government.

The current decree No.45/2010 issued by the Ministry of Education seems to accommodate the pressure of the public by considering the students' mark gained from school formative evaluation. Under this new 
decree that will become effective from April 2011, students' success in NE will be determined by a combination of their exams result in NE $(60 \%)$ and their final exam from school (40\%).

\section{Teacher Status in Education Reform}

The low quality of Indonesian education still remains a problem for the Indonesian government as evidenced by its low rank in the Human Development Index (HDI) and low ranking achievements in international testing, particularly in science and mathematics (Jalal, et al., 2009). A 2005 UNDP (United Nations Development Programme) report of human development puts Indonesia's HDI rank at 110 among other Asian countries which is lower than that of Japan (11), Singapore (25), Brunei (25), Malaysia (61), Thailand (73), Philippines (84), and Vietnam (108) (Hendayana, 2007). In addition, its participation in international survey such as Trends in International Mathematics and Science (TIMSS) and Program for International Student Assessment (PISA) also depicts similar result: respectively Indonesia was ranked $30^{\text {th }}$ and $40^{\text {th }}$ among the participant countries (Jalal, et al., 2009).

Moreover, another problem with education in Indonesia is the low teacher qualification. Nowadays, of 2.7 million teachers in Indonesia, only one million meet current qualification requirements and 1.7 million need education upgrading - most of these are primary school teachers who 
work in remote areas with little access to higher education (Jalal,et al., 2009). Current policy requires all teachers should have a minimum qualification of at least four years of post-secondary education or S1 degree (equivalent to a bachelor degree). MoNE (2005) reported only $15 \%$ of primary school teachers currently hold an S1 or D4 degree. For junior and senior secondary teachers, the number of under-qualified teachers (teachers who do not have a bachelor degree) is $40 \%$ and $23 \%$ respectively.

In response to the above situation, the Indonesian government issued Act No 4/2005 on Teacher and Lecturer (hereinafter called Teacher Law) to provide a great deal of incentive for teachers to improve their qualifications and professional skills (Jalal, et al., 2009).For teachers, this new regulation mandates that "(1) all teachers and school managers must have at least S1/D4 (equal to bachelor degree) qualification and subsequent performance certification, (2) in-service up-grading will be provided through a new program, managed and delivered by accredited University education departments, (3) innovative in-service teacher education delivery system will be introduced, and (4) performance based incentives for teacher will be introduced, linked to achieving academic and professional credentials and willingness to work in more difficult and remote areas" (World Bank, 2007, p. 144). 


\section{Teacher Certification}

New Teacher Law (TL) mandates that teachers must be certified in order to receive professional allowances that doubles their salary. The certification participants are both government and non-government teachers with a minimum education level of a bachelor's degree or four year Diploma (S1/D4) who teach in all level of schools. The certification is implemented through a portfolio and self-appraisal assessment in which teachers must provide documents which show their competencies in line with set criteria such as length of time of service, age, rank, teaching load, position/extra tasks, recognition, and work performance (Jalal, et al., 2009; Kartadinata, 2009; Sulaksono, et al., 2009). The certification is carried out by lecturers from the Teacher Training Institution (locally termed as LPTK) who are specifically designated as assessors by the Teacher Certification Consortium.

By 2009 , nationally, the number of teachers who have passed the accreditation is $50 \%$ out of the eligible teachers, and those who have not succeeded gaining accreditation must attend a 90-hour course of professional teacher education program (locally termed as Pendidikan Profesi Guru or PPG ) which is conducted by LPTK in each province (Jalal, et al., 2009; Kartadinata, 2009). This course aims at developing teachers' competency and professionalism in the area of subject content, teaching methodology, and teaching practices, (Jalal, et al., 2009). At the end of programme, they sit a written and practical test to get certified without 
being required to re-submit their portfolio. Anyone failing this test still has a chance to take another test or undertake further training by the education district office (Jalal, et al., 2009).

Teachers who have passed the certification program both from portfolio and PPG are awarded a Professional Teacher Certificate and receive registration number called Nomor Unik Pendidik dan Tenaga Kependidikan or NUPTK (a unique teacher and education staff number) from the Directorate General of Quality Improvement of Teacher and Education Personnel to get incentive for their profession (Kartadinata, 2009).

However, teachers who do not hold a bachelor's degree are sent to in-service education in local LPTK in each province. For remote area teachers, a distance learning education program is set out for them. By 2010, there are 81 LPTKs throughout Indonesia, all of which assigned to hold in-service education for teachers to obtain their bachelor's degree (Kartadinata, 2009).

Furthermore, based on the new law, pre-service teachers who want to enter the teaching profession, must attend two semesters of professional training that focus on pedagogy and teaching methodology in the appropriate subject areas to obtain training credits and pass the certification test (Jalal et al., 2009). 


\section{Teacher Competencies}

The new TL has defined the level of competence required for the teachers to meet the certification standard. There are four main competencies that must be possessed by certified teachers: pedagogical, personal, professional and social competencies. Jalal, et al., (2009) explain that pedagogical competence covers such things as understanding students, designing and implementing learning strategies, study result evaluation, and professional development; personal competence relates to personality, leadership qualities, and nurturing of students; professional competence relates to subject mastery, teaching method repertoire, learning methods, knowledge and understanding students' behaviour, knowledgeable about both social and general science; and social competence relates to having good behaviour, interesting personality, and good moral values.

The above standards have been embedded in all pre-service and in-service training since 2006 and incumbent teachers are required to improve their competency through various types of upgrading pathways (Jalal, et al., 2009).

\section{Continuous Teachers Professional Development}

Following the adoption of the TL, developing teachers' professionalism has become a central issue in conjunction with addressing the problem of 
students' low achievement. It is regulated in the TL draft that "the teacher must have opportunities to develop and enhance their academic qualifications and competencies, and receive professional training and development in their field on an on-going basis" (Jalal, et al., 2009, p. 45). Furthermore, as mentioned in section 45 of TL, the teaching competencies can be enhanced through "a system for sustainable guidance and development of the teaching profession that recognize the achievement of functional-position credits" (Jalal, et al., 2009, p. 45). According to Jalal, et al. (2009) teacher can gained the credits from variety of activities as below:

a. teachers' collective activities to enhance their competencies and professionalism;

b. education and training;

c. collective activities to enhance their competencies and professionalism;

d. scientific publication on research results or innovative ideas;

e. innovative works;

f. presentation on scientific forums;

g. publication of textbook verified by the National Education standard agency;

h. publication of enrichment books;

i. publication on teaching handbooks;

j. publication on practical experiences in special education; and/or

k. rewards for achievement or dedication as teachers awarded by the government or regional government. (p. 45)

One of the new pathways which aims to support and facilitate teachers professional grow comes from expanding existing teacher working groups (locally termed KKG and MGMP) at the district level in each province (Jalal, et al., 2009). The KKG (Kelompok Kerja Guru or elementary teacher working group), and the MGMP (Musyawarah Guru 
Mata Pelajaran or secondary subject teachers working group) are professional development network that exist at local level which help teachers in self-improvement activities through weekly meeting at which problem in pedagogy are discussed (Hendayana, 2007; Jalal, et al., 2009). Previously, the above working teacher groups emphasised their activities on creating lesson plans and developing test items (Hendayana, 2007). This group also experiences a lack of support and funding to sustain its activities (Jalal, et al, 2009). Under the new programme, Better Education through Reformed Management and Universal Teacher Upgrading (BERMUTU) funded by Word Bank and the Netherlands government (project 2008-2014), teacher's developments are expanded in the level of the KKG and MGMP. BERMUTU programme establishes a modular learning package to improve the knowledge and skills of teachers at the local level and aims to strengthen and extend the working group structure. It is expected this program will become a self-sustained professional development (Jalal, et al., 2009).

The BERMUTU programme is set out in six activities: (a) school curriculum and lesson plan development; (b) test development, analysis and test item banking; (c) Classroom Action Research (CAR); (d) subject materials and clinical review; (e) teacher mapping and performance evaluation; and (f) study visit, internship, and teacher exchange program (Jalal, et al., 2009). Jalal, et al. (2009) identify further provisions and requirements across the programme as including: 
a. the above activities take place within subject content;

b. the focus is on the improvement of classroom teaching effectiveness and students achievement;

c. it is a structure program;

d. regular meetings are conducted by the KKG and MGMP each year;

e. the provision of funds to support activities;

f. monitoring system is applied periodically; and

g. recognition of teachers' success in the program.

Unfortunately, the BERMUTU program has not yet covered all teachers in Indonesia. To date, this programme has been implemented in 75 districts/cities in 16 provinces of 33 provinces in Indonesia.

Furthermore, teachers from elementary and junior secondary schools get more priority than those in senior secondary education (the focus of my study); this aligns with government policy to enhance basic education as mandated by the education law No. 20/2003.

\section{CAR as a Teacher Professional Development Tool: government policy}

It is no doubt that the quality of teaching skill impacts on the quality of education (Fullan, 2001). This is acknowledged and reflected by the Indonesia government issuing of the Teacher Law 04/2005 which aims to enhance the quality of education in Indonesia through the mechanism of developing the quality of teachers. Under this law, teachers gain a professional award under the mechanism of formal teacher "certification". To be certified "a teacher must have a four-year college or university 
degree, accumulate sufficient credits from post-graduate training, and teach a minimum of 24 hours per week" (World Bank 2010, p. 8). This law has also mandated that teachers must have four competencies: pedagogical, personal, professional and social competence (Jalal, et al., 2009).

In conjunction with the above policy, classroom action research (CAR), which is believed to be an impetus to develop teacher professional development, has been embedded as part of any in-service teacher training. Furthermore, teachers can use their CAR report for certification purpose. Moreover, under the current policy (MENPAN decree No.16/2009) teachers are further encouraged to get involved in CAR by the prerequisite that all teachers produce a scientific work which can be in form of a CAR report or articles for career enhancement purposes.

In terms of teachers' career enhancement, the previous policy (MENPAN decree No. 84/1993) had obliged teachers to do tasks based on their profession which are: (1) education, (2) teaching and learning, (3) professional development, and (4) supporting activities of teaching and learning. For those teachers who have successfully.completed all the four tasks, credits were given for the purpose of career enhancement which ultimately affected their salary or income - the higher their career was, the more salaries or incentives they received (Widoyoko, 2008). 
However, the process of teachers gaining a high level in their careers had not run smoothly. Most teachers in Indonesia got stuck in a certain rank ${ }^{7}$ (rank IV/a or master teacher) for years and found difficulties in moving on from this rank. Teachers were obliged to gain more credits from the professional development tasks, one of which was to write a scientific work (such as research report, article, book, translation products) (Widoyoko, 2008). Many teachers found it difficult to accomplish the above tasks due to the fact that most were not familiar with the required writing culture; this was compounded with the low level of reading habit (Roza, 2008). Data shows out of 2.6 million teachers in Indonesia, the percentage of them who hold a high rank career is low $-0.87 \%$ are in rank IV/b, $0.07 \%$ in rank IV/c and $0.02 \%$ in rank IV/d (Kompas online, 2010).

In terms of career advancement, the new policy (MENPAN decree No.16/2009) stipulates that all state-employed teachers (locally term as Guru PNS or pegawai negeri sipil) from rank III/a (or middle teacher position) till top rank IV/e (or master teacher position) must perform the professional development tasks (one of them is conducting CAR) which were previously only required for rank IV/a teachers. As a consequence of this new policy, teachers must be actively involved in a CAR project in their schools. Therefore all parties that are concerned in teachers professional development - including those providing training and

\footnotetext{
${ }^{7}$ PNS teachers are paid based on their ranks. Teachers' ranks start from II (the lowest or equal to novice teachers) to IV (the highest or equal to master teachers). Ranks II and III have four grades $(a, b, c, a n d d)$ and rank IV has five grades $(a, b, c, d, a n d e)$.
} 
workshops - need to support teachers to be maximally involved in CAR activities as a part of their professional development growth.

\section{Research Setting}

Central Sulawesi is one of the provinces out of 33 other provinces in Indonesia. Its location is in the centre of Sulawesi Island and it is surrounded by 5 other provinces: North Maluku, South Sulawesi, South East Sulawesi, West Sulawesi and Gorontalo. Administratively, Central Sulawesi has 9 districts (Donggala, Sigi, Parimo, Poso, Tojo Una Una, Banggai, Banggai Kepulauan, Morowali, Toli-toli, Buol and 1 city, the capital city, Palu). The population in 2008 numbered 2.438.400 (Bappeda Sulteng, 2010). There are 12 main ethnicities and tribes and approximately 22 native languages across central Sulawesi. However, other people of other ethnicities from other provinces in Indonesia have also enriched the diversity of population, cultures, and languages of Central Sulawesi. Although, it is diverse in languages, people in Central Sulawesi use Bahasa Indonesia as a national language and informal language. The map of Central Sulawesi is shown below. 


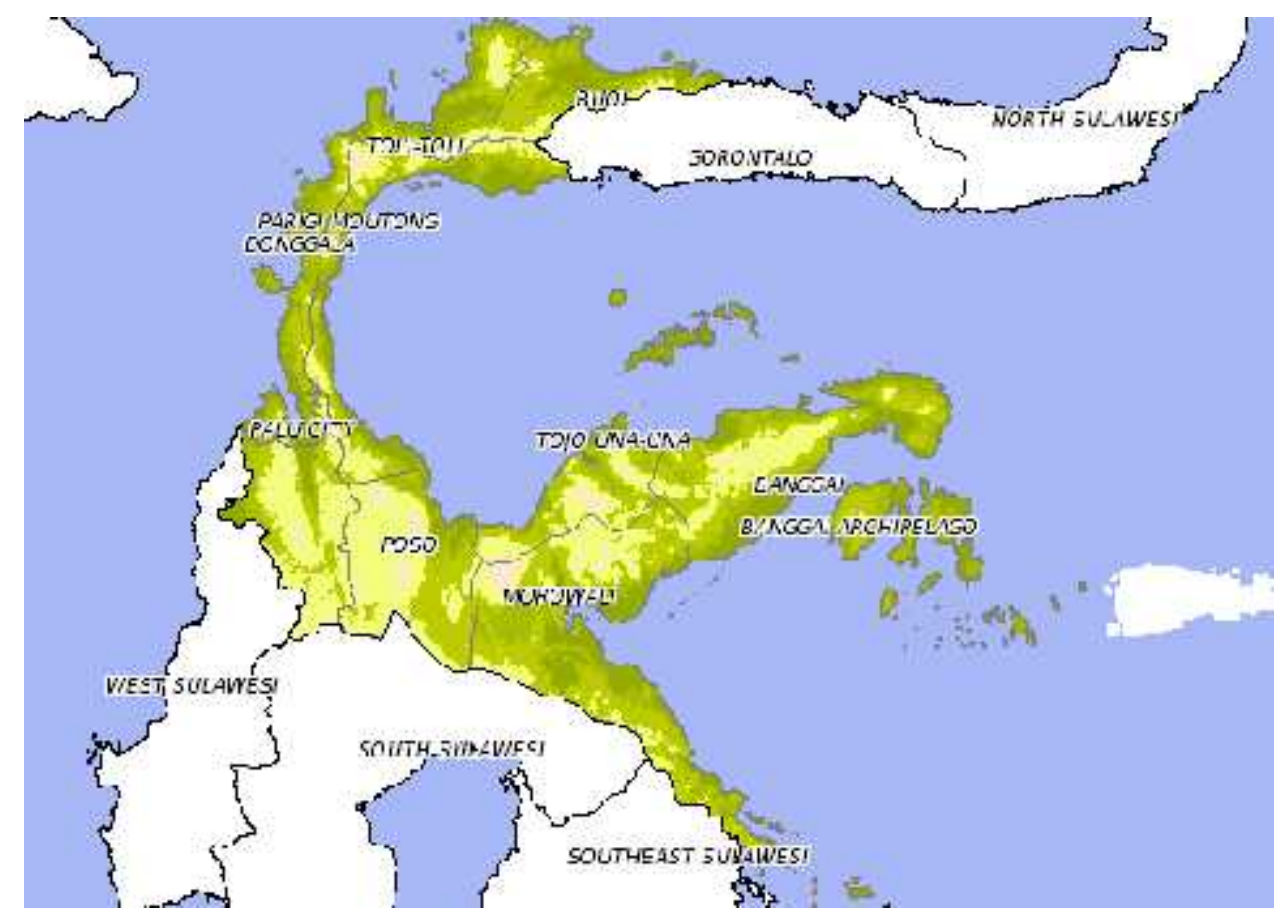

Figure 2: Map of Central Sulawesi.

(Source: http://regionalinvestment.com/newsipid/en/area.php?ia=72)

Palu is the capital city of Central Sulawesi province. The total population of Palu is 309.032 (2008 census) which across four subdistricts (Bappeda Sulteng, 2010). The local people of Palu are called Kaili and the native language is called Kaili. However, as an open city for visitors, the current population is heterogeneous and comprises many ethnicities, tribes, and religions which come not only originally from central Sulawesi itself but also from outside it. The diversity of population and cultures has shaped this city's growth as commerce and education as well as the government (administrative) city in Central Sulawesi. Bahasa Indonesia is used as formal language in formal context (such as meetings, offices, schools etc) and informally (such as between friends, in the market, and in social relationship). During informal occasions, people also use 
their own native languages (locally termed as bahasa daerah) to interact with their friends, or family who share the same languages. In the economic sector, there are various sources of income that constitute potential revenue to this capital city such as services, commerce, hotels and restaurants, industries, agriculture etcetera (Bappeda Sulteng, 2010).

\section{Education Profile of Palu City}

Palu City Schools range from pre-school/kindergarten to university. The schools are both state schools and privately-owned schools. In addition, there are schools are under the supervision of Ministry of National Education (MoNE) and Ministry of Religious Affair (MoRA). Data shows that the numbers of schools are as follows: kindergarten 129 , elementary schools 185 , junior secondary schools 67 ; senior secondary schools 34; vocational schools 22 and universities 3, and institute/polytechnic 14 .

In terms of number of students, there are a total of 49,400 as follows: elementary schools 38,204 , junior secondary schools 6,811 , senior secondary schools 2,486 , and 1,899 vocational school students. With regards to teachers' number, statistic recorded there are 2,511 in total: 776 elementary schools, 860 junior secondary schools, 402 senior secondary schools, and 473 vocational schools teachers (Dispendik Palu, 2010). 


\section{Purpose of the Study}

This present research, then, set out to investigate the experiences of English teachers in secondary schools in Palu city, Central Sulawesi Indonesia, who had attended the first CAR workshops and training and had then conducted CAR projects. The focus of the study is to explore the benefits gained by the teachers from doing CAR, the problems they faced while conducting CAR, the kinds of support which can facilitate and sustain teachers to continuously conduct inquiry in their classroom or in the school context, and whether the teachers continued to engage in action research after the first CAR project. It also explores how they experienced the CAR programme (in terms of training and the CAR project) and asks them to reflect on the best ways for both policy makers and teachers themselves to facilitate teachers to do CAR and to sustain the practice.

\section{Significance of the Research}

This study is expected to produce valuable information to all those involved in teacher development such as the policy makers, schools' staff, and teachers support groups, as well as to me as the researcher. The significance to each of these groups is broadly explained below:

a. For policy makers (such as DIKJAR of Central Sulawesi, the District Education Office, Provincial LPMP), this study provides 
useful information, from teachers' perspectives, on how to run effective AR workshops/trainings as well as how to provide effective support for teacher researchers;

b. For school communities (such as Principals and Colleagues), the study provides valuable information about how to support teachers to conduct AR as well as facilitating teachers to continuously do CAR as part of their practice which aims to improve their teaching practice and so contribute to school improvement;

c. For the English teacher network group (locally termed MGMP or Musyawarah Guru Mata Pelajaran), this study gives information from the teachers' perspectives of how CAR has benefited teachers, as well as information about how to initiate a learning community avenue for teachers to grow together through engaging with CAR.

d. And for me, as the researcher, the research provides a valuable basis for providing support and facilitation to English teachers (both in pre-service and in-service) to reflect on their practices through various self-directed PD such as collaborative action research, reflective teaching, teacher support groups, peer coaching, and critical friends. 


\section{Research Questions}

The research questions sought to explore the experience of teachers who engaged in CAR. The questions revolve around the benefits of doing CAR, barriers found during engagement with CAR, support gained, the sustainability of the practice and the aspect of CAR training and project involvement that best facilitate teachers' professional growth.

\section{Question 1}

What do teachers consider to be the benefits of CAR to themselves and what do they consider they have learned from doing CAR?

\section{Question 2}

What barriers, if any, did teachers encountered in conducting CAR in the classroom?

\section{Question 3}

What support did teachers receive from their supervisors, colleagues and school principals while conducting CAR projects?

\section{Question 4}

Do the teachers who participated in the 2005-2006 pilot continue to employ CAR as a tool for their professional development five years on? What reasons do these teachers offer as to why they do or do not still use action research? 


\section{Questions 5}

How do the teachers believe CAR programmes (training and project) should best be designed and implemented to facilitate professional growth?

\section{Brief Overview of the Research}

This study investigates the experiences of five teachers of senior secondary schools in Palu city, central Sulawesi, Indonesia, who participated in a CAR pilot (both workshop and project) in 2005-2006. It is a qualitative case study that aims to explore the teacher research phenomenon in an Indonesia context. In particular, the study is intended to shed light on what the teachers' perceived to be the benefits, challenges, and support gained during their involvement with the CAR project; whether or not teachers continue to engage with CAR after the pilot and their reasons for this; and the teachers' perceptions of how the CAR programme, as a PD tool, should be comprehensively implemented. Data was collected from teachers through short interview in the first meeting and in-depth interview in the second meeting, requested CAR documents in form of CAR proposal and reports. Supporting data was gained from one of the DIKJAR staff members and one of workshop instructor through informal interview and requested documents such as the pilot guidelines or reports, and workshop materials. Data was analysed qualitatively using thematic analysis. 


\section{Chapter Summary and Thesis Organisation}

This chapter has provided a brief overview of the rationale of my interest in studying CAR as professional development tool for teachers in the Indonesian context. It also briefly describes the research problem that this thesis explorers: teachers' experiences of engaging with CAR and their perceptions of how these practices should be maintained to facilitate professional growth through CAR practices. This chapter has also provided an overview of the education system of Indonesia. It describes and briefly discusses education reform and government policy that is concerned with improving teachers' professional development, particularly through engaging with CAR. It also provided the background information about the setting of this study.

Chapter two provides a description of the theoretical framework of action research ranging back to its origin and the importance of it. It also highlights the results of studies internationally which support the employment of CAR as an effective tool of professional development. Specifically, this chapter presents some studies of the benefits and challenges of teachers of doing CAR. Finally, it discusses literature supporting teachers to engage with CAR project as a means of PD.

Chapter three covers the methodology of the research including design, data collection, data analysis, and the robustness and trustworthiness of the study (reliability and validity). This chapter also 
describes the background of research participants. Ethical issues related to this study are also discussed.

Chapter four describes the background of the pilot in which the 5 teachers in this study participated. It provides a description of the CAR workshop and the pilot information that happened five years ago.

Chapter five elaborates on the findings of the interviews with the study participants based on the five research questions and provides discussion of the study findings and relates them to relevant literatures and studies.

Chapter six summarises the main findings and discusses their implications. 


\section{CHAPTER 2}

\section{Literature Review}

This chapter reviews the literature related to action research generally and classroom action research (CAR) more specifically in the field of education. It discusses the origin, types, and the importance of action research as used in education. It describes how action research applied to educational problems can be used as a professional development tool. It gives an overview of some studies of teachers' experience of CAR in the field of the teaching of English at the high school level both in international or Indonesia context. In the final section, there is a discussion of how to facilitate and sustain this particular type of action research (CAR) from the perspective of the teacher.

\section{What is action research?}

The concept of action research was first introduced by Kurt Lewin in 1946 as an alternative to the traditional positivist approach to research that was dominant at that time (Hinchey, 2008). He developed the spiral cycle design of research and action informed by what has been learnt. A key feature of action research is that inquiry is conducted collaboratively with participants, challenging the positivist ideas that objectivity is of prime importance in research and that there must be a clear line drawn between 
the researcher and the researched. Finally, action research promotes reflection on ones' own situation and participants need involvement in improving work environments (Lewin, 1945, cited in Hinchey, 2008) and dealing with group processes or community problems in other settings (Burton \& Bartlett, 2005; Hendricks, 2009; Pine, 2009).

Action research also builds on the critical pedagogy of Paulo Freire in 1970 who was concerned with those who lack privilege or voice in communities or society. His concept of participatory education as a dialogue or conversation between the teacher and learner fits well with the aims of action research. Freire's concept of "praxis" is highly relevant, the idea that dialogue between researcher and practitioner can lead to change. Freire built community action components into traditional research plans, involving those people in vulnerable social conditions in the research so that they had developed better self-awareness of their own situations and were able to analyse the situation and look at the possibilities for action and change (Hinchey, 2008). For both of them (Lewin and Freire), action research is a critical tool to empower the practitioner or the community to make changes based on new understandings and reflection.

There has been much published about action research but most definitions agree on the following common features: collaborative relationship between researcher and practitioner or the "researched"; reflection leading to action or change, a cyclical process where ongoing reflection leads to further action or change; understanding of the practice 
or the situation that the participant is part of. Carr and Kemmis (1986) define action research as "a form of self-reflective inquiry undertaken by participants in social situations in order to improve the rationality and justice of their own social or educational practices, their understanding of these practices, and the situation in which the practices are carried out" ( $p$. 220). Hinchey (2008, p. 4) defines it as "a process of systematic inquiry, usual cyclical, conducted by those inside a community rather than by outside experts; its goal is to identify action that will generate some improvement the researcher believes important". In this sense it is an approach to research that challenges some of the assumptions underlying more traditional quantitative research approaches features such as objectivity, detachment, and truth. Many educational researchers conduct action research working collaboratively with practitioners. From the above features, it is no wonder action research is also called practitioner research that may empower practitioners to be professionals (Koshy, 2005). In the field of education in particular, action research is a popular approach for shaping the teachers to be professionals through engaging in reflective practice, and doing systematic data collection to understand their practice and decide action planning for improving it (Hendricks, 2009; Koshy, 2005; Mertler, 2009). 


\section{Action Research Applied to Education}

It was Stephen Corey in the1940s and 1950s in the United States who first experimented with the use of action research in educational settings (Hinchey, 2008). Corey's work focused on improving curriculum, supervision, and instruction by working with teachers, principals, and supervisors in school districts (Hinchey, 2008; Pine, 2009; Zeichner, 2009). Corey believed that teachers need to improve their practice through action research as a part of advancing their professionalism and status (Hinchey, 2008) and promoted teachers as educational investigators (Noffke, 1992). In Britain, the movement of action research in education was influenced by the work of Lawrence Stenhouse in 1975 who introduced the term "teacher as researchers" and viewed teachers as playing an important role in curriculum development and suggested that teachers needed to be reflective with their practice and to evaluate their pedagogy for the sake of the improvement of their pupils' education (Barlett \& Button, 2005, Hopkins, 2008; Noffke, 1992). Furthermore, during the 1970s, action research had been popularized in Britain by John Elliot, Jack Whitehead, Wilfred Carr and Stephen Kemmis (Whitehead \& McNiff, 2006). Since then, the action research movement spread to Australia, the USA and Canada, France, Chile and many other countries (Hopkins, 2008). Following this, in particular at the first decade of $21^{\text {st }}$ century, action research has been regarded not only as an approach of solving teachers' problem in the classroom but also can be used for school improvement (Hopkins, 2008). 
To date, in term of purpose, action research falls into two categories: practical and critical action research. Practical action research, growing enormously in popularity in the USA, focuses on empowering teachers to do their own classroom research for improving practices (Manfra, 2009). Teachers identify problems that they want to address and systematically work to find action strategies for solving those problems (Hinchey, 2008). Practical action research such as CAR is viewed as relevant to day-to-day teachers' work where they are required to reflect their practices and improve them. It also has benefits for teacher professional development (PD) and effective school reform (Hinchey, 2008; Manfra, 2009; Zeichner, 2009). The proponents of practical research support Dewey's ideas (1933) that it is important for teachers to do reflection and inquiry to improve their practice (Manfra, 2009). Practical action research is defined as "research conducted by teachers as they go about their daily work. It is enmeshed in the context of the classroom", (Mclean \& Mohr, 1999, cited in Manfra, 2009, p. 38).

Meanwhile critical or emancipatory/participatory action research focuses on encouraging teachers to study beyond the classroom strategies or practice and to identify political and social issues that impact student learning and so play a significant role as agents of change (Manfra, 2009). The proponents of critical action research believe that schools' problems are driven by social conditions that must be examined and considered as a part of meaningful educational reform (Hinchey, 2008). 
Hence, emancipatory action research involves multiple stakeholders to do inquiry in the school community. A popularly accepted definition of action research from the proponents of critical action research, Carr and Kemmis (1986), state action research as "a form of self-reflective inquiry undertaken by participants in social situations in order to improve the rationality and justice of their own social or educational practices, their understanding of these practices, and the situation in which the practices are carried out" (p. 220).

\section{Definition of Action Research Applied to Education}

The term "action research" has been defined differently by the experts but these definitions have in common that the goal is to improve practice through systematic ways. Some of definitions are presented below:

a. Bassey cited in Koshy (2005, p. 8) sees "action research as an enquiry which is carried out in order to understand, to evaluate, and then to change, in order to improve educational practice".

b. Burns (2010, p. 5) defines action research as "a self-reflective, systematic and critical approach to enquiry by participants who are at the same time members of the research community. The aim is to identify problematic situations or issues considered by the 
participants to be worthy of investigation in order to bring about critically informed changes in practice".

c. Johnson $(2008$, p. 28$)$ defines action research "as the process of studying a real school or classroom situation to understand and improve the quality of actions or instruction".

d. Mills (2003, p. 20) defines action research as "Any systematic inquiry done by teachers (or other individuals in the teaching/learning environment) to gather information about - and subsequently improve - how their particular schools operate, how they teach, and how well their students learn".

From the range of definitions offered by the experts, Koshy $(2005$, p. 10) identifies the common features of action research. Action research:

- involves researching your own practice - it is not about people out there;

- is emergent;

- is participatory;

- constructs theory from practice;

- is situation-based;

- can be useful in real problem-solving;

- deals with individuals or groups with a common purpose of improving practice;

- is about improvement;

- involves analysis, reflection and evaluation; and

- facilitates changes through enquiry.

Mertler (2009, p. 19) compiles a list of action research characteristic in educational practice which he derived from other action research experts. He stated that action research is: 
- a process that improves education, in general, by incorporating change.

- a process involving educators working together to improve their own practices.

- persuasive and authoritative, since it is done by teachers for teachers.

- collaborative; that is, it is composed of educators talking and working with other educators in empowering relationship.

- participative, since educators are integral members - not disinterested outsiders - of the research process.

- practical and relevant to classroom teachers, since it allows them direct access to research findings.

- developing critical reflection about one's teaching.

- a planned, systematic approach to understanding the learning process.

- a process that requires us to "test" our ideas about education.

- open-minded.

- critical analysis of educational places of work.

- a cyclical process of planning, acting, developing, and reflecting.

- a justification of one's teaching practices.

\section{Why Action Research is Important for Teachers}

Literature reveals that it is important for teachers to engage with action research practice since it has considerably benefited them. Mertler and Charles (2008) cited in Mertler (2009) provides five reasons why teachers should be involved in action research. These are: (1) it deals with teachers' problem; (2) it is flexible in time; they can do it whenever they are ready and provides immediate results; (3) it provides teachers ample opportunity to understand and improve their practice; (4) it promote collegial partnership with other teachers; and (5) it provides alternative ways of dealing with educational issues. 
McBee (2004) reviewes the benefit of action research that teachers can gain based on the claim of supporters of teacher research that by involving in research they are able "to make better decisions in conjunction with curriculum, instructional techniques, grouping arrangement, and materials; the research process forces teachers to be reflective, to ask questions about classroom events, to notice ways that their own behaviours influences the classroom, and to experiment with a new approaches to teaching; the teachers could be empowered by the process and gain confidence and authority; and the professional status of teachers as experts is enhanced by the increase of knowledge, confidence, and authority created by the research experience" (p. 5).

Borg (2010, p. 402) lists some of the benefits of action research for teachers as suggested by literatures and studies, thus it has the potential to "develop teacher's capacity for autonomous professional judgements; reduces teachers' feeling of frustration and isolation; allow teachers to become more reflective, critical, and analytical about their teaching behaviours in the classroom; make teachers less vulnerable to and less dependent on external answers to the challenges they face; and foster connection between teachers and researchers". 


\section{Classroom Action Research}

Hendricks (2009) states that CAR is a type of action research that teachers do in the classroom which focuses on improving their teaching practice for the sake of students' learning achievement. In this case, teachers use students, classrooms, and content area as a basis for collecting the data to inform what decisions could be made to improve teaching. CAR can be conducted individually or collaboratively with other teachers. The focus of study is regarded as the most practical and applicable to solving issues related to teaching practices in the classroom. Unlike other types of action research such as critical or participatory, the result of which can be used to improve the social condition beyond the classroom; CAR emphasises its findings on improving students' learning and achievement, teaching instruction, classroom management, and assessment and so on.

Hendricks (2009, p. 9-10) the distinguishes CAR from the following other three types of action research.

- Collaborative action research: a system of action research in which multiple researchers from school and university setting work together to study educational problems. Collaboration among teachers and administrators may occur as well as collaboration among school personnel and university researchers. The goal of this type of research is to utilise the expertise of the collaborators and to foster sustained dialogue among educational stakeholders in different settings.

- Critical action research: a form of action research utilised in educational setting that encourages wide collaboration among university researchers, school administrators, teachers, and those 
in the community. The goal of this type of research is to evaluate social issues so that results can be used for social change.

- Participatory action research: a social, collaborative process of action research. The goal is to investigate reality so that it can be changed. It is considered to be emancipatory (the action research is able to explore practices within the limit of social structures); critical (the action researcher's goal is to challenge alienation, unproductive ways of working, and power struggles); and transformational (changing both theory and practices).

Mettetal $(2001$, p. 7$)$ says the goal of teachers engaged in CAR is "to improve your own teaching in your own classroom". In addition, CAR focuses its study on the practical significance of findings rather than statistical or theoretical significance (Mettetal, 2001). In this sense, the focus of study is more practical and applicable to teaching practices which in the classroom (Manfra, 2009). When conducting CAR, teachers can work individually or collaboratively with their colleagues or teacher educators (Hendricks, 2009).

Based on the above statements, it might be concluded that CAR is a process of inquiry or reflection conducted by teachers towards problems of teaching and learning they face in the classroom with a commitment to improve and change teaching practices through a cyclical series of systematic action and reflection, sometimes individually and other times, collaboratively with a "critical friend".

Numerous models of CAR, ranging from simple to complex, have been presented by authors and researchers (Mertler, 2009). However, all 
such models have adopted the same process, a "cyclical" process (Johnson, 2008). For instance, Reil's model (2007, cited in Mertler, 2009) has four steps in each cycle: planning, taking action, collecting evidence, and reflecting; Piggot-irvine's model consists of plan, act and reflect; and Hendricks' model requires reflection, action and evaluation (Hendricks, 2009).

A more complex model of CAR proposed by Mettetal (2002) has seven stages such as identify a question, review the literature, plan a research strategy, collect data, analyse data, take action based on result, share findings. In addition, Mettetal (2001, p. 7) maintaines the characteristic of CAR as follows:

- It is systematic, yet less formal;

- It is research conducted by practitioner to inform their action;

- It aims at improving teachers' own teaching in the classroom (or department or school);

- Its result can add to the knowledge base;

- It uses informal research practice such as a brief literature review, group comparisons, and data collection and analysis;

- Its validity is achieved through the triangulation of data;

- Its focus on the practical significance of findings, rather than statistical or theoretical significance;

- Its findings are usually disseminated through brief reports or presentations to local colleagues or administrators.

In Indonesian context, Kemmis and Taggart's (1988) model is very popular and most literature used in the in-service CAR workshop is based on this. The model consists of four main spiralling process of planning, action, observation, and reflection in which the teachers required to: 
- develop a plan critically informed action to improve what is already happening,

- act to implement the plan,

- observe the effects of the critically informed action in the context in which it occurs, and

- reflect on these effects as the basis fro further planning, subsequent critically informed action and so on, through a succession of stages. (Kemmis \& McTaggart, 1988 cited in Burns, 1999, p. 32).

Burns (2010, p. 8) further illustrated the above four stages into more practical ways as she adapted from Kemmis \& McTaggart as follows:

Planning. In this phase you identify a problem or issue and develop a plan of action in order to bring about improvements in a specific area of the research context. This is a forward-looking phase where you consider: i) what kind of investigation is possible within the realities and constraints of your teaching situation; and ii) what potential improvements you think are possible.

Action. The plan is a carefully considered one which involves some deliberate interventions into your teaching situation that you put into action over an agreed period of time. The interventions are "critically informed" as you question your assumptions about the current situation and plan new and alternative ways of doing things.

Observation. This phase involves you in observing systematically the effects of the action and documenting the context, actions and opinions of those involved. It is a data collection phase where you use 
'open-eyed' and 'open-minded' tools to collect information about what is happening.

Reflection. At this point, you reflect on, evaluate and describe the effects of the action in order to make sense of what has happened and to understand the issue you have explored more clearly. You may decide to do further cycles of AR to improve the situation even more, or to share the "story" of your research with others as part of your ongoing professional development.

\section{Criticisms of Action Research}

The issue of the robustness of action research finding has been identified as the weakness of action research study (e.g. Cardno, 2003; Foster, 1999, cited in Barlett \& Button, 2006). Foster, for instance, claimed that teachers' action research study provided lack of robust data to support claims they made; thus lack of any validities. They (Foster and Cardno) argue that the validity of the action research process needs to be considered by teachers conducting action research

Refferring to the above claim, Barlett and Button (2006) view that Foster saw the teachers' product of action research from the lens of traditional academic of research such as positive research that more emphasizes on generating theories than on practical matter. Hence, they argue there should be clear distinction between research that oriented on 
developing theories and that of solving the practical problems such as action research; and so is the criteria of validity should be weighted and interpreted differently. In addition, Mettetal (2009) contends that it was wrong and not in the right position to expect teachers to produce high quality of action research since they are not academicians or researchers; thus the extent of quality of their research is highly related to the benefits of the reseach finding for its target audience. She further argues that there may be no generalibility of action research as its findings are "context specific and unique to the particular participants and their setting and situation" (2009, p. 25). Relevant to Mettetal's statement, McNiff and Whitehead (2005) argue that action research cannot be generalised, yet through validating evidence and making one's work available to critical scrutiny and critique, the researcher will legitimise his/her claims to knowledge. Moreover, to ensure validity of action research study, Mettetal (2009) proposes some ways such as: repetition of the cycle, prolonged engagement and persisten observation, experience with the process, triangulation of data, member checking, and participant debriefing.

\section{ESOL (English for Speakers of Other Languages) Teachers' Perception of Doing Action Research (AR): Benefits and constraints}

There is evidence that promoting teachers to conduct a classroom action research in the field of language teaching may considerably benefit 
them. A study by Burns (1999) of 20 ESOL teachers who conducted action research showed that teachers gained benefits in terms of increasing personal insight and self-awareness, growing personally or professionally, and being able to reflect on the educational decisions they made. Similarly, a study by Sowa (2009) of six practising teachers who attended an ESOL methods course shows that all teachers felt an AR project benefited them. These teachers said that they became more cognizant of their teaching repertoire, more reflective and critical which led them to change their teaching habits. Even, some teachers admitted that conducting AR project potentially helped them to grow personally.

Perkins (2001), a novice teacher who did an action research project in her ESOL classroom, admitted that the AR project helped her to carry out various things in the classroom. She (2001, p. 18) said "Action research project gave the opportunity to observe, to be reflective, to think hard, and to try new things in the classroom. I believe these processes take teachers from the role of technicians into the realm of professionalism".

In an Asia context, some studies have also shown that by doing AR projects, ESOL teachers gained tremendous benefits. In a study by Curtis (2001) of 20 secondary English teachers in Hongkong, one of the teachers (Richard) said that doing AR project had increased his teaching strategy skills as well as developed his teaching skills. Gebhard (2005) found that three English teachers in Japan gained more awareness about 
their teaching, became more reflective, and had a forum to discuss their practice as a result of doing action research. Similarly, in China, Thorne and Qiang (1996) found that English teachers who practiced action research became more aware of the teaching and learning process, developed more sensitivity about the classroom situation, and taught English with more variety of classroom activities. Chou's study (2010) of in-service elementary English teachers in Taiwan found that action research experiences contributed to teachers' knowledge construction, helped them gain practical teaching practices and developed their confidence in teaching English.

Similarly, a study of 10 Indonesian secondary English teachers in 2005 , found that teachers who did an AR project for six month experienced various benefits (Burns \& Rochsantiningsih, 2006). Teacher $D$, for instance, commented that her experience involved in AR project had changed her awareness of her teaching practices. Another teacher (Teacher J) said that doing AR project gave him more authority to plan and do the study compared to other studies where he was only the object of the research. In addition, Teacher $\mathrm{H}$ said that AR provided a tool of PD for teachers since not every teachers had the same chance to participate in PD activities. More importantly, Teacher E confessed that AR project had changed his attitude to teaching, saying "I become more engaged in my teaching, more careful in preparing the lesson. And I become more 
diligent in correcting the students' work”, (Burns \& Rochsantiningsih, 2006, p. 28).

Although there are the above documented benefits for teachers doing AR, other studies report that in the process of pursuing their PD through AR projects, teachers found problems and difficulties. A study which was conducted by Kitchen and Jeurissen (2006) of eight New Zealand teachers (two primary and six secondary teachers) shows that school support, time constraints, and the research process had become problems for teachers during the process of doing AR project. In terms of school support, many teachers claimed that the school environment did not fully support them doing AR projects for example: the school saw no value to their research and they gained negative impression from other colleagues. In relation to time constraints, some teachers complained they had less flexible time and minimum contact with student as they were not full-time teachers. Teachers also admitted that during the process of doing AR project they had problems in managing their research although they had been provided support from supervisors.

Similarly, Burns and Rochsantiningsih, (2006) identifies three categories of difficulties in implementing AR projects These three problems were "general problems such as: managing time, limited funds, and work overload; research problems such as: formulating and focusing problems, planning cycles in AR, diary writing research report; and individual problem such as: lack of confidence to complete the AR, 
criticism from senior teachers, criticism from colleagues, lack of motivation, family commitments and conflict with school priorities", (p. 29).

Furthermore, some studies revealed that teachers often find difficulties in implementing AR projects and tend not to continue doing it after the first experience. A survey study by Rayney (2000) of English teachers in 10 countries (China, Colombia, Greece, Japan, Morocco, Poland, Qatar, Saudi Arabia, Thailand, and Tunisia) concluded that teachers who knew how to do AR did not necessarily practice it mostly due to the following reasons: lack of time, no supports from friends (lack of collaborative friends available) or administrators, lack of motivation, and confusion about the AR concept. Borg (2009) also reports his finding of 500 English teachers in 13 countries and concludes that the lack of time, limitation of attitude, knowledge and skills, limited access to material compounded with unsupportive institutional conditions became prominent factors that led them to limited engagement in action research. Volk (2009) found that English teachers in the Middle East did not continue to do their project after first training due to the lack of time, motivation and conviction to make action research as integral part of their professional development.

Further to this, Burns (2009, p. 292) identifies the following factors as constraints to the action research teachers: "lack of time and recourses, problem gaining consent/ support from school administrators, skills in acquiring the discourse of research and research writing, limitation on source of advice, criticism from colleagues and self doubt". 


\section{CAR and Reflective Practice: New professional development tools}

CAR as a means of PD. Diaz-Margiolli (2003, p. 1) defines professional development as "an ongoing learning process in which teachers engage voluntarily to learn how best to adjust their teaching to the learning needs of their students". Zuljan and Vogrinc (2009) argue that willingness for in-depth learning and knowledge that is relevant to professional practices, critical evaluation and reflective integration of new findings into pedagogical works are the core elements for teachers' professional development. In line with this, action research has become well-known as a form of professional development for teachers (Licklider, 1997) and "can be used to replace teacher in-service as a means of professional growth and development" (Johnson, 2008, p. 34). This is due to traditional in-service courses such as a "brief one-shot workshop without follow up", (Ponte, 2005, p. 274), not providing enough time, activities, or content to develop teachers' knowledge or affect their practices (Birman, Desimone, Porter, \& Garret, 2000; Burbank \& Kauchank, 2003), being ineffective (Burnaford, 1996), boring, and irrelevant as well as teachers feeling they forget easily what they learned (Miller, 1998). Moreover, Darling-Hammond and McLaughlin (1995, cited in Levin \& Rock, 2003, p. 136) state that "professional development today should provide occasion for teachers to reflect critically on their practice and to fashion knowledge and belief about content, pedagogy and learners". 
Promoting teachers engagement in research is in line with the principle of professional development in schools. Little (1993) in Burnaford (1996, p. 138) suggests professional development should "prepare teachers (as well as students and parents) to employ the techniques and perspective of inquiry". The process of inquiry or reflection on a problem which leads to a solution has indicated the teachers do professional growth for themselves (Burnaford, 1996). In terms of learning, action research facilitates teachers' professional growth through learning from their teaching practice and systematically observing their teaching practice (Johnson, 2008). Furthermore, research has found that action research is a tool of professional development through inquiry and reflection that enhance practical change at school (Levin \& Rock, 2003; Neapolitan, 2000; Rosaen \& Schram, 1997; Smith, 2005; Wigglesworth \& Murray, 2007; Zamorski \& Bulmer, 2002; Zeichner, 2003).

Parson and Brown (2002, cited in Mertler, 2009) argue that action research may serve as a means for improving teachers' problem solving, their attitude to professional development and school change, as well as enhancing their confidence and professional self-esteem. In addition, Mertler (2009) asserts action research provides a huge chance for teachers to link their practice with theory, to become more reflective and risk takers; these attributes, he believes, enable teachers to grow professionally through action research. 
In conjunction with their roles as classroom researchers, teachers observe and analyse their plans and actions, make informed decisions about their practice, solve their students' and own problems, and ask questions as well as systematically find the answers, make data based decision and validate their practice, and, most of all, implement change (Foeyo \& Koorland, 1997). Referring to those attributes, it is no wonder that Fueyo and Neves (1995, cited in Foeyo \& Koorland, 1997 ) claim teachers as researchers are professionals since they constantly ask "how can my work be modified to produce better results?" (Sagor, 2009, p. 10).

Collaborative action research. Collaborative aspects of doing classroom action research have been categorized by some experts as a process of professional development. Action research promotes meaningful and collaborative teacher-teacher relationships and provides great opportunities for meaningful dialogue (Levin \& Rock, 2003). Hendricks (2006, p. 67) states that "collaboration encourages educators to engage in ongoing professional development". She (2006, p. 67) then explains that "when the teachers engage in dialogue to improve their practice in the classroom, professional growth is likely to occur". A study by Wigglesworth and Murray (2007) with English teachers in Australia found that, as a result of doing research collaboratively, the teachers grew professionally and changed their practice through reflecting together and learning from each other. Similarly, Atay (2006) found that in-service teachers who did collaborative action research with pre-service teachers in 
Turkey were developed their research knowledge and skills, developed more awareness to the value of collaboration, and were motivated to implement new instructional practices.

However, studies have also found that collaboration sometimes lead to dilemmas, particularly in situation where teachers conducted action research in partnership with university researchers (e.g., Goldstein, 2000; Reimer \& Bruce, 1994). While Levin and Rock's study (2003) also notes issues of time constrains and differences in priorities in collaboration between pre-service teachers and their mentors (in-service teachers), however, the positive aspects of collaboration outweigh the negative effect. Goldstein (2002) states interpersonal problems and power imbalances frequently occur as challenges for collaborative researchers. Likewise, the problem escalated which eventually lead to teachers not wishing to meet or work together (Platteel, Hulshof, Ponte, Driel \& Verloop, 2010). This contradicted with the notion of collaboration; as Burbank and Kauchak (2003, p. 500) note "true collaboration involves equity and mutual participation". Hence, Platteel, et al. (2010) suggest that encouraging good communication and trust in groups can diminish the potential conflict in research partnership between teachers and university researchers; they acknowledge, however, that building such trust takes some times to do.

Despite the challenges, in terms of learning opportunity, classroom action research provides practical possibilities for teachers to continue to learn and grow (Burnaford 1996). Congruent with the aim of 
long life learning, classroom action research holds promise as a tool for teachers to learn and develop their self-capacity.

Reflective practice and classroom action research. Reflective practice is defined by Hatton and Smith (1995, cited in York-Barr, Sommers, Ghere, \& Montie, 2006, p. 40) as "deliberate thinking about action with a view to its improvement". In the classroom, reflection exists when "a teacher reconstructs, re-enacts, and/or recaptures the events, emotions, and the accomplishment of his and her teaching", Farrel (2007, p. 3).

The term "reflection" was first found in the work of Dewey in 1933 in which he characterises it as "a systematic, rigorous, disciplined way of thinking with its roots in thinking" (Rodgers, 2002). In education context, this term becomes a buzz word in 1980s when Schön proposed that teachers need to engage in reflection to solve their problem in teaching (Farrel, 2007). Schön asked the teachers to critically reflect and examine both during and after the teaching process. This process is well-known as reflection in-action or reflection occurs during the action and on-action or reflection occurs before the action or after the action (Zeichner \& Liston, 1996). Richard and Lockhart (1994, p. 1) suggest that teachers should "collect data about their teaching, examine their attitude, beliefs, assumptions, and teaching practices and use the information obtained as a basis for critical reflection about teaching". 
Zeichner and Liston (1996, p. 6) describe a teacher who is reflective as one who "examines, frames, and attempts to solve the dilemmas of classroom practice; is aware of and questions the assumptions and values he or she brings to teaching; is attentive to the institutional and cultural contexts in which he or she teaches; takes part in curriculum development and is involved in school change efforts; takes responsibility for his or her own professional development". Moreover, they contend that "if a teacher never questions the goals and the values that guide his/her work, the context in which he/she teaches, or never examines his/her assumptions, then the teacher is not engaged in reflective teaching", (1996, p. 1).

Based on the belief that by engaging in a conscious and systematic reflection of their teaching, teachers can improve their teaching practice, reflective practice is used in teacher professional development (Farrel, 2007). Osterman and Kottkamp (1993) state that the ultimate goal of teachers engaging in reflective practice is that they can be able to develop a sense of self-awareness which is believed as a tenet factor to grow professional. York-Barr, et al. (2006) state that one of the characteristic of a reflective teacher is they demonstrate awareness of self, others, and surrounding context.

Being reflective is a tenet and prerequisite of doing action research (Blàzquez, 2007; Craft, 2002). Reflection has become a pivotal part of classroom action research since it mostly relates to examining teachers' 
own practices (Mertler, 2009). Likewise, action research is believed as "a structured way to promote reflective practice", (York-Barr et al., 2006, p. 141). In action research, teachers ask these questions "What am I doing? What do I need to improve? How do I improve it" (Whitehead \& McNiff, 2006, p. 1) and the literature notes that, through the growing of skills needed to investigate and analyse a situation, action research leads to teachers becoming more reflective and critical. In addition, studies also show that action research practices are effective to enhance teachers' critical reflection (Atay, 2006; Ginns, Heirdsfield, Atweh, \& Watters, 2001; Gore \& Zeichner, 1991; O’Sullivan, 2002; Sowa, 2009).

Given that teachers need to engage in reflective practice, professional development literature for language teachers, in particular, encourages teachers to engage in a critical and reflective review of their own practices through various means such as self-monitoring, analysing critical incidents, teacher support groups, and action research (Richard, 2008). In general education, reflective practice has been embedded as an approach in pre-service and in service training in Western countries since the 1980's (O'Sullivan, 2002).

\section{Teachers Learn to Research: Some models from other countries}

Some studies or reports have revealed different forms of AR models of learning that teachers have experienced. For instances, 
teachers in Parkland school, USA, attended AR class which embedded in the "Teaching Fellows Programme" - a program designed for teachers to do master study at school (Gilles, Wilson and Elias, 2010); eleven teachers in Brisbane, Australia who lived in different areas formed a "network of research project" (Ginns, Heirdsfield, Atweh \& Waters, 2001); English teachers in Turkey attended an “ INSET program” facilitated by university mentor (Atay, 2008), and teachers in Singapore involve in a "Learning Cycles" teacher network, (Hairon, 2006). Interestingly, these models have in common characteristics in terms of length of learning, mentors facilitation, process of doing research action.

First characteristic of the above teachers' in-service programs, teachers do not learn AR in a very short time (or one short workshop). Learning time of AR is intensive and take some times, from 6 weeks to 12 month. In the "Teaching Fellows Programs" the class runs for an entire school year in which the teachers met twice a month; In the "Network of Research Project", the programme runs for one term where network meeting was conducted only for three times while regular meeting occurred at different times in the year both face to face or using technology such as email and telephone conferencing. In addition, the "INSET programme" was carried out in the afternoon class for 6 weeks with each session lasted for four hours. Similarly, in the "Learning Cycles" programme participants were entitled to 100 hour of training ranging from 4-12 month period of learning. 
Another point that the above models have in common is mentor facilitation. All models utilised mentors from the university as the participants' facilitators. For instance, in the "Teaching Fellows Programme" the class was facilitated by a mentor from the local university who helped the teachers to choose a research question, learn how to collect, code, and interpret data, and create an action plan. In the "Network of Research Project", teachers who formed cells were facilitated by university research teams. Similarly, in the "INSET programme" in Turkey, where 18 teachers voluntarily attended PD in AR, the class was facilitated by a state university mentor. The "Learning Cycle" programme was slightly different, being facilitated by Teachers Network Professional Development Officers. The last point which all the above models have in common is that all of them required full support from mentors during the process of doing AR. Mentors assisted teachers throughout the process from initial reflection, planning, action and observation, to the stages of critical reflection and documentation. In addition, critical friends were encouraged to participate in meetings or classes as they play the important role of supporting the teachers in solving individual problems during action research. More importantly, mentors also encouraged teachers/participants to use reflective journals when doing AR. 


\section{Facilitating and Sustaining Teachers to Do CAR}

Action research has the potential to promote school improvement through teachers generating knowledge about their practice and sharing that knowledge with their colleagues (Hendrick, 2009). In addition it "becomes the guiding forces behind professional development, allowing practitioners to study their own practices and take charge of developing their professional work as educators" (Hendricks, 2009, p, 11). Therefore, this practice should be supported and sustained (Calhoun, 2002).

Sustaining teachers to do action research has become a major concern of researchers (e.g., Burton, 2000; Volk, 2009) due to the fact that this practice has profound benefit to teachers. Burton (2000) suggests that maintaining teachers' involvement in research can be achieved by including them in a large-scale research project. However, Volk (2009) viewed sustain practice may come from teachers' angle and contended that it is imperative for teachers to be aware of action research by saying "If action research is viewed as an essential part of the teaching, the teachers would be expected to make adjustments to such features as the scope and topics undertaken for any new research, regardless of the limited time and recourses they perceived as being available in their particular teaching situation (p. 328).

Literature suggests conditions that may support teachers to sustain their practice such as the role of mentoring (Borg, 2006), support from school leaders and colleagues in the form of learning community 
(Burnaford, 1996), and support from school administrator and policy makers (Tinker Sachs, 2000). Burnaford (1996, p.148) suggests six ways for school administrators to facilitate teachers do research as PD in school, such as by :

"(a) providing a climate of safety and freedom to take risks, (b) being reflective leaders, (c) making it possible for teachers to collaborate and share their research with each other, (d) mobilizing sources to support classroom research, (e) providing time consistently for research, and (f) listening and being informed about the research teachers are doing in the building".

Borg (2006, p. 24) suggests that there are ways that mentors can facilitate teachers to do action research, including "assisting in setting up a general framework for the conduct of the research, helping teachers to find a focus, commenting on teacher's initial attempts to collect and analyse data, being an audience who responds to teachers' efforts to communicate their work by commenting on drafts of reports they write".

Burns (1999, p. 202-209) suggests that these following activities can facilitate and sustain teachers doing their inquiry: integrating a research base into professional development, teachers' network, research partnership, integrating action research into school renewal. In addition, Tafel and Fischer (2001) suggest that building a learning community within schools may facilitate teachers to share their ideas, tryout new ideas, and explore ways to improve their teaching through inquiry. Similarly, Fueyo and Korland (1997) suggest that school-based research can be promoted 
to deal with teachers' constraints of dealing with action research, which may provide peer-support for teachers to discuss their teaching and learning improvement. More importantly, Calhoun (2002) called for organisation-wide support in promoting inquiry among school staff.

A recent study by Gilles, Wilson, and Elias (2010) shows how a school principal and a teacher's colleague played a pivotal role in supporting and facilitating teachers in doing their AR projects. They found the school principal encouraged all teachers to participate in AR classes offered in "Teaching Fellow Programme" in their school, attended the meeting to see the progress of her staff research, and even used AR in her case study. They also found colleagues became partners for AR teachers to share and discuss findings and problems.

In his reviews, Borg (2010) concludes that there are three main conditions that facilitate teachers to engage in action research. These are workplace condition, teacher condition, and project condition. He elaborates on the characteristic each of these conditions thus:

a. Work place condition - teachers are more likely to become involved in action research when their workplace has the following characteristics:

- Time for teachers to do research

- Recourses (including access to research reports or summaries, and funding, where necessary)

- Positive attitudes to teacher professional development

- An expectation that staff engage in professional development

- An awareness of the value of teachers research engagement 
- An open, trusting culture

- A collaborative ethos

- Incentive for teachers to be research-engaged

- The support of the management for teachers' efforts to be research-engaged

- A desire to use teacher-generated research evidence for school improvement

- Opportunities for staff to be engaged in research

- A culture of enquiry

- An openness to change

- Recognition for teachers' attempt to engage in research

- A genuine interest in the outcomes of teacher research (Borg, 2010, p. 419)

b. Teacher condition - teachers are more likely to engage in research, when they have following attributes

- Positive attitudes to professional development generally

- Appropriate conception of what teacher research is

- An awareness of their potential as knowledge generators

- Motivation to begin and sustain a teacher research project

- Relevant knowledge and skills for doing research

- A willingness to take risks

- Openness and a desire to collaborate with others in being research-engaged

- Socio-economy stability, including good working conditions

- Previous positive experience of engagement in research

(ibid, p. 420).

c. Project condition - teachers are more likely to engage in research, when the projects they participate in are:

- Relevant, to the teacher's working context, professional goals and specific classroom concerns

- Feasible, given the time and resource available

- Structured, to give the activity a clear sense of purpose and direction

- Supported, by a more expert mentor

- Voluntary, so that teacher's participation is willing 
- Democratic, so that teachers determine the focus of their work

- Collaborative, involving work with peers (and learners)

- Pedagogical, in orientation

- Shared, through various form of dissemination

- Concrete, in terms of its outcomes

- Integrated, to minimize additional work and disruption to normal professional activities

(ibid, p. 420).

Of particular relevance to this study, Burns and Rochsantiningsih, (2006) conclude that, in the Indonesia context, both schools and AR facilitators have pivotal roles in encouraging and supporting teachers when involved in AR projects. They suggested, in the future, the teachers' Education Faculty (university) work with teachers through collaborative action research (CAR) as a means of helping teachers to examine their practice and solve problems they encounter in their classroom. Furthermore, derived from the experience of facilitating action research as PD programme for master teachers in Indonesia, Lim, Pagram and Nastiti $(2009$, p. 7$)$ recommend that to attain success as a PD program, PD designers need to consider the following factors:

- PD needs to be collaborative;

- PD needs to be job-embedded, site based, and need- based;

- PD design should take into account the background situation of the schools and teachers involved. The model of the programme needs to consider teaching' learning style;

- ongoing support from school leader, providers of PD and local educational authorities are essential for the sustainability of change; and

- Long-term and intensive programme are more likely to support change. 


\section{CHAPTER 3}

\section{Methodology}

\section{Research Design}

This study uses a qualitative approach for collecting and analysing the data. The intent was to conduct an intensive, descriptive study of the experiences of a small number of purposively selected high school teachers about what they had learned through doing Classroom Action Research (CAR) in the Indonesian context. Specifically, the study employed a case study research design in order to conduct "research that provides a detailed account and analysis of one or more cases" (Johnson \& Christensen, 2008, p. 406) and that "examines a specific phenomenon such as a program, an event, a process, an institution or a social group" (Merriam, 1988, p. 9). I selected a qualitative approach as the best fit to the purpose of the study which was to portray in detail these case study teachers' reported experiences rather than attempting to collect data that would generalize beyond the specific context of this research (Denzin \& Lincoln, 1995). A qualitative approach is also appropriate in that I wanted to understand the benefits and the limitation of the phenomena from the perspectives of the teachers themselves (Creswell, 1994). 
For data collection, I employed those qualitative strategies suggested by Patton (2002, cited in Merriam, 2009) for conducting case study research, conducting interviews with participants and locating key documents. Patton (2002, cited in Merriam, 2009, p. 85) states that interviews can be used to obtain "direct quotation from people about their experience, opinions, feelings, and knowledge", while documents can be used to extract "excerpt, quotation, or entire passages" (2002, in Merriam, 2009, p. 85).

\section{Theoretical Framework}

I chose an interpretive approach as the theoretical framework for my research since I was interested in studying a particular case of professional development ("bounded system", Merriam, 2009) as experienced by 5 senior high school teachers in Palu City who participated in CAR pilot in 2005-2006. Following Merriam (2009), by using a qualitative case study methodology, I would be able to understand the phenomena of classroom action research through the lenses of these teachers who participated in this pilot by exploring with them their experiences, thoughts and beliefs.

My research can be defined as an intrinsic case study (Stake 2005, cited in Merriam, 2009, p. 48); that is, a type of case study in which "the researcher is interested in the particular case itself - it is intrinsically 
interesting" and "the focus is one the case itself because the case presents an usual or unique situation", (Creswell, 2007, p. 74). I used the case study approach as I was interested with the specific case in which teachers participated in CAR pilot five years ago and keen on exploring the five teachers' perceptions after participating in CAR pilot (both workshop and the project). Specifically, I explored what were the benefits of CAR to them, the challenges they faced, support gained as well as the possibility of sustaining the CAR practice as a tool of their PD.

Although Creswell (2007) and Merriam (2009) caution that single case study can be criticised for their lack of representativeness since their findings cannot be generalized beyond the particular study, I believe there are values or lessons to be gained from participants that will add knowledge to the literature on how CAR could potentially develop teachers' professional development in the Indonesian context.

\section{Context and Setting: Brief overview}

This present study investigated four English teachers and one Chemistry teacher ${ }^{8}$ who participated in the CAR pilot that was provided and organized by the Provincial Education Office or DIKJAR (Dinas Pendidikan dan Pengajaran) in 2005-2006. More detailed background

\footnotetext{
${ }^{8}$. The background description of the teachers is further described on p. 83-86.
} 
information about the pilot is provided and discussed in Chapter 5; therefore this section only provides brief information about it.

In 2005, the Central Sulawesi Provincial Education Office held its first CAR workshop (the pilot referred to on p. 13) which was attended by 150 teachers from Palu City district and 9 other districts in Central Sulawesi (outside Palu). The workshop was located in Palu City, the capital City of Central Sulawesi, and was held for five days, from 4-8 December 2005. This workshop was attended by senior secondary teachers who taught a variety of subjects (English, Science, Maths, Geography, Civics among others). In this short time workshop teachers learned the basic knowledge of conducting CAR projects, and writing a CAR proposal and a report. They had no prior experience of doing CAR since it was not offered in any previous courses in pre-service training class. The training material was delivered by an instructor team appointed by the DIKJAR which came from local university staff and LPMP (Lembaga Penjamin Mutu Pendidikan or Educational Quality Assurance Council). Following the workshop (a month after the training), teachers were advised they could then participate in the follow-up CAR project (also provided by the DIKJAR). Teachers could apply for funding to do their own projects in their own schools. The procedure for getting grants included a provision requiring teachers to form a collaborative team and then submit the CAR proposal to be examined. Once their proposal had been approved, the teachers started to work on their research projects (from 
planning to research reports), within a set time line from April to November 2006. In the end of project, they were to submit the projects reports to DIKJAR as the physical proofs that they had completed the whole process of doing CAR projects. Following this project, in December, 2006, the 10 best teacher researchers presented their findings in a forum which was attended by teachers, principals, and all parties who were involved in this pilot. (Source: DD; DS:I)

This current study focused on a small sample of the 150 teachers involved in this workshop and who had their research proposal approved.

\section{Negotiating Entry}

Entry to do research involved negotiation with several parties to get permission before conducting the field work research (Creswell, 1994). In the Indonesian context it is very pertinent to make the first approach to the top and to meet with the leader of any institution in order to gain access to conduct research in that setting. Therefore, my first "gate keeper" was the Head of Division of Secondary Education Affairs in the Palu City Education office. This person had a strategic position in the office and supervised senior secondary schools in Palu City. I was aware from my reading that gaining access to teachers using this top-down approach could compromise my relationship with the participants in that they might view me with suspicion or see me as part of the administration. I understood 
that I would have to gain the trust of the teachers by showing them that I was independent of the local education authority.

I met the Head of Division in person and I expressed my intention to do research with some teachers from schools under his supervisions. In addition, I asked for help to locate the current place of employment of the above teachers who attended the pilot workshop as confirmed by the DIKJAR Province.

At the meeting, I provided a brief written statement of the purpose of my study detailing my reasons for conducting the study and the significance of my study for Indonesia education policy (Creswell, 1994), and the ethic approval letter from Victoria University Ethics committee. I also brought a document with the names of teachers who had attended the workshop five years ago, some of whom I wanted to recruit in my study. I had been given this list from the DIKJAR Province.

In my preliminary meeting with the above staff, he advised me to write formally to the Head of the Palu Education office requesting a letter of approval to conduct study in some schools located in Palu City. I provided this letter ${ }^{9}$ (written in Indonesian) a day after that meeting and successfully gain the approval letter two weeks after the submission. This delay was due to the official staff member who was responsible for processing my letter to the top leader being on leave for a week. He also

\footnotetext{
${ }^{9}$ Letter and its English translation is included in appendices list.
} 
provided me the current employment place of 10 teachers from my list. From all the names I had provided, I did not specifically inform him which of them would become my participants.

Having gained the letter of approval, I wrote letters ${ }^{10}$ (written in Indonesian) to the principals of each of the identified schools (five schools in all) and with the letter from the Palu Education office attached. These letters stated clearly that I was asking consent only to make contact with the teacher to invite them to participate in my study. The teachers would need to give me informed consent to participate and would have the right to not take part in the research without needing to give me any reason. I met each principal in person and handed them the letter at these meetings. This gave me an opportunity to have a conversation about professional development and explain the purpose of the study. The meetings also provided me some time to get to know the principals as well as the schools. During these meetings, I expressed my intention with each school principal to do study with the teachers who were posted in their schools. Written approval letters from all schools principals were then gained 2-3 days after each meeting. I used these letters to meet my prospective participants afterwards.

${ }^{10}$ Sample of letters is put on the appendices list. 


\section{Consent from Teachers}

My first meeting with each of the teachers was in their own schools. At this meeting, I brought supporting documents such as the consent letter from the principal, the letter of invitation to participate in the study, and the consent letter for them to sign. I explained the purpose of the meeting and handed them the letter of invitation. After the teachers read my letter, I encouraged them to ask any questions in relation to it and I provided further explanation of points they wished to have clarified. Five teachers agreed to take part in my study and signed the consent form provided.

\section{The Role of the Researcher and the Relationship with Participants}

This is an exploratory study and the stance I took in my meetings with the participants was one of an educational professional in conversation with another teaching professional. The purpose of this study was not evaluative and I expressed to participants my interest in their experiences and openness to learning from them.

In this research, my position was solely as the researcher. Although, I am on the teaching staff in a local university which sometimes deals with in-service teacher training, I had no prior experience that involved in any training, supervision, or evaluation of any of the participants, nor had any of them been my former students at the university. Therefore, any teacher who decided to withdraw from the research did not risk or experience any 
disadvantage or negative effect as I stand quite outside their individual professional teaching experience. I took care to assure these teachers that I was not in a position to make decisions concerning their careers and promotion and that the top-down negotiation for entry only served solely to gain permission to conduct study in schools; it was not permission for providing performance evaluation of teachers or any other purposes.

\section{Research Sample}

In this research, I employed purposive sampling technique in selecting the research participants. Johnson and Christensen, (2008, p. 239) define purposive sampling as "a non-random sampling technique in which the researcher solicits persons with specific characteristics to participate in a research study". In line with this, I identified the following three criteria for participant inclusion in my study: (1) Secondary English (or other subject teachers) in Palu City; (2) Teachers who attended the CAR workshop/training and did a CAR project which was held and funded through the project of quality enhancement of Central Sulawesi Education

office in 2005-2006; and (3) Those teachers meeting criteria 1 and 2, who still remained teaching in secondary school in Palu City.

Data obtained from the DIKJAR office indicated 10 of the original 150 teachers who were involved in the 2005-2006 CAR pilot were the secondary English teachers from Palu City. These 10 teachers, then, were 
selected to be invited to participate in this study for which I required a minimum of five teacher participants. The 10 sufficiently represented experiences in different school contexts and different professional histories. I had anticipated that not all 10 teachers would be able to include as it would be difficult to interview all of them in the short-timeframe allowed for my fieldwork; furthermore, I was aware of the possibility that some of those teachers had been posted to other school out of Palu City or had got their pensions. As a backup plan, I approached teachers in the other subject areas who fulfilled the three above requirements.

In practice, not all the 10 English teachers were able to be involved in my study. The data from DIKJAR Palu City revealed that two of identified teachers had got pensions and retired, three had been posted to a position outside the Palu area, and one teacher had been promoted as a school supervisor. The remaining four teachers were keen on participating in my study. In addition to those four teachers, one chemistry teacher who I invited to participate agreed to be involved as well. Overall, I had five teachers who were available and interested to take part in my study.

\section{Description of the Sample}

The five participants were all senior secondary teachers who were teaching in state-owned senior high schools (Locally termed as SMUNSekolah menengah umum negeri) in Palu City, Central Sulawesi. Their 
education level and teaching experiences varied. Due to the length of their teaching services, four of them are regarded as senior teachers in their schools. The following descriptions of teachers' background were gathered through the first brief interview using a short questionnaire in my first meeting with them. The descriptions are below.

Teacher A. Teacher A teaches English as a subject. She graduated from a local privately-owned university in Palu City and holds a Bachelor in English teaching degree. She commenced her teaching career five years ago as PNS teacher (State-employed teacher) in a senior high school (SMUN) in Palu . In her school, she is actively involved in helping students to develop their English speaking ability through various programmes such as an English debating programme. Some PD workshops she had participated in were related to curriculum and scientific writing. She attended the first CAR workshop and the CAR pilot conducted by DIKJAR in 2005-2006. Following this, she continued to participate in other CAR workshops and training including a CAR workshop conducted by LPMP (the Educational Quality Assurance Council) in 2008. In her class, she continues to implement CAR projects; her most recent project focused on dealing with students' problem in reading English texts. At the time of the study, she had conducted two CAR projects and indicated that she was keen on sustaining this practice (Source: TA:SI ${ }^{11}$ ).

\footnotetext{
${ }^{11}$ More on labelling the data is on p. 93 in this chapter
} 
Teacher B. Teacher B is regarded as a senior English teacher in SMUN, Palu City; this is due to her 22-year teaching experiences. She passed the certification in 2008 and got a "certified teacher" label from the government ${ }^{12}$. As a senior teacher, she was appointed by her English teacher fellows to be a secretary of MGMP of English teachers group in Palu City. She holds a Bachelor degree of English teaching and recently (2010) she gained her Masters degree in Teaching English as a Foreign Language from the local state-owned university in Palu City. Many PD workshops or training in which she has participated were related to her teaching field and profession as an English teacher. Following the pilot, she attended another 2 -day CAR workshop conducted by LPMP in 2008. However, she did not continue to practice the CAR project after the first pilot until it became a requirement for completing her postgraduate study. Thus, her last CAR project was completed for the sake of getting her Masters degree (Source:TB:SI).

Teacher C. After passing the test for certification in 2009, teacher C also officially gained the status and professional allowance of "certified teacher" in 2010. Since 1990 she has taught English in different schools in Palu City, ranging from junior secondary school or SMP to senior

\footnotetext{
${ }^{12}$ A "certified teacher" is a teacher who is eligible to receive a professional allowance from government as mandated by the Teacher Law. Teacher certification is discussed more fully in Chapter 1, p. 22-24.
} 
secondary school or SMU. She graduated with a Bachelor of English teaching education from the local state-owned university in 2000 and is currently pursuing her Masters degree in the same university. She has participated in PD activity both in schools and other institutions such as DIKJAR and LPMP; some of this PD activity is related to pedagogy and the use of ICT, and curriculum. Her involvement in CAR (both workshop and project) was very limited; the only CAR workshop and project she engaged with was the one conducted by DIKJAR in 2005-2006. Following that, there was no attempt from the teacher to continue the practice. She also lacked opportunity to attend more CAR training after the pilot (Source: $\mathrm{TC}: \mathrm{SI})$

Teacher D. In 2007, this English teacher gained his certification from the government. His experience in teaching is about 20 years; given this fact he is regarded as a senior English teacher in his school and also has additional task as vice principal of student affairs. His Bachelor of English teaching degree was gained from the local state-owned university in 1996 in Palu City and he has just finished his Master study in the same university in 2010. Some PD training he has participated in is relevant to his teaching profession; these include the use of language laboratory and teacher training workshop. He also participated in a scientific writing workshop in 2007. His involvement in CAR project began with his participation in the DIKJAR CAR pilot in 2005-2006. Following that, he completed another CAR project individually with his own budget. He 
submitted the reports of the two CAR projects to be published in a teacher journal in other provinces for the sake of getting credit points. In turn, he used those credits for career enhancement ${ }^{13}$. Another CAR project was completed for the purpose of completing his study to gain a Masters degree in English teaching education (Source: TD:SI).

Teacher $\mathbf{E}$. This teacher commenced her career as a chemistry teacher in 1995 after graduating from a local state-owned university in Palu City. She gained her Masters degree in chemistry. She participated in both local and national PD workshops/training related to her expertise as a science teacher, as well as a CAR workshop. In terms of research experience, she was first involved in research activity in her school in 1999; that is, before being involved in the CAR project in 2006 . Following the first CAR project, she continue to do the project in her school and to date has published three CAR articles - one in national mathematics and science journal, another in local university journal, and the third one in an online education journal. Given that, she has rich experiences in research in her field, and she is currently a contributor to an online site for sharing knowledge in Indonesia. On this site, she shares her CAR research as well as other information related to her teaching expertise to other teachers (Source: TE:SI).

\footnotetext{
${ }^{13}$ How CAR reports/articles can be used for career enhancement is discussed in Chapter 1.
} 


\section{Data Collection}

Data were collected when I met with participants individually on two occasions; first, a brief initial semi-structured interview to complete a short questionnaire about their professional background, followed a few days later by an in-depth interview about the participants' experiences in doing CAR (Merriam, 2009). I also collected written documents from each participant related to the workshop and their research projects. Additional data in relation to background information about the purpose, content, and materials of the workshop was also collected from the trainer and education officer in short, focussed interviews conducted in face-to-face meetings (Kvale, 1996). Further, means of data collection are described below.

Questionnaire. A brief questionnaire (appendix 2) was used to gather background data from the five participants about their teaching careers and their involvement in PD. The questionnaires were completed in the form of a semi-structured interview during my first meeting with each of the participants (Merriam, 2009). The brief questions were written in English (these are all teachers of the English language). In addition to the written questions, I also interviewed each teacher briefly about their teaching experience and PD (CAR in particular). Although the questionnaire in English I decided to conduct the interviews in the Indonesian language as I reasoned it would be easier for the participants to express their ideas in Indonesian. All the meeting were conducted in 
teachers' own schools and each took about 30 minute to complete. At the conclusion of these initial individual meetings each of the teachers then agreed to a follow-up interview to be conducted a week later.

Interviews. An in-depth interview is used to explore rich detailed information from research participants (Kvale, 1996). This took place in my second meeting with each of the five participants. Two types of questions are used in structured open-ended interviews (Best \& Kahn, 1998): basic questions and clarification questions. The exact wording of basic questions is predetermined and all interviewees are asked the same questions in the same order. Clarification questions are used when it is necessary to probe the responses to the basic questions.

In this study, the in-depth interview was designed to guide the "conversation" through open-ended questions and a series of probes to ensure that all topics of interest to my research questions were addressed. The interview consisted of five main open-ended questions (appendix 1) and each one was from 60 to 90 minutes in duration. During the interview, a digital audio recorder was used to record responses from interviewees. This in-depth, one-to-one interview was conducted using Indonesian language and the interviews were transcribed by myself as the researcher.

Following the first meeting, I contacted each of the teachers to remind them about the interview time that we had agreed to do. With the consent of the teacher, the second round of interviews was conducted in each of the participants own school that took place mostly in their work 
area room which was small and private to ensure privacy. During this meeting, I also offered them if there were follow-up questions that I missed, I would contact them to get more data. To show my appreciation, I also gave each of them a token of gift in my second meeting with them. All interviews with the teachers were made in one month. Following this, I wrote transcription of each interview in Indonesian and brought it back to them to the teacher concerned for checking purpose.

Documents. Merriam (1988) defines documents as the source any form of data not gathered through interviews or observations. Documentbased data inform the research by increasing the credibility of the research findings and interpretations. Such data can be used to describe, understand and explain how things function at the sample sites. In this study, the documents acquired from the participating teachers served as additional evidence of their experiences in conducting action research. I had access to the documents related to the CAR projects that had been conducted by these case study teachers five year previously. Some of these documents were in the form of articles that the teachers had successfully submitted to teachers journal both offline and online (from Teacher D, both documents were from the same education journal; from teacher $\mathrm{E}$, one was in national mathematics and science journal, one in local university journal, and one in an online education journal); others were still in the form of original reports (to ensure confidentiality, these reports were not put on the reference list). The reports were solicited in the 
first round of meetings with the teachers at which they gave their consent for me to copy those documents. In the second meeting with me, the teachers brought the copy of their CAR proposal, reports, or articles to be copied by me. By this means, in all I managed to obtain one proposal, three CAR reports, and 2 CAR articles which teacher had had published in Journals.

\section{Gathering Data from Trainer and Education Officer}

As well as gathering the participant teachers' perspective, I also sought other perspectives on the CAR process through interviewing key people who delivered or designed the workshop. The collection of this additional data - from the workshop trainer and from the DIKJAR officer involved in the workshops and grant processes and the monitoring of the project - was aimed at gaining more background information on how the policy of CAR workshop and pilot was developed and designed. To collect this data, I set up informal interviews to find out which documents were publicly available and where these documents were located or published.

I was able to meet one member staff of provincial Education office who had been a project leader of this CAR pilot and he was keen to provide me with some relevant information about the background of the CAR pilot. I chose him as he was the key player in this pilot and knew well the background of the pilot. Prior to interview session, I visited him in 
person in his office and expressed my intention to find out information needed for my study particularly related with the backgorund of the CAR pilot. In addition, during this meeting, I shared with him what was the concern of my study and the possibility of the contribution of this study toward the effort of DIKJAR office to promote the teachers' professional growth in Central Sulawesi. I gave him a letter of invitation to participate in my study as well as the consent letter to sign. He agreed to be the participant of this study and keen on being interviewed as well as providing me some documents that were relevant to my study - that is, a complete report and guideline of the pilot in the form of a soft copy document. I ensured him that all information gained from him would not be informed to others; except for the purpose of this study. I was able to interview him for about fourty five minutes and the interview took place in his office room. For this interview, I used a guided question list that helped me to gain information from him (See appendix 3)

In addition, to gain background information from the trainer's side, I set up a meeting with one of the workshop instructors who delivered CAR material to the participants. I selected this particular instructor as he was the only one who delivered CAR materials in the workshop. I believed he could provide me some information that I needed in this study. This instructor works for LPMP institution and was actively involved in providing CAR workshops for teachers. This instructor agreed to meet him after I previsouly made a phone call contact to arrange meeting with him. I met 
him in his office and I expressed my intention in relation to my study and handed in letter of invitation to study accompanied the concent letter for participating in my study. Having read and understood the letter, he agreed to provide me some information through interviewing. This interview took place about 45 minutes. He provided me with inputs of how CAR workshop was delivered and evaluated as well as explaining his roles as assessor team and the monitoring team. In addition, he gave me some materials (in soft copy) that he used in the CAR workshop. The interview question was attached in appendix 4.

\section{Research Data-reference}

Given that I used more than one ways to gather the data, I provide a code for each source of data I used to refer it in the other chapters. Coding of research data-reference is presented in the table below.

\section{Table 2. Research data-reference}

\begin{tabular}{|l|l|}
\hline \multicolumn{1}{|c|}{ DATA } & \multicolumn{1}{c|}{ Refers to } \\
\hline A/B/C/D/E & Specific teacher (e.g. Teacher A) \\
\hline$T$ & Teacher \\
\hline DS & DIKJAR staff member \\
\hline WI & Workshop instructor \\
\hline SI & $\begin{array}{l}\text { Short interview 1 guided by } \\
\text { questionnaire }\end{array}$ \\
\hline I2 & In-depth Interview two \\
\hline I & Interview \\
\hline CR & CAR Report \\
\hline DD & DIKJAR Document \\
\hline WM & Workshop Materials \\
\hline & Examples: \\
\hline
\end{tabular}




\begin{tabular}{|l|l|}
\hline \multicolumn{2}{|l|}{} \\
\hline TA:I2 & Teacher A: from interview two data \\
\hline TA: CR & Teacher A: data from CAR report \\
\hline WI: I & $\begin{array}{l}\text { Workshop instructor: from interview } \\
\text { data }\end{array}$ \\
\hline
\end{tabular}

\section{Data Analysis}

For the data analysis of this research I applied grounded theory techniques for coding and deriving patterns and themes (Strauss \& Corbin, 2007, cited in Boieje, 2010). This was a single case study design (Merriam, 1998) and therefore the data recording the experiences of these five senior secondary teachers was considered a single case study of CAR in an Indonesian setting aggregated when analysed. In this case, thematic analysis was used as it was considered the most suitable method for analysis of the data as it dealt with naturally occurring events and it provided thick descriptions and information that lead to answers (Miles \& Huberman, 1994).

The thematic analysis in this study involves collecting, recording and transcribing the interview data as well as doing coding (Miles \& Huberman, 1994). Coding was done by hand and not using the NVivo software; this was because I found it was easier to do that than using other means, and because I had a small number of participants. In this case, data from the interviews and documents were then coded in three ways: open coding, axial coding and selective coding (Strauss \& Corbin, 
2007, cited in Boieje, 2010). Open coding refers to the initial interpretive process by which raw research data are first systematically analysed and categorised (Matthew \& Price, 2010, p. 155) and the data collected are read carefully and divided into fragments which then be compared, grouped, and labelled with a code (Boieje, 2010).

The next step was doing the axial coding. Wicks (2010, p. 154) describes axial coding as "the process of relating categories to their subcategories, the outcome of open coding". In this stage, categories found in open coding are grouped (Merriam, 2009) and tested by confronting them with new materials (Boieje, 2010). In this stage, "the relationship between salient categories (axes) and subcategories can be generated, modified, refined, elaborated, or even rejected", Boieje (2010, p. 108). The last stage of the coding process is selecting coding which refers to "the final stage of data analysis to be completed after core concepts emerging from coded data categories and, subcategories have been identified through open and axial coding, (Mathew \& Price, 2010, p. 157). Boieje (2010) describes the activity in this stage as determining core concepts and the relationships between the concepts as well as verifying them, thinking about the answer to the research questions, and drawing conclusions.

Prior to analysing the data, I transcribed all the data in Indonesian myself and then translated it into English. Likewise, data analysis was done in Indonesian. For me, doing transcription and data analysis in 
Indonesian made it easy for me to interpret and express the teachers' experiences as well as to ensure that none of teachers' expressions were "misinterpreted" in the analysis. It was important to keep their expression in context.

Once I had gathered and transcribed the data, I began the process of analysis. I firstly read the data transcription from each teacher and I coded a word, or phrase, or even sentences that I thought relevant to my research questions (Merriam, 2009). I labelled this by putting in the small column and put in the margin side of the transcript to capture the ideas from the participants. From this phase, I then grouped some of the codes as the themes emerged. I put all the same categories in a matrix column so that I could group and compared all codes from the transcription and derived certain themes as they emerged from these codes. In the end, I grouped all data of the same categories to which I applied labels. These categories are discussed in Chapter 5

To illustrate how I did open coding, I provide one example thus: I read through all the transcripts seeking any mention of any barriers or difficulties the participants had experienced when conducting their projects. I coded any words, phrases and sentences that related to this theme from each transcription of the teachers' interviews. From Teacher B, for example, I coded the phrase "no mentoring took place"; from teacher A, I coded the short sentence "I didn't find the right place to expose my problems". From this open coding, I then grouped all the codes phrases 
into categories, putting similar statement or phrases together and labelled each category, finally grouping all these categories together as a new theme.

\section{Data Triangulation}

Johnson and Christensen (2008, p. 276) describe triangulation as "Cross-checking information and conclusions through the use of multiple procedures or sources". Lancy (1993, p. 20) notes that "using multiple data sources also allows one to fill in gaps that what would occur if we relied on only one source". In qualitative research, the use of data triangulation may increase the credibility the research findings by providing corroborating evidences from a variety of data sources (Creswell, 2007).

In this study, once I had found my themes through the in-depthinterview data analysis, I matched these data with other data from my interview from DIKJAR staff member and a workshop instructor. I took any statements from these sources that supported the themes that I had grouped and put them in matrix column too. Likewise, a similar procedure applied if there were any data from documents both from teachers and the above parties that I though relevant to support my themes. 


\section{Validity, Reliability and Trustworthiness}

It is essential to ensure trustworthiness of this research through validity and reliability. Validity refers to the degree to which the data collection procedure measures what it is intended to measure, while reliability refers to the degree of consistency that an instrument or data collection procedure demonstrates (Johnson \& Christensen, 2008). In qualitative research these terms correspond to credibility (internal validity) consistency/dependability (reliability) and transferability (external validity), (Lincoln \& Guba, 1985, cited in Merriam, 2009).

Credibility. Credibility (internal validity) in qualitative research refers "to the extent to which a research account is believable and appropriate, with particular reference to the level of agreement between participants and the researcher", (McGinn, 2010, p. 244). (Merriam, 2009, p. 213) asserts that credibility is related to the question "are the findings credible given the data presented?" Merriam (2009) further suggests that five strategies to ensure the degree of credibility of study can be met: use of triangulation, member checks (respondent validation), and adequate engagement in data collection, reflexivity and peer review. Denzin in Merriam (2009, p. 215) proposes four types of triangulation "the use of multiple method, multiples sources of data, multiple investigators, or multiple theories to confirm emerging findings". In member checking, "the researcher solicits participants' views of the credibility of the findings and interpretations", (Creswell, 2007, p. 208). The notion of reflexivity refers to 
"the process of reflecting critically on the self as researcher", (Lincoln \& Guba, 2000, cited in Merriam, 2009, p. 219). In this case, Merriam (2009) suggests that the researcher "needs to explain their biases, dispositions, and assumptions regarding the research to be undertaken, (p. 219).

Of the five above strategies, Creswell (2007) recommended that triangulation and member checking are essential to do as well as costeffective procedures. For the purpose of my study, the use of different kinds of data collection (data triangulation) was used; data was collected both from interviews with teachers and policy documents. Furthermore, I checked teachers' understanding of the purpose of CAR against the understanding of the trainer and the DIKJAR officer, thereby gathering different perspectives on the same events (workshop and CAR project pilot).

In addition to this, I also used member checking to ensure there was no discrepancy between my understanding of the teachers' responses and the meaning they intended in their responses. My understanding was checked by returning the written transcriptions of the interviews to interviewees so that they could review the data for necessary amendment. In this case, no changes to the transcription were made by the participants and they agreed with the content of the transcription.

Transferability. Transferability or internal validity refers to "the extent to which the findings of one study can be applied to other situations", (Merriam, 2009, p. 223). This can be achieved through "thick 
description" and the use of "purposeful sampling" (Jensen, 2008). Jensen (2008) describes that "thick description means that the researcher provides the reader with a full and purposeful account of the context, participants, and research design so that the reader can make their own determination about transferability", (p. 886).

In line with the above statement, to ensure transferability, I have included detailed description of participants and their professional background as well as lengthy excerpts from the interviews that provide thick description of themes that are central to my findings (Creswell, 2007).

Consistency/Dependability. Consistency or reliability is concerned with "whether the results are consistent with the data collected", (Merriam, 2009, p. 221). Merriam (2009) suggests four strategies to achieve consistency/dependability: triangulation, peer examination, investigator's position and the audit trail. Further, Merriam (2009) explains audit trails "describes in details how data were collected, how categories were derived, and how decisions were made throughout inquiry", (p. 223).for this purpose, she suggests to use a research journal or to record memos in which the researchers can write reflections, questions, decisions that they made that pertain to problems, issues, ideas they face in collecting data.

Pertaining to this issue, this study adopted the use of data triangulation through understanding teachers' perspectives as expressed in interview and official views revealed in documents. This also adopted 
corroborating the teachers' understanding with related parties involved in CAR pilot.

\section{Research Ethics}

In undertaking this study, I was aware that I must abide the procedures of code of ethical conduct of Victoria University of Wellington. Ethical approval for this study was sought and given by the Human Ethics Research Committee at Victoria University, in August 2010. Throughout this study, one of the most important considerations was to protect participant confidentiality. Therefore, considerable care was taken to ensure that no harm would be done to the participants during the field works phase (Bogdan \& Biklen, 2003).

To ensure confidentiality, I provided information about the project both in written form (Appendix 5) and through explanation at meeting for the potential participants (both teachers, the DIKJAR staff and workshop instructor). Participants were also solicited for their consent to be involved in the project by signing a checklist of procedures that would be taken to preserve their confidentiality and anonymity as participants in the study (Appendix 6). These included also such precaution as the use of pseudonyms for participants and not identifying the school site in any published records of this research. I also made a commitment to 
participants that research data would be stored securely, and destroyed within two years of the project's completion.

However, I reflected that my way of gaining entry negotiation using top-down strategies could possibly compromise the confidentiality I was promising the participants and could result in the teachers being reluctant to take part in my study. Hence, during the first round of meeting I emphasised that the purpose of obtaining consent from the local Education office was only to gain access to the schools and not for other purposes such as evaluating teachers' performances, and that Education office would never be informed as to which teachers I finally did include in my study. To gain teachers' interest, I stressed my intention that the output of this research would be valuable for enhancing the teachers' professional development in the future. Therefore, most teachers regarded me as the one who explored the story for them for the sake of improving the condition of teachers' community in Palu City, specifically among English teachers' network groups.

\section{Limitations of the study}

This study had two notable limitations that potentially affected the outcome of this study. The first one was related to the representativeness of the sample and the second one was connected with the time lapse between the case that I investigated and the study was being conducted. In the previous one, I was aware that the inclusion of the chemistry 
teacher in my study could provide the bias results of my study as I focused my study to explore the experiences of English teachers engaged with CAR. Yet, as I was informed by the studies which revealed that regardless of what subjects they teach, teachers in general benefited from doing CAR as well as face challenges in practicing it; hence the need of support should be executed to facilitate them to grow professionally through CAR (e.g. Atay, 2008; Borg, 2009; Burnaford, 1996; Calhoun, 2002; Ginns, Heirdsfield, Atweh, \& Watters, 2001; Gore \& Zeichner, 1991; Hancock ,1997; Tinker Sach, 2000; O'Sullivan, 2002). Therefore, this study also could not be applicable and generalized in other context in Indonesia, particularly, and in other countries in general.

The latter limitation concerned with the CAR pilot was investigated took place in year 2005-2006. For my study, I found difficult to get as many as possible the sample of my research since most of them got pension and were posted to other areas. This implicated to the small number of participants selected for the study. In addition, I was aware that the pilot condition in 2005-2006 that I investigated could be different condition from recent pilot that might be executed by other party which may give less contribution to the PD providers in Palu city. However, my worryness could be diminished as I was informed from this study that none of similar pilot has been initiated by the PD providers in Central Sulawesi generally, and particularly in Palu city (see page 121). Hence, the output 
of this study could potentially contribute to the related party who wish to enhance the teachers' PD through CAR pilot.

\section{Chapter Summary}

This chapter has discussed the methodological approach which was used for the study. This study adopted a single case study using qualitative approach. This approach was selected as appropriate to explore experiences of the five teachers who participated in the CAR pilot conducted by DIKJAR province of Central Sulawesi. Purposeful sampling was used to select the five teachers for the study. Additional information was also gathered from the DIKJAR staff and workshop instructor. The main form of data collection was through in depth semi-structured interviews with the teachers and from teachers' documents relevant to the study. Additional data was gathered from informal interviews with and documents from other parties involved in the pilot. An explanation is provided of how the data was analysed using thematic analysis. Finally, the ways in which rigorous was ensured throughout the study are fully explained. 


\section{CHAPTER 4}

\section{The Classroom Action Research Pilot Case Study}

This chapter provides a description and critical consideration of the original CAR pilot that had been conducted by the provincial Education office (DIKJAR) of Central Sulawesi under the sub-section of secondary and tertiary education project. This description is derived from the documents that contain guidelines and reports of the pilot that I obtained from DIKJAR staff and from workshop materials given to me by the trainer, as well as from the interviews with these parties (a DIKJAR staff member who was previously the project leader of the pilot and the workshop trainer). Likewise, this chapter discusses the follow-up pilot programme including the evaluation and monitoring of the pilot. The chapter critically assesses the objectives and format of the pilot in the light of the international literature on CAR and, at the end of this section, brief analyses of five teachers' CAR reports are presented. This chapter provides key conceptual information for making sense of the teachers' experiences in the following chapter.

\section{A. CAR Workshop}

The workshop key player. The CAR pilot workshop was conducted in $2005-2006$ by DIKJAR of Central Sulawesi Province, and was part of the project to enlarge and develop the quality of secondary 
schools. It was designed by the DIKJAR staff who also officially appointed a team to set up the workshop and this CAR project. This team consisted of two lecturers from a local university and three teacher trainers from LPMP institution (or the Educational Quality Assurance Council) of Central Sulawesi. DIKJAR's role was to provide financial support and to manage the workshop participants' needs such as accommodation, transportation, pocket money, printed materials, and other needs. The design of workshop in terms of the purpose of the workshop, length of the workshop, what materials were presented, and the selection of instructors was given to this team; two from LPMP had previous experience in designing similar workshops for teachers at the junior secondary level in 2000 . Hence, this workshop was adopted from that previous project (DD, DS:I).

Workshop instructors. The instructors for this workshop were the team as mentioned above and who, based on their qualification degree and experiences, were considered qualified in education research as well as classroom action research. The two instructors from the state local university hold Ph.D degrees in Education and are active trainers for teachers organised by provincial and local DIKJAR. These instructors delivered research in education materials in this workshop. Three other instructors were the master teachers from LPMP institution - an institution which is in charge of providing training for teachers and now focuses on educational quality assurance. Two of them were from a teaching background before becoming teacher trainers and working for this 
institution. These two instructors had previous background experience in doing CAR projects with university teacher educators and had helped teachers to learn to do CAR through another project (enhancing the quality of junior secondary teachers project held by provincial DIKJAR in 2000 under ADB funding ${ }^{14}$ ). Currently, all instructors from LPMP are involved as trainers for CAR under the current BERMUTU ${ }^{15}$ program. Other instructors came internally from DIKJAR staff which presented the policy of the institution in developing teacher's professionalism (Source: DD, DS:I, WI:I).

Rationale of the workshop. The CAR workshop was conducted to meet the government mission of enhancing Indonesian teachers' pedagogic competence through doing research. Prior to this workshop, there had not been a massive training which broadly informs the CAR approach toward senior secondary teachers in Central Sulawesi province ${ }^{16}$. Hence, the CAR workshop was held to introduce the concept of CAR to teachers, as well as giving those teachers skills to be able to implement this CAR approach in their own schools. In particular, the CAR workshop had generally aimed at:

- Informing teachers about the concept and methodologies of CAR design and its potential for improving the teaching and learning process among the teachers.

\footnotetext{
14 This project has been mentioned in Chapter 1, p. 10-11

15 BERMUTU project is mentioned and explained in Chapter 1.

16 Information how CAR was firstly introduced in Central Sulawesi context is explained in Chapter 1, p. 10.
} 
- Facilitating teachers to be able to write a proposal and a report about CAR projects conducted in their own schools.

- Outlining the policy of DIKJAR from the division of directorate of secondary and tertiary education, contextual teaching and learning, the ethics of the teaching profession, school culture, effective school, and active, creative and joyful learning approach (DD).

Objective of the workshop. It was expected that by the end of the workshop the participants would understand the concept of CAR as well as be able to apply it in the classroom. Furthermore, they should be able to write a good CAR proposal and report based on their projects in their own schools (DD, DS:I).

Participants. Participants of the CAR workshop were recruited from senior secondary high schools, both state and privately owned schools in Central Sulawesi ${ }^{17}$. The 150 teachers came from one municipal city and nice districts across Central Sulawesi ${ }^{18}$. They taught a range of subjects (such as math, science, history, civics, geography, and English) and the workshop was not specific to a single subject. The recruitment of participants was largely given over to each local Education Office who could nominate schools in their area who were then invited to attend the workshop. In this case, each district Education Office followed the guidelines from DIKJAR of the quota number of teachers that they could

\footnotetext{
17 State and privately owned schools are described in Chapter 1, p. 13.

18 The location of Palu city and 9 other districts is shown on the Central Sulawesi Map, p. 32.
} 
send to attend the workshop. Of the 150 participants, 80 were teachers from Palu city (the capital city of Central Sulawesi) and 70 others came from the nine other districts. At this first pilot for senior secondary teachers, not all senior high school teachers in Central Sulawesi had an opportunity to attend the workshop. However, it was expected that the trainees would share this concept to the other teachers who had not been given a chance to participate in the workshop. Due to the large number of participants, the workshop was offered in two groups: participants from Palu city and those from outside Palu city. The participants of this study attended the workshop along with the 150 other teachers (Source: DD, DS:I)

Location of workshop. Palu city hosted the workshop for the participants who came from all over the province. The committee chose one location that became the centre of all activities including the accommodation of participants from nine remote districts (Source: DD).

Content of workshop. During the workshop, participants learned materials that related to their practice as well as the basic knowledge of doing research and most importantly workshop materials that related to classroom action research. The content materials of workshop were as follows:

- the policy of the DIKJAR in relation to teacher's professional development

- developing teachers' professionalism through writing scientific works 
- basics of scientific research in education

- qualitative research

- classroom action research

- technique of writing CAR proposals and reports, and

presenting CAR reports (Source: DD)

Participants learned the history of action research, the differences of the CAR approach to other type of research, the strengths and weaknesses of action research, characteristics of action research and methodology of CAR (Source: WM).

In terms of CAR methodology, the trainer used a model by Kemmis and Taggart (1988) which is popular in the Indonesian context (WM:I). This model adopts the cyclical process from planning the action, implementing the action, observing the action, and reflecting on the action. In the planning phase, teachers learned how to identify the problem, analyse and formulate the problem, and plan solutions to it. In the implementing phase, they learned how to prepare the action, and make changes. In the observation phase, they learned how to use different kinds of observation and procedures of good observation. Lastly, they learned to reflect and analyse the action for further action in the reflection phase (Source: WM). Kemmis and Taggart's model can be seen below. 


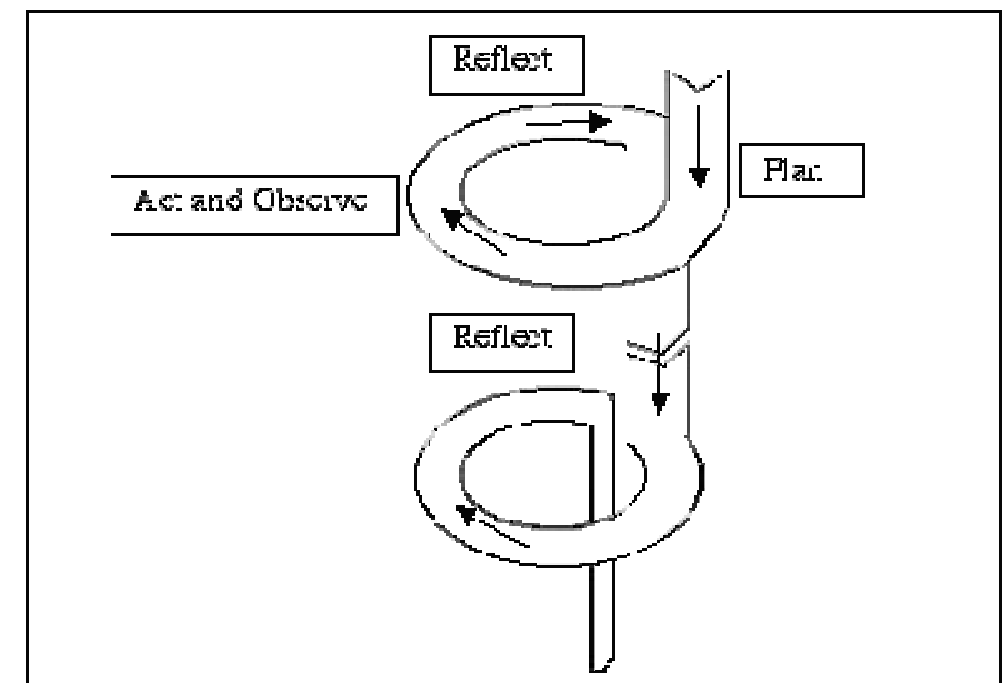

Figure 3: Action Research Model of Kemmis and Taggar

\section{http://www.iier.org.au/qjer/qjer14/howden.html}

In the workshop participants learned only the basic concepts of how to do CAR based on the above model. They did not learn specific techniques of applying the CAR concept in their own teaching subject. The participants of my study were mostly English teachers, one of whom commented that the materials presented - in particular the concept of CAR - were quite general and did not specifically address their questions related to their teaching background (TB:I). According to the CAR workshop provider, this policy was applied to accommodate the various teaching backgrounds of participants. In addition, it was hard to accommodate their specific needs coupled with the insufficient time allocated for explaining the concept of CAR (DS,WI:I). 
Besides learning the above material, the teachers were guided to write a proposal and report of CAR project. Writing a proposal was regarded as critical for the sake of applying for research grants. In terms of dissemination, teachers learned how to report their research in a wellstructured report. At the end of workshop, group leaders presented their group's written proposal to the class for 5-10 minutes and had the chances to get feedback from other groups (Source: DD, WI:I). Some teachers (e.g. $T A, D, E: I)$ found that this type of material was beneficial for them to be able them to apply for grants and write the CAR report in good way.

Time of workshop. The workshop was held over five days, from 48 December 2005. From these five days, only three days were effectively used for delivering materials to the participants. In addition, only 26 hours was allocated for presenting materials to the participants (Source: DD).

Times allotted to content of the workshop are presented below:

Table 3: Content of workshop and its allocation hours

\begin{tabular}{|l|c|}
\hline \multicolumn{1}{|c|}{ Content of workshop } & Hours allotted \\
\hline $\begin{array}{l}\text { The policy of the DIKJAR in } \\
\text { relation with the supervision of } \\
\text { teacher professionalism }\end{array}$ & 2 \\
$\begin{array}{l}\text { Developing teachers' } \\
\text { professionalism through writing } \\
\text { scientific works }\end{array}$ & 1 \\
$\begin{array}{l}\text { Basics of scientific research in } \\
\text { education }\end{array}$ & 3 \\
Qualitative research & 2,5 \\
\hline
\end{tabular}




\begin{tabular}{|l|c|}
\hline $\begin{array}{l}\text { Classroom action research } \\
\text { concept }\end{array}$ & 2 \\
Techniques of writing CAR & \\
proposals and reports & 3 \\
Presenting CAR proposal & 4.5 \\
Presenting CAR report & 3.5 \\
\hline \multicolumn{1}{|c|}{ Total } & 26 hours \\
\hline
\end{tabular}

As shown in the above table, of the 26 hours, 2 hours was allocated to present the CAR concept and 7.5 hours were devoted to writing CAR proposal and reports. One instructor revealed that time allocated for explaining CAR itself limited. Based on his experiences involved in the BERMUTU programme, he estimated that to expect teachers to well understand and apply the concept of CAR in the classroom needs 16 sessions of 4 hours each.

Workshop mode of learning. The delivery of material took place through both lecturing and practical activity. The trainer used lecturing mode to explain the concept of CAR and, later, participants got a chance to apply what they had learned, such as writing a CAR proposal or orally reporting to the other participants. Mostly, students were assigned to groups to complete tasks. The trainer said that of the six hours CAR allocated to material, 2 hours were designated to explaining the CAR concept and the other four hours were allocated for practical activity such 
as a group of five teachers collaborating to write a proposal and presented their works afterward (Source: DD; WI:I).

\section{B. Conducting CAR Project Following the Pilot}

Following the workshop, DIKJAR of Central Sulawesi set up a contestable fund for teachers interested in conducting CAR projects in their own schools. They were required to work collaboratively with other teachers and this fund was open to all teachers regardless of whether or not they had attended a CAR workshop or not (DD; DS:I). Following the pilot, teachers who had their CAR proposal project approved by the assessor were provided grants of five million rupiah (equals to approximately 850 NZD) to support them to conduct their projects. This grant was designated to 100 CAR proposals, (in this case, teachers formed groups of three) who were eligible to get the funds (Source, DD: DS:I).

Objectives of the pilot research project. The pilot aimed at:

- Enhancing the quality of input, process, and output of education and teaching and learning at school (in particular of general high schools and vocational schools)

- Helping teachers to combat the issues of teaching and learning inside and outside schools

- Enhancing the professionalism of teachers 
- Developing academic culture at school that lead to creativity, proactively, and initiative for improving the quality of education and sustainable learning

- Enhancing skills of teachers to do classroom action research, and

- Enhancing professional partnerships among teachers at schools (Source: DD).

CAR scope of study. Teachers chose the topics for their CAR projects related to students' learning problems, design and strategy of learning in the classroom, tools, media and source of learning, assessment and evaluation processes, students and teacher's personal development, or curriculum issue (Source, DD).

Expected outcomes of the pilot. DIKJAR identified the following expected outcomes from the teachers' CAR project:

- The enhancement and improvement of students' learning achievement at schools

- The enhancement and improvement of quality of learning process in the classroom

- The enhancement and improvement of the use of tools, media and other learning sources by teachers

- The enhancement and improvement of the means of evaluation that used to measure the progress and the students' learning achievement 
- The enhancement and improvement of students' education problems at schools, and

- The enhancement and improvement of the quality of curriculum implementation and developing the students' competency at schools (Source, DD).

The pilot process. Commencing on February 2006, DIKJAR distributed a letter of invitation to senior high school teachers in one municipal city and nine districts in Central Sulawesi. A guide to writing a CAR proposal and its assessment were also sent off with this letter. This invitation was open to all teachers from senior secondary schools (private or state-owned) ,whether they had attended workshop or not, who intended to do CAR projects funded by the DIKJAR grants. It was a very competitive process in which all the submitted research proposals went through a selection process by the proposal assessment team. It encouraged teachers who had attended the CAR workshop to form a team with those who had not attended yet. This pilot provided 100 grants to each research team of three teachers respectively.

Of the 100 awardees, the majority were teachers from schools around Palu city and the rest of them were represented by teachers from some districts. Since the grant was competitive, not all teachers' proposals could be funded only those which followed the criteria set by the assessors. Furthermore, to promote partnership among teachers, each 
proposal funded was represented by a group of three teachers (one served as leader, other two served as team members). Teachers could collaborate with colleagues from their own schools or outside schools. The five participants of my study were among the 100 awardees (Source:DD).

Collaboration in CAR. It was an obligation for teachers who applied for grants to collaborate with their colleagues doing the CAR project as assigned by the PD provider. The teachers could involve teachers from within their own schools or teachers from outside their schools who teach similar subjects. The pilot provider (DIKJAR), considered doing CAR collaboratively would provide more collegial conversation among the teachers and provide more chance for teachers to work together, although this aim was not a key feature of this pilot as mentioned in the pilot outcomes ${ }^{19}$. Hence, in their proposals, teachers needed to clearly identify the role of each member of the research team at every stage of the research activity - diagnosing the problems, writing proposals, conducting CAR process (planning, acting, observing, and reflecting) analysing data, disseminating CAR results and writing the final reports (Source: DD).

Assigning the teachers to collaboratively work with their colleague fits with one of the features of CAR where teachers work together to improve their own practice, and with the aim of CAR itself to promote collegial partnerships (Mertler, 2009).

19 See page 115. 
CAR Proposal Phase. Teachers and their collaborators who were keen on participating in this CAR pilot commenced working on the proposals. They followed the guidelines for writing CAR proposals and the assessment criteria provided by the DIKJAR. The timeline given for teachers to work on their proposal was a month. The proposals needed to be approved by school principals to show that principals supported the projects. Following that, teams to submit their proposal to the province DIKJAR office in Palu to be assessed by the assessor team (Source: DD).

The selection of teachers' CAR proposals was conducted by the assessor team appointed by the DIKJAR. These assessors were mainly instructors who were previously involved in the CAR workshop. The team was able to select only 100 proposals to be eligible for a grant and these proposals had to comply with the criteria of the CAR proposal. The team assessed on the following points:

- Formulating the problems (such as relevancy and problem scope)

-Ways of problem solving (such as: action plan, criteria of success of an action)

-The significance of research outcomes

-Procedure of the research (such as: problem diagnosis, planning the action, implementing the action, observation, evaluation, reflection the result of action) 
-Supplementary activity (such as: research schedule, budget feasibility)

After the selection process, all successful proposal entries were announced. The grant awardees (represented by the team leaders) were invited to sign the contract and immediately received $75 \%$ of the grants for operational expenses of their projects. Following that, teachers had to commence their projects (Source:DD).

Action Phase. Teachers and collaborators conducted their projects in their own schools. The timeline to complete the projects - including conducting the project and writing and submitting the report - was approximately seven months, from 26 April to 11 November 2006. Progress reports were required three months before due data of the project (namely September, 2006). Any issues that emerged during the action phase had to be discussed and resolved within each team (Source: DD).

During this period, there was no support in form of provision of consultation or supervision for teachers. From the beginning of the proposal stage till the end of the action stage (actually conducting the CAR project), teachers mainly worked with their own collaborators without assistance from trainers or instructors. In addition, no venue of consultation through mail or any communication devices were set up to help teachers to do their CAR project (Source: WI:I). 
At the end of their project, teachers had to submit the final reports of their work to the committee. These reports served as evidence that the teachers had completed the process of conducting the CAR project and as a result they deserved to receive the rest of the grants. The reports then proceeded to the assessor team to be marked. There was no revision or feedback given about these reports. Marking was done for the sake of selecting best 10 research teams to make an oral presentation about their work at a panel forum which was held two weeks after the final submission. The best 10 teams received a bonus from DIKJAR (Source: DD).

Presentation was made by the 10 teams' leaders at the forum which was attended by the leaders of each of the 100 teams. Among the 10 presenters, one of them was a participant of my study (Source: DD; TE:I).

Evaluation of workshop and pilot. Although DIKJAR appointed a team to monitor and evaluate the pilot these tasks were unable to be executed and be realized (WI:I). According the DIKJAR staff and monitoring team, this was mainly due to the lack of personnel sources they had and the huge amounts of participants involved in this pilot (DS:I). Consequently, to decide the success of the pilot DIKJAR relied solely on the teachers' reports document which submitted twice (in the form of progress report and final report) Source: WI:I; DS:I).

Follow up program after pilot. Due to the absence of the appropriate evaluation of the pilot (both workshop and project), there was 
no baseline data for DIKJAR to conduct another CAR pilot. Moreover, due to the changing role of local education office, schools and MGMP forum to actively involve designing and conducting training for teachers, Provincial DIKJAR did not schedule further CAR pilots. Hence, this CAR pilot was the only programme provided by the education office of Central Sulawesi. Nowadays, the role of provincial DIKJAR serves as supervisor and finance supporter (DS:I). Further explanation of the these changing role is provided below.

1. Following the decentralization policy, Law 22/1999, the district education office is given the opportunity and responsibility for training and development for teachers at the district level. Each local education office in each district is expected to plan, design, and do any relevant programme aligned with PD including CAR. This is aimed at providing a large opportunity for all teachers in each local education office to attend any PD program specifically CAR workshops and projects. As a consequence of this policy, the role of provincial education office serves as supervision and supporting budget to execute any PD program.

2. The introduction of school-based management (SBM) has required schools to take more initiative to run their own PD programmes for their teachers. Each school, therefore, has the right and chance to plan its own CAR workshop. 
3. The teachers' network group (locally termed as musyawarah guru mata pelajaran or MGMP) can programme CAR as PD activity. As MGMP works with subject teachers in their own area, small-scale in-house training is more encouraged.

(Source, DS:I)

\section{The CAR Pilot Project: Lessons Learned}

As the pilot took place five years ago, it is timely to reflect on any lesson that may be learned from it. This reflection of the pilot is based on the international and national (Indonesian context) literature that I have reviewed and from feedback from the participants of my study.

As this pilot was initiated to provide several opportunities for senior secondary teachers to know and apply the concept of CAR, some degree it has achieved the outcomes set by its providers. Teachers of my present study, for instance, experienced considerable benefits such as being able to improve their teaching practice and to enhance students' achievement ${ }^{20}$ which led to enhancing their PD (Ts:I). However, from the perspective of how this pilot meets the criteria of successful PD programmes in the Indonesian context as suggested by Lim, Pagram, and Nastiti (2009) and Setiawan (2009), there are some critical points that need to be considered for future PD programmes, in particular for CAR as a PD programme.

\footnotetext{
${ }^{20}$ Further benefits of CAR for teachers are explained in Chapter 5.
} 
First, CAR as PD should be job-embedded, site-based and, needsbased (Lim, Pagram, \& Nastiti, 2009). This current pilot was provided for a large number of teachers and located in one place. The material was not based on the teachers' needs related to their specialty areas nor could it accommodate teachers' specific questions and problems: for example; one of my participant (TB:I), found it difficult to apply the CAR concept since the materials were too general and did not address her problems in the classroom. This experience is congruent with the statement of Setiawan (2009, p. 3) who contends that in Indonesia "the training delivered was usually not preceded by appropriate professional development needs analysis".

In the future, CAR as PD would ideally be held in the schools or teachers' network groups such as MGMP to accommodate the specific need of teachers and their teaching practices issues in the classroom. It is expected that smaller scale workshop would better to facilitate teachers to do CAR projects in their own classroom.

Second, there should be ongoing support, such as mentor support, from PD providers (Lim, Pagram, \& Nastiti, 2009; Borg, 2009). One of the weaknesses of this current pilot was the absence of support from mentors or instructors to provide teachers with assistance whenever they found problems in conducting their CAR projects. Such support would increase the likelihood of teachers producing good quality projects as well as promoting more sustainable teachers' PD. Schools and MGMP can 
collaborate with teacher educators from university or teacher trainers from LPMP.

Finally, there should be monitoring and evaluation of the pilot (Setiawan, 2009). As mentioned earlier (p. 127), monitoring and evaluation did not run well for this pilot. As a result, the PD provider did not receive exact data whether about its effectiveness; the only evidence of the success of the programme was based on the teachers' report about whether they had applied what they had learned in the workshop or whether collaboration among teachers occurred or not. Setiawan (2009) notes that the majority of "one shot" PD programme in Indonesia are conducted without monitoring and evaluation, and contends that that trainer providers are more concerned with the quantity of PD programmes than with their quality.

\section{Five CAR Reports: Teachers' Topics}

This discussion draws on the teachers' reports of the CAR project that they had conducted. The content of the reports followed the guidelines set by the assessor team including the rationale for doing the CAR, the literature review, explanation of the CAR procedure, and presenting and discussing the results of the action. These questions guided my review of these research reports: how did the teachers chose the topics, what alternatives did they offer to solve the students' problems, 
and what procedures did they used to deal with those problems. This analysis does not discuss each report individually but mainly seeks differences and similarities between the reports to address the above questions.

The CAR topics and their rationales. Three of four of English teachers focused their action research on how to deal with students' problems in speaking ability and the other attempted to alleviate students' problems in listening to English sounds. The chemistry teacher found ways to develop learning students' achievement in learning chemistry. The common element of all of the topics was that they focus on alleviating students' learning problems. A more complete description of each topic and its rationale from each teacher is presented below.

Teacher A. The focus of the teacher A's action study was to solve the students' problems in English speaking skills by enhancing vocabulary through the use of a variety of visual aids when teaching vocabulary. On reflection, this teacher and her team thought that most of the students were passive in speaking activity class due to the difficulties they found in expressing ideas in English which was caused by their limited vocabulary. From this reflection, the teacher and her team reported that they were keen to find solutions to develop students' vocabulary. They found from references that using visual aid techniques can be effective in increasing the students' stock of vocabulary. Thus, in their action study, 
they used visual aid techniques in teaching vocabulary as to support students to develop their speaking ability (Source: TA:CR).

Teacher B. This teacher also attempted to solve the students' problems in speaking English. She reported that most of the students found it difficult to speak English and she was not satisfied with her teaching technique that so far had not impacted on students' ability in speaking English. She also reflected that students unmotivated to speak and tended to be passive during the speaking activity. Her team discussed what techniques were available that might motivate students to speak and ultimately solved the students' problem in speaking English. As a result of team's discussion and investigation of some literature of teaching speaking they decided to apply the questioning strategy in teaching speaking exercises. Different types of questions about topics of interests of the students were used to motivate them to speak (Source: TB: CR).

Teacher $\mathrm{C}$. Teacher $\mathrm{C}$ and her team attempted to deal with the students' problems in listening to English sounds through the use of language laboratory for practicing English sounds. However their report provided little about how teacher reported the students' problems in her class and what made her to decide to use the technique. The process of selecting the topics which triggered the teacher to do the action research was not even mentioned (Source: TC:CR). 
Teacher $\boldsymbol{D}$. This teacher saw that the ability of his students to speak English in the classroom was low. Some teaching techniques had been used to solve this problem. However, he found that many students still has difficulty in expressing their minds when speaking English. Given this fact, he had some discussion with other teachers and came up with the idea of giving students more chances to talk by adopting a story telling technique in teaching speaking (Source: TD: CR).

Teacher $\boldsymbol{E}$. This chemistry teacher focused her study on improving her students learning achievement on chemistry subject. She found that most of her students did not comprehend the concept of electrochemistry as evidenced by the results of their summative assessment. She also reflected that her teaching technique did not involve students to ask questions, to express ideas etcetera. In addition, the learning environment was dominated by the teacher who employed a lecturing style for presenting materials. Given this, she decided to use a peer coaching learning strategy by maximising the involvement of students in the learning process. However, this report did not show the process of reflection and discussion conducted collaboratively with other teachers (Source: TE: CR)

Procedures of doing CAR: how teachers did their action? All reports showed that the action research was implemented by using Kemmis and Taggart's model. Further description of each report is presented below. 
Teacher $\boldsymbol{A}$. Teacher A reported that the action was implemented in two cycles with the following stages in each cycle: planned the action, implemented the action, observed the action and reflected upon the action. How the teacher worked with her two collaborators at every state was not clearly explained. In addition, in all stages the teacher clearly presented what she did from - planning the action to reflecting on the action. At the stage of planning, teacher $A$ reported what she did before the action was implemented for example: preparing lesson plans, teaching scenario, observation sheets, teaching material and tools etcetera. For the action implementation stage, the teacher mentioned that she did the teaching scenario as planned; however, the explanation was short and did not describe what she really did during the action (teaching vocabulary using visual aid). The observation stage was explained in terms of how the teacher collected the data through tests and observation sheets from students. It was clearly explained how she collected the data and analysed them. She reported that in the reflection phase she did reflection based on the analysis of the results of the students' test, and observation both from students and teacher. In addition, the process of reflection enable her to identify the weaknesses of the first cycle which then became a baseline to revise it for the next cycle until attaining the successful criteria as set by the team. How the teacher reflected on the action in both cycles was clearly reported (Source: TA: CR). 
Teacher $\boldsymbol{B}, \boldsymbol{C}$, and $\boldsymbol{D}$. Similar to the teacher A, these teachers did the same stages of action which started from planning to reflection in two cycles. However, what was missing in every stage was the description of each teacher's role in conducting the action. All three stages of how the teacher did them were sufficiently reported except for the implementation of action stage; it was explained less concisely and did not describe how the teaching technique was applied in the classroom. For instance, teacher B did not clearly explain how she applied the questioning techniques in teaching speaking, while teacher D did not show how the story telling technique was presented in the classroom (Source: T B,C,D:CRs).

Teacher $\boldsymbol{E}$. The teacher's report showed that her action research project used the same approach as the above teachers. All four stages of action (planning, implementing, observing, and reflecting) were clearly explained to show how she did the action research in three cycles. For instance, in the planning stage she prepared learning materials, lesson plans, and the teaching scenario, selected students to play the role of peer coach, and prepared evaluation procedures; she described the implementation stage by explaining how she used the peer coaching strategy to help students learn the concept of electrochemistry; she observed the action by using the data collection as prepared before; and she analysed the results of her action and reflected on that to see the weaknesses for improvement in the next cycle. However, she did not 
sufficiently provide enough information to show that the action was conducted collaboratively (Source: TE: CR).

\section{Chapter Summary}

This chapter has provided comprehensive background information about the CAR pilot in which the five teachers in this study participated. It has elaborated on the information about how the PD provider (in this case, DIKJAR provincial) delivered the CAR workshop for teachers as well as organised the CAR project phase for teachers. The chapter also provides a brief analysis of five study participants' CAR reports about how they conducted their CAR projects. 


\section{CHAPTER 5 \\ Findings and Discussion}

This chapter considers the study findings of the experiences of the five case study teachers both as participants in the initial workshop on CAR and when conducting their own action research projects in the classroom. Of particular interest is an understanding of how the teachers believe they may (or may not) have grown professionally through these experiences. The discussion in this chapter is organised around answering my research questions. I took these questions to guide the intense oneon-one interviews with the teachers: (1) how did the teacher believe CAR was of benefit to them?, (2) what barriers to doing CAR did they report?, (3) what support did teachers receive from their supervisors, colleagues, and school principals while conducting CAR projects?, (4) did they continue to do CAR projects after the first pilot? what reasons did they provide as to why and why not they do it?, and, (5) what were the teachers' perceptions of how CAR as a PD programme should be delivered and be facilitated by the policy makers and related parties to meet teachers' needs and achieve more sustainable CAR practice.

I have divided the discussion of this section into three parts. Part A discusses and analyses the experiences of these five teachers in terms of the positive experiences or the benefits of CAR they had with CAR, the barriers they encountered when conducting CAR, and the level and type of 
support they received from colleagues, principals, and supervisors when they did their projects. This part, then addresses the research questions 13. Part B discusses the longer term commitment of the teachers to CAR and what motivates them to take on further classroom-based research or, conversely, the reasons why they have discontinued the practice. Thus, part $B$ addresses the question 4. Part $C$ addresses the last questions and discusses what these teachers now recommend as to how CAR as a PD programme should be executed in the future. In the end of each part of the above study results, discussion of the findings of the study is presented to reflects on how this research leads to a better understanding of the major objectives of this study.

\section{A. Teachers' Experiences of Classroom Action Research}

This section describes the teachers' experiences of engaging with one or more CAR projects. It describes their story of the positive experiences they found when conducting CAR, kind of barriers or negative experiences they found, and support they received from their school principals, colleagues and supervisors.

Positive experience. All five teachers believed that engaging with CAR benefited them. There were some positive experiences they all shared but they also raised some different benefits of CAR that impacted on them. Three themes emerged from their responses (1) how CAR 
affected the teaching practice of all five teachers, (2) how CAR increased an awareness of their students' needs and problems, and also their teaching instruction, and (3) how CAR helped them to learn and develop as professional teachers.

How CAR benefited teachers' teaching practice? All teachers in this study identified that engaging in CAR had provided an opportunity to improve their teaching practice. Among the benefits they found was the opportunity to experiment and adopt various teaching techniques, thereby changing their way of teaching and giving instruction in the classroom. Teachers also learnt new strategies to cope with students' problem in the classroom, and felt more confident about their teaching.

Two teachers spoke about how CAR supported them to use teaching techniques that students enjoyed and really engaged with. Teacher A stated that engaging with CAR had equipped her with many more teaching techniques that she had before being involved in any CAR projects. She commented "Before doing CAR, I just taught without using particular techniques. I only followed the instruction from books. Engaging in CAR helped me to think creatively to find teaching techniques that facilitate my students' to speak English...Indeed, I became a more creative teacher and now possess a rich variety of teaching techniques" (TA:I2).

The experience of engaging with CAR had helped Teacher A to develop a new teaching strategy. In her reflections she remarks that most 
of her students found it difficult to comprehend the English reading text. To address this problem, she used a "reading speed" strategy in solving her students' learning problem. This was the second project she had conducted independently two years following the first workshop project. For this project, she said "I did CAR again aimed at solving my students' problem in comprehending English reading text. For this, I used 'reading speed' strategy" (TA:I2).

Similarly, Teacher D revealed that engaging in CAR had enriched his teaching techniques as well as finding enjoyable ways to motivate students to learn English. He said "CAR helped me to create enjoyable teaching techniques that catered to my students' learning problems; finding new ideas of motivating students to learn English. Shortly, I can help students to develop their English speaking skill" (TD:I2).

For teacher $\mathrm{D}$, his experience with his first CAR project using a "story telling" technique (TD:CR) to develop his students' speaking skill gave him a new experience of using fun and enjoyable techniques to teach English speaking. He used the same strategy in his second CAR project by adopting a fun technique in teaching English speaking for his grade-12 students - using English drama (TD:CR,I). He commented:

My second project aimed at eliminating the students' problem in speaking. Since, I taught the last grade students (year 12) and I observed they still felt difficult to speak in longer expression, I decided to do my CAR project using "drama" technique to teach English speaking for them (TD:I2). 
Teacher E had the same story. Having engaged with her first project, she used different teaching techniques in teaching her students to learn chemistry materials. From her three CAR reports that I solicited, she used various techniques that ranged from using peer learning to cooperative learning model (TE: CR). In relation to this, she said, "In my first CAR project, I used a peer learning method. Following that, I used constructivist approach and cooperative learning of jigsaw model for my other CAR projects (TD:I2).

Teachers also found that their experiences with CAR had affected the way they taught, had increased their confident to teach, and given them new ways to cope with students' learning problems. Teacher B felt that she needed to change her way of teaching English "speaking drills" to her students as a result of engaging with CAR. Although she had been in teaching service for almost 20 years (TB:SI), when dealing with speaking drills with students she felt that she only used routine instead of using a variety of topics. She reflected, "Before doing CAR, I constantly did the same technique when teaching English speaking drills to the students; however after gaining experience with CAR I changed the way I teach students in my speaking class" (TB:I2).

Teacher C, likewise, felt confident and found, after conducting her CAR project, that her teaching was more enjoyable when presenting new learning materials to students. She revealed that solving the students' problem in teaching becoming an enjoyable work for her: "Since my action 
research study benefits to motivate my students to learn, I feel more confident to teach and feel more enjoyment in delivering more materials to them" (TC:I2).

Teacher $\mathrm{E}$ felt that her teaching practice was increasingly affected through engaging with CAR. She revealed that it was easy for her to solve the students' problem learning in the classroom. She said "Using the peer learning strategy in my project, I managed to develop slow learners' learning achievement" (TE:I2). She revealed this change as she reflected that almost every year now she did CAR projects to deal with her students' learning problems. By 2010, Teacher E had engaged with CAR four times (TE:CR).

All five teachers described their positive stories after engaging with CAR projects. They felt that these experiences benefited their teaching practices which ultimately made them able to solve their students' problem in learning or even to enhance the students' learning achievement. This benefit was highly relevant to the expected outcomes of the first CAR pilot. In addition, it also met with the objectives of CAR pilot to help teachers to combat the issues of teaching and learning inside and outside schools (DD).

Furthermore, all teachers' CAR reports reported that when using certain teaching strategies they succeeded in reducing their students' specific learning problems. Although they did not specifically report that 
CAR impacted on their teaching practice too, the interview data revealed that engaging with CAR potentially improve teachers' teaching practice which possibly leads to improving students' learning performances.

CAR's impact on teachers' awareness. It is interesting to note that all teachers in this study became more aware both of students' learning problems and of their own teaching practices as a result of doing CAR. Teachers stated they became aware of students' problems inside or outside the classroom which prompted them to find solutions. Meanwhile, teachers also felt that they became more aware of their own teaching practices by reflecting and improving their approach and themselves.

In regards with catering to students' needs, three teachers revealed these stories. Teacher A noted her first experience with CAR had shaped her to become more aware of her students' problems both inside and outside the classroom and she was keen to find the solutions to those problems. She noted below.

Having experience with CAR, I sometimes reflect on my students' problems, such as why they come late to school or why they lack motivation to learn in the classroom. I wished to find the answers two my questions by doing a small-scale inquiry (TA:I2).

Teacher A's first experience with CAR led her to be more aware of her students' learning problems. It can be seen from her reflection in her second CAR project, when she found that most of her students had problem in reading comprehension, that she was aware of their situation 
and keen to solve this problem through CAR. She said, "I did a CAR project again aimed at solving my students' problem in comprehending English reading text. For this, I used reading speed strategy" (TA:I2).

Teacher $\mathrm{D}$ noted that as a consequence of action research he was aware of when his teaching plan did not successfully help his students to learn. He said, "I always think that if I find my teaching plan did not solve the students' problem, I would keep trying to find the solution for their problems" (TD:I2). Teacher D demonstrated his growing awareness of when he found out that most students in his class were reluctant to speak English. In his second CAR report, he said that due to the low ability of his students to give long responses and express ideas at length as well as their low motivation to speak at all, he designed a teaching strategy (using English Drama technique) to solve his students' problem (TD: CR).

Teacher E explained that as the consequence of CAR, she became more concerned about her students' problems in the classroom and this prompted her to find the best solution. She said, "I become more concerned about the students' learning problems. If they have problems, I would be delighted to find the solutions for their problem. Indeed, this is a fruitful way of dealing with students' problem- through CAR" (TE:I2). Teacher E's concern about students' problems was evidenced by her productivity in conducting CAR projects that aim to solve her students' learning problem in chemistry. So far, she had done four CAR projects and all of them addressed the learning issues of her students (TE:CR). 
Teacher $\mathrm{C}$ said that she felt more aware of the students' problems as a result of doing CAR coupled with her teaching experience of almost 20 years (TC: SI). She said, "I sometimes think about my students' problems in the classroom and this triggered me to solve their problems. This may be caused by my involvement in CAR projects compounded with my experience of teaching since 1990" (TC:I2).

In terms of becoming more aware of their professional responsibility, two teachers $(A \& B)$ shared similar reflections after being involved in CAR projects. Teacher B noted that after reflecting on her students' problems in English speaking skills as well as her own low proficiency of communicating in English, she realised that in order to help her students to be able to speak English, she firstly needed to improve her own English proficiency. She commented, "Engaging with CAR revealed to me that I have to improve myself (my teaching competency and language proficiency). This is because my students needed me to facilitate them to deal with their English speaking skill problems" (TB:I2).

From this self-reflection Teacher B decided to change the way she gave instructions to students. As she commented, "I used to give more instruction in the classroom to students using Indonesian. Now, I use more English than Indonesian" (TB:I2). For her, the decision to change her teaching mode was based on her self-reflection at the end of her project. She felt that her students' low of command of spoken English was due to herself never evaluating the way she taught and so she became a model 
for her students to speak English in the classroom. She said "For a long time, I have not done too much to help my students to improve their English speaking skills" (TB:I2).

Likewise, Teacher A said, "I become more aware of my teaching profession - that I have to keep growing as a teacher to meet the students' needs (TA:I2). For teacher A, CAR was a venue of learning ${ }^{21}$ for herself since she just had been in service for only five years (TA:SI).

It is clear from the teachers' statements that they benefited in terms of their growing awareness from doing CAR. This can be understood since teachers learn to reflect on their practice in their CAR project. According to the workshop materials, one of the skills teachers learn is to reflect on their CAR process or to reflect on the teaching and learning problems in their classroom as a basis for conducting CAR (WM). CAR can develop teachers to be more reflective (e.g. Sowa, 2009); being reflective leads teachers to develop their sense of self-awareness as one of factors to grow professionally (Osterman \& Kottkamp, 1997). The teachers' statements about their growing awareness are in line with the objective of the CAR pilot ${ }^{22}$ to enhance the professionalism of teachers through the practice of reflection (DD).

\section{CAR helped teachers to learn and to develop as professional}

teachers. Literature notes that CAR provides a great possibility and

\footnotetext{
${ }^{21}$ Further described in p. 141 of this Chapter

${ }^{22}$ Described in Chapter 4, p. 114.
} 
chance for teachers to learn and grow (e.g. Burnaford, 1996). All teachers in this study found that they could learn many things by engaging with CAR projects. Moreover, two teachers (Teacher D and E) revealed that CAR helped them to grow personally which benefited their teaching career too.

CAR as a venue for learning. Teachers in this study found that CAR provided them great opportunities to learn during the process of doing their projects. From doing their CAR projects, the teachers could learn how to improve teaching practice in a systematic way, to reflect on their practice, experience working collaboratively with other teachers, and to disseminate their works in a scholarly way.

Teacher A revealed that she learned a lot from the process of doing CAR and found that engagement with CAR provided her opportunity to learn from the process. She stated, "CAR benefited me in terms of learning as from the process I could use it for self-learning such as how to identify problems, plan the action, solve the problem and reflect upon the process" (TA:I2).

Teacher A's reflection was based on the fact that during the CAR process, she was expected to use the CAR approach which constitutes four systematic cycle steps that she had learned from the CAR workshop 
beforehand. In the CAR workshop, teachers learned the basic knowledge of how to conduct CAR project in a systematic way ${ }^{23}$.

Teacher $D$ found that engaging in CAR, prompted him to learn more from other sources such as references books, journals and so on. He commented that while doing CAR he read a lot of references related to his topic. He stated, "Another benefit of CAR, I have high motivation to read books or references that relate to the topic I am doing; something that I never do beyond CAR activity" (TD:I2).

Teacher such teacher $D$ to do research taking part in this pilot, were required to include a literature review in their proposals and/ or reports (Ts:CR, DD). For teacher D, finding literatures or references that supported his project, gave him an opportunity to learn more from what other writers say had to about what they wanted to research.

Teachers in this study also learned to reflect from the process of doing CAR; this ultimately developed their sense of self-awareness and led to changes in their teaching practice. Teacher B revealed that she found CAR provided her chances to reflect and evaluate her practice. She learned that by reflecting on what she had done to improve students' learning through CAR, she decided to change her practice in teaching English speaking. She stated, "What I could learn from this CAR project, I reflected that I need to improve my English proficiency too if I want to help

${ }^{23}$ Workshop CAR material is presented in Chapter 4, p. 109-113. 
my students to be able to speak English. I found that since I decided to change, my English is improved now" (TD: I2).

Teachers in the study also found that engaging with CAR provided an opportunity to work in a collegial way. In the CAR pilot that the teachers in this study participated in, they were obliged to do their project collaboratively with other teachers from their own or other schools (DD) ${ }^{24}$. Teacher $\mathrm{C}$, revealed that the requirement to do her CAR project collaboratively taught her to work with other teachers from different schools. She stated, "I did the CAR project with other teachers from other schools; it was not easy though to negotiate about times to discuss our project, but I learned how to deal with this problem as well as to handle differences in ideas among us" (TC:I2)

Teacher C's story was in line with what DIKJAR expected from teachers - learning to work in partnership. For DIKJAR, the notion of pairing teachers to do their projects aimed at enhancing the professional partnership among teachers as set out as one of the objectives of the CAR pilot $^{25}$ (DD).

CAR helped teachers to learn and to grow personally. Being a teacher not only requires knowing teaching competency, but demonstrating professional competency such as conducting CAR and disseminating work publicly through written or oral mode (through journals or report in the forum). In the Indonesia context, this professional

\footnotetext{
${ }^{24}$ See page 117

${ }^{25}$ See page 114
} 
competence that teachers must demonstrate is mandated by the Teacher Law $14 / 2005$ and the current policy of MENPAN decree No.16/2009 ${ }^{26}$. Teachers in this study revealed that as a result of engaging with CAR, they had an opportunity to learn to disseminate their work through written reports and oral presentations. Two teachers, in particular, had the opportunity to develop what they had learned (writing reports) by sending their writings to Journals for publication.

Teachers $D$ and $E$ felt that after engaging with CAR, their professional competency to write articles grew enormously. These two teachers modified their CAR reports and published them in Journals. Teacher D published two CAR articles and Teacher E published three of her CAR reports (TD,E: CRs). In relation to this, Teacher D said, "First benefit, I learned to write my CAR reports and rewrite them into articles which I sent to a teacher journal in south Sulawesi. I found my writing habit grew and this can motivate other teachers to follow it" (TD:I2).

Similarly, teacher E noted that by engaging in CAR she developed her writing skill and she grew from doing that. Reflecting on what she had produced (three published articles) she commented, "Experience with CAR has made me more productive in writing. I have high motivation to write and get incentive from doing that. I have now become a contributor writer for an online teacher site. Shortly, I gain self-development benefit from doing CAR" (TE:I2).

\footnotetext{
${ }^{26}$ Both are described in Chapter 1.
} 
From the CAR reports I sought from Teacher E and my first short interview with her, I discovered she had published three of four CAR projects she had conducted - one in a national mathematical and science Journal, another in a local university Journal, and the other one in an online education journal. Meanwhile, Teacher D published two of her CAR project reports in an education Journal outside Central Sulawesi Province.

Another example of how a teacher learns from CAR and how CAR can impact on personal growth comes from teacher $E$ who spoke about the opportunity to present her CAR project in the forum which developed her confidence to present her works before the public. She noted, "Another benefit, I am able to present the result of my CAR before the people; previously I had no experience with any scientific forum such as presenting my works" (TE:I2).

The above experience gave Teacher E more self-confidence; she explained that in 2009 , she had a chance to present her master work study in an international conference (TE:SI).

Data found from DIKJAR, revealed that at the end of the CAR pilot, ten teachers' CAR reports were selected as the best CAR projects. The selected teachers had to present their projects in the forum attended by other teachers, assessment team, and DIKJAR staff (DD). Teacher E, in this case, got the highest ranking of these ten teachers (TE:I: DD). For 
teacher $\mathrm{E}$, this first experience provided her a venue to learn sharing her work before the public and finally facilitate her to grow personally.

Teachers' negative experiences of doing CAR. Doing action research is not always a straightforward process. There are barriers that could impede their progress with CAR. Teachers in this study noted some barriers that they found during engaging with CAR such as: insufficient knowledge of CAR, lack of advice, no assistance from collaborators and time constraints. Each teacher faced different problems conducting CAR project.

Insufficient knowledge of doing CAR. To be able to successfully do action research project in the classroom, teachers need to equip themselves with sufficient knowledge of CAR. The knowledge and skills to conduct action research can be gained through one-shot workshops or training. In relation to this pilot, teachers did participate in the initial CAR workshop. However, due to the short time frame of the workshop, not all materials ${ }^{27}$ were able to be grasped by participants. This barrier was compounded by the instructors' inability to cater to all teachers' specific needs in relation to their specific subjects. For English teachers, in particular, this workshop did not specifically train them as how to identify students' problem in learning English vocabulary, collect data from English speaking class, evaluate the students' achievement in vocabulary etcetera.

27 Materials that presented in CAR workshop were discussed in Chapter 4, p. 109-113. 
Hence, some teachers experienced problems in conducting CAR due to this.

Teachers $\mathrm{C}$, for instance, noted that she and her collaborators found it difficult to conduct CAR fieldwork in the classroom due to insufficient knowledge of CAR. She felt that her CAR project was far from a good result. She commented, "My problem with doing CAR was that my collaborators and I had not adequate knowledge of doing CAR due to the very limited knowledge as well as practice I got in the CAR workshop. Sadly, no support from the instructors post workshop by providing consultation or whatsoever which cater to our needs" (TC:I2).

These reflections of Teacher $\mathrm{C}$ were also evident in the CAR report she made with her collaborators; the report did not clearly explain how they did identify the problem of study nor how they did the CAR procedures in a structured way (from planning to reflecting phase) (TC: CR).

Likewise, Teacher B experienced that the CAR workshop materials were too general and consequently she found it difficult to do her CAR project. She stated, "I thought the CAR workshop that I had attended did not answer all my questions and needs. It was too general and not specifically designed for English teachers...no wonder I found difficult to do my CAR's project" (TB:I2). 
This problem was experienced by Teacher $\mathrm{E}$ in her first pilot too. She found it problematic to report CAR in a good systematic way. However, she handled her problem by seeking help from other teachers who did the same projects or even from a certain instructor individually. She said, "My problem dealt with how to report my CAR project. Yet, I sought help from my colleagues and could sort it out" (TE:I2).

The teachers' statement about their limited knowledge of how to conduct CAR point both to the limited time of CAR workshop as well as the general materials presented. This was justified by one of the workshop instructors who said the time allocated for CAR was limited and the CAR material were general because they were designed to cater for the varied needs of the range of teachers who attended the workshop. He claimed that "During the three-day workshop, only 2 hours was allocated for explaining the concept which I think quite limited to satisfy the teachers' need who came from range of subjects...in my delivery, I just presented the general concept of CAR which is commonly practiced by teachers in Indonesia" (Wl:I).

Moreover, the CAR workshop ${ }^{28}$ itself was conducted effectively in three days, with only two days allocated for teachers to learn CAR knowledge concepts and practices. In addition to this, CAR materials were not were not specifically designed for certain subject teachers such as English or chemistry (DD).

${ }^{28}$ Explained in Chapter 4, p. 108-113 
Lack of advices from mentors. The role of mentors in supporting teachers to conduct small-scale research in their classroom is of vital importance (Borg, 2006). Mentors play a role in providing advice or feedback when teachers get stuck with their projects. Teachers in this study complained that they found no support from mentors when conducting the CAR projects. Four teachers stated that there were no mentors, tutors, or supervisors who came to their schools to provide them with help when they encountered particular problems with their projects. Some teachers also experienced that even though they had sought help with friends, none of them were able to provide the feedback expected by those teachers. The exception was Teacher E who got help from her close friend - one of the instructors of the CAR pilot - who offered personal assistance corresponding to her problems in the CAR project.

Teacher B felt vulnerable where she and her collaborators got into difficulties with their project and had no place to seek for help. She stated:

If I got stuck with my project, I myself solved my problem since It's difficult to find someone who is highly competent with CAR. My collaborators could not help me out as well as my other colleagues. At the time, there was no mentoring available from the DIKJAR team. We ourselves found the solution for our problems in the classroom (TB:I2).

Teacher $\mathrm{D}$ also commented that he really wished there could someone who could provide them with a solution when coming up against the problem. Given that not all teachers were experts in CAR, he wished 
the pilot organiser could provide those mentors. He explain, "I really wanted the institution that organised this pilot (DIKJAR) to provide us mentors or facilitators that could help us dealing with problems in doing CAR; I found no such things existed" (TD:I2).

Although some teachers sought assistance from their friends when they experience major issues with their projects, Teacher A and B felt it was more difficult to get satisfactory advice from their colleagues than they expected. Teacher A said below.

Although my colleagues was very supportive with my problems, I did not find their answers satisfied me...It seems I didn't find the right place to expose my problems...I really need someone who can be my mentor to guide me doing my project (TA:I2).

Similarly, Teacher B responded as "When my collaborator and I got problems with our project, I tried to seek help from my friends. However, they didn't provide us with solutions...we were so confused to whom we should ask for help" (TB:I2).

The above teacher statements align with what DIKJAR staff stated: that the reasons why there was no such consultation available was due to a lack of instructor coupled the high numbers of teachers doing the CAR project in the same time (DS:I) ${ }^{29}$. Therefore, any issues emerged during this phase had to be discussed and solved among teachers themselves.

${ }^{29}$ See page 117 , Chapter 4. 
No assistance from collaborators. Ideally, teachers who do action research project in the classroom collaboratively gain mutual benefits and this can be achieved if all parties (the researcher and collaborators) can work together according to each job description (Burbank \& Kauchak, 2003; Platteel et al, 2010). However, this did not happen for two teachers, in particular, in this study who were required to do the CAR project collaboratively.

Teacher A complained that she herself did most of the project alone (such as the reflection, planning and the action, writing the report and so on) and her collaborators were only sometimes involved when they were available. She assumed that it was likely her collaborators were more senior teachers than her, so they made her almost entirely responsible for the project. The teacher said

I could say that my collaborators did not intensively assist me to do CAR. I mostly did the steps of the projects such as reflecting, planning the action, did action in the classroom. They did only small portion of the projects. I didn't understand why they did not want to get more involved, perhaps I am the most junior teacher among three of us (TA:I2).

Teacher E commented that the reluctance of her collaborators to get involved in the project and that as a consequence she herself did the CAR process from the beginning to the end. She said, "I myself did all the process of our CAR project and my collaborators did not engage at all. 
Maybe they were too busy with their teaching load or they had low motivation to do this project with me" (TE:I2).

The CAR pilot project that teachers in this study took part in required teachers to do collaborative research (DD). This was in line with the pilot's objective; to enhance teachers' partnership in schools ${ }^{30}$. However, some teachers found that their collaborators did not fully participate in the projects. This problem was caused partly because there was no monitoring conducted to find out whether or not teachers did their projects collaboratively (WI:I). The only proof that was only sought was from the mid term and final reports of the projects (DD).

Time Constraint. Teachers in this study also noted that time become a constraining factor for them when conducting CAR projects. Three teachers experienced this problem. Teacher $\mathrm{C}$ who did her CAR project collaboratively with two teachers from different schools found that time scheduling to meet was the main problem. It was hard for her to arrange times between the team members who came from different schools. For this barrier, she commented "The problem existed when the team wanted to meet each other. It was very hard to match our time and conflicted with school hours. This was because my collaborators came from different schools" (TC:I2).

\footnotetext{
${ }^{30}$ See page 114 of Chapter 4.
} 
In addition, teachers $A$ and $B$ revealed that doing CAR consumed too much time. Teacher B, for instance, noted that she had a lot of things to do with her other school workload. As she stated, "I found that doing CAR needed much time. Besides, I have other school tasks to do such as creating lesson plans, preparing materials, marking tests and so forth. (TB:I2).

Similarly, Teacher A noted that to do CAR individually consumed too much time while she had other administration tasks to do as a classroom teacher and other school tasks. She stated that "Time was a problem for me since I did the CAR alone...it needed a lot of time. Meanwhile, I had other tasks to do such as preparing lesson plans, creating action plan, and teaching materials, plus school's tasks such as supervising students' extracurricular (English debate program for student)" (TA:I2). However, teacher A states that her problem might be solved by involving other teachers to do CAR "I think if I do the CAR project collaboratively, my time problem will be diminished".

Experiences of support with their projects. Much of the literature and many studies have highlighted that support from school stakeholders plays a pertinent role in facilitating teachers to do CAR projects in the classroom (e.g., Burnaford, 1996; Tinker Sach, 2000). This section discusses whether there was any support provided by school principals, colleagues, and the supervisor' team while teachers did their projects and if it existed, how it was provided to the teachers. All teachers revealed that 
they gained support both from school principals and colleagues; yet no support was received from CAR supervisors.

Support from Principals. Ample school principal' support had been noted by the teachers in this study. Most of the teachers stated that their principals' support to made it for them possible to do CAR projects. The kinds of support provided by principals ranged from administrative, to moral, to giving rewards.

All teachers revealed that in their schools, principal gave them the opportunity to conduct their CAR pilot and allowed them to participate. This support began by principals signing the proposal that teachers needed when applying the grants. Principals also signed all CAR reports or gave moral support such as asking about the progress of the teachers' work. This was reflected from one of the statements from Teacher C, "My principal broadly supported my project through allowing me to follow this pilot by signing my proposal for the sake of getting grants (TC:I2).

Teacher C's statement refers to DIKJAR's requirement for teachers to gain principal's consent when applying for grants. Principals needed to acknowledge that teachers participated in the CAR pilot and that they had conducted the projects in their own classroom; for this principals signed the proposals before the pilot and completed CAR submitted to the pilot provider (DIKJAR) (Source, DD). 
Teachers also revealed that principals gave their moral support during the CAR project. Teacher $D$ said that his principal encouraged him to do the project as it was in line with the school mission of improving the quality of students' achievement. He said as "My principal felt so pleased to see teachers doing CAR project because it can have benefits for improving the students' achievement ....He then encouraged us to do CAR" (TD:I2). Similarly, other teachers reported moral support from their principals as stated by Teacher $\mathrm{C}$ and $\mathrm{A}$ such as "He also motivated us, teachers, to do CAR and offered help such as allowing us to use school facility for the project purpose" (TC:I2); and "My principal indeed encouraged me to do the CAR project. Even for my second project, he kept supporting me" (TA:I2).

Support from principals also included giving rewards (financial bonus) and recognition to teachers who involved in the CAR pilot. Teacher A stated that when she was involved in the pilot she got a bonus of money and a certificate of recognition from her principal to show his appreciation. This teacher said that many teachers from her school were participating in the CAR project and all received recognition.

Besides providing administrative support, my principal allocated some bonus (money) for teachers who did a CAR project. Although, the bonus was low in nominal, it really showed his respect toward teachers. Moreover, in the end of our project, he gave us a certificate of recognition of doing a CAR project in school...I think this is very important for us teachers which reflected that our work was appreciated (TA: I2). 
After her first project funded by DIKJAR, Teacher E's her next two projects were funded by her own schools. She stated, "In my school, all teachers are encouraged to the CAR project; the principal provided incentive by allocating a budget for us every year to do CAR projects" (TE:I2)

In the Indonesian context, following the implementation of schoolbased management in $1999^{31}$, schools are given broad responsibility to hold their own PD programmes including encouraging teachers to conduct their CAR projects (DS:I). Teacher E's school has been practicing this policy; as she said "Since 2007, my school has allocated budgets for all teachers to do their own projects" (TE:I2).

Support from Colleagues. Teachers in this study sought help from their colleagues in both their own school and outside schools. They mostly asked for help to discuss their problems in conjunction with CAR projects. These colleagues were senior or master teachers who had rich experiences of doing CAR. Two teachers (D and E), in particular, got considerable support from their colleagues regarding with their problems with CAR projects.

Teacher D sought help from his close friend from another school who was quite experienced in doing CAR. His friend who is teaching junior secondary students in Palu had completed a CAR project ten years

\footnotetext{
${ }^{31}$ This policy was discussed in Chapter 1.
} 
previously (in 2000) when CAR was first introduced to junior secondary teachers by DIKJAR of Central Sulawesi through an ADB (Asian Development Bank) project ${ }^{32}$. He said, "I sought help from my friend who is more senior and experienced in doing CAR than me. Although he is teaching in a different school, he is keen to lend a hand...we were close friends when we were still in campus" (TD:I2).

Similarly, Teacher E got support from her colleagues both inside and outside the school. She had mentoring from a close friend who was the instructor of CAR in this pilot that helped her gretaly. In addition, she also discussed her work with teachers from her school that did the same projects as her.

I was fortunate to have a close friend who was more knowledgeable of CAR and he is the instructor of CAR workshop for teachers. Whenever I got a problem with my project, I called him and he was ready to give a hand. He was my mentor indeed...I also discussed my CAR project with those teachers who did CAR projects in my school (TE:I2).

No support from supervisors. Teachers reported that when they conducted their CAR projects, the programme being initiated by DIKJAR, none of the supervisory team came to schools to do supervision or monitoring tasks. As explained by one participant:

During the project, we never gained help from the supervisor or any related party appointed by the Education office. They never came to

\footnotetext{
${ }^{32}$ The same programme that I participated as I mentioned in Chapter 1.
} 
our school...Indeed, we needed them to discuss our problems related to our CAR project (TD:I2).

Both the education office staff who was the head of the pilot as well as one of the instructors who was appointed to the supervisor team supported this criticism, noting that it was hard to supervise all the teachers due to the lack of resources available as well as the huge amount of teachers who did the project at one time ${ }^{33}$. The instructor commented, "I was involved in the monitoring team, however, sadly this team did not work at all at the time...I think a weakness of pilot five-year ago was lack of coordination among the education office staff and related parties involved in this pilot" (WI:I).

\section{Discussion: CAR as a Tool of Professional Development}

Benefits of CAR for teachers. This study reveals that those teachers who took part in this CAR pilot improved their teaching practice or pedagogical approaches. They experimented with more varied techniques in teaching, changed the ways of teaching from routine techniques to include more fun enjoyable and activities, learned strategies to cope with students' problems, and became more confident about teaching as a result of solving students' problems through CAR. It appears that these are outcomes commonly reported by action research

\footnotetext{
33. See page 108-109 of Chapter 4.
} 
practitioners in a variety of contexts, both in Asia and in a number of Western settings.

In the Indonesian context, these same results were reported in the study of Burns and Rochsantiningsih (2006) which found that being involved in action research impacted on teachers' teaching practice by providing new ideas and strategies in teaching, teachers being able to solve students' problems, and feeling motivated to teach. Other studies in Asian contexts revealed that after engaging with CAR teachers' teaching strategies skills were developed (Curtis, 2001), and taught with more variety of classroom activities (Thorne \& Qiang, 1996). This finding also supports O'Connor, Greene, and Anderson's (2006) study that found action research impacts on teachers' teaching practices as well as building their confidence and autonomy. In terms of benefits of teaching techniques, Robert (1993 cited in Borg, 2010) contends that by possessing rich teaching techniques teachers will be able to get rid of their frustration with students' problem in the classroom. Similarly, Falk and Blumenreich (2005) say that doing research helps the teachers to develop new teaching methods and strategies. Likewise, this finding supports the study of Gebhard (2005), Thorne and Qiang (1996), and O'Connor et al. (2006) which noted that teachers became more aware of their teaching practices after practicing CAR.

This present study also found that engaging with CAR enhanced the teachers' awareness of the importance of growing professionally. This 
finding is congruent with study of Sowa (2009) that revealed teachers became cognisant of their teaching repertoire which in turn changed their teaching style to meet their students' need. As an illustration of this particular outcome, one teacher in this current research attempted to improve her "English speaking" proficiency after reflecting that to help her students' to be able to fluently speak English, teachers should firstly master the language. Given the fact that, many Indonesian English teachers do not master the language they teach (Dardjowijoyo, 2000), this study provided new insight that teachers who are intent on solving their students' English speaking problems through CAR approach may also advance their own speaking proficiency as they become aware of it through reflection on their practice.

In addition to being aware of themselves, teachers also noted that they became more aware of their students' problems both inside and outside of the classroom as a consequence of engaging with CAR. This finding is consistent with the statement of Mertler (2009) who asserts that the main purpose of teachers engaging in CAR is to improve practice which in turn diminishes their students' learning problems, and enhances their learning achievement. In particular, it also supports the study of Levin and Rock (2003) that revealed teachers' awareness of students' needs get increased after engaging with collaborative action research. Moreover, Haberman (1992) states that teachers who engage with action 
research tended to engage with students over time and as a result their awareness of students' needs in the classroom increased.

The growing awareness of teachers - like those in this study - who do CAR projects is asserted by Osterman and Kottkamp (1993) as the ultimate aim of the concept of a reflective practitioner or teacher. The expectation is that the teacher will change attitudes and ideas through greater self-awareness. Likewise, since the reflective teacher demonstrates awareness of themselves, others, and surrounding events (York-Barr, et al., 2006), teachers who showed growing awareness in this finding can be categorised as reflective teachers. Zeichner and Liston (1996, p. 6) say a reflective teacher is the one who "examines, frames, and attempt to solve the dilemmas of classroom practice". Mertler (2009) states that being reflective through action research leads the teacher to grow professionally. Numerous studies of teachers demonstrating higher self awareness after engaging with action research have been highlighted by many researchers (e.g., Atay, 2008; Burns, 1999; Ginns, Heirdsfield, Atweh, \& Watters, 2001 ; Gore \& Zeichner 1991; O’Sullivan, 2002; Sowa, 2009).

Teachers in this study also revealed that CAR benefited them as it helped them to learn and to grow. Specifically, they noted that CAR was a venue to learn how to do research, to reflect on their practice and themselves, and to work with colleagues in professional works. This finding accords with other literature that has noted how teachers use CAR 
as a professional learning tool (Burnaford, 1996; O'Connor et al., 2006) and a path of learning and growing (Watkins, 2006). In terms of learning, action research facilitates teachers' professional growth through learning from their teaching practice and systematically observing their teaching practice (Johnson, 2008).

In reference to another theme - that is, that CAR can promote collegial work - Levin and Rock (2003) argue that research provides great opportunities for teachers to have meaningful dialogue with one another and to build teacher-teacher relationships collaboratively. Hendriks (2009) claims that when teachers engage in professional dialogue and collaboration, such activities would lead to professional growth for them.

Findings from this study also show that teachers grew personally as demonstrated by teachers ( $D$ and $E$ ) who were able to disseminate their CAR projects in written form such as in published journal articles. Teachers noted that they can publish their work for the public audience and acknowledged that their writing ability largely developed after engaging with CAR projects. This finding adds to the characteristic of action research teachers in Indonesian context that they were eager to attend international seminars, and publish papers in seminar proceedings (Sukarni et. al., 2007, cited in Sukarni, Winarni \& Nirmayanti 2009). Other studies have revealed that teachers grew personally and professionally through engaging with CAR which was demonstrated by the growing knowledge of research skills (Atay, 2008; Burns, 1999), adopting new 
ideas in the classroom (Perkins, 2001), having more authority about teaching practices (Burns \& Rochsantiningsih, 2006), and possessing skills of investigating and analysing challenges in the classroom (Sowa, 2009). Given this, CAR can be a tool of teachers' professional development since it provides teachers with a learning venue which brings about on-going improvement (Fullan, 1995, cited in Smith, 2005).

Challenges faced by teachers in doing CAR. Teachers in this study noted that during the process of conducting their small-scale research in the classroom, they encountered the following difficulties that impeded progress with their projects: insufficient knowledge of CAR concepts, lack of advice and assistance from collaborators, and the time constraints. These findings are in line with the findings of other researchers who found numerous challenges faced by teachers when doing their CAR projects (e.g., Borg, 2009; Burns \& Rochasantiningsih, 2006; Rayney, 2000; Volk, 2009).

Some teachers in this study noted that they got into difficulty in conducting CAR due to insufficient knowledge of CAR. This problem was mainly caused by the fact that the materials presented at the workshop were too general and did not cater specifically to the teachers' needs and interests, limited time allocation for explaining the concept of CAR (2 hours) in the workshop; and combined with the absence of mentoring during doing the action phase. Lim, Pagram and Nastiti (2009) reveal that to be able to successfully run any PD workshop in the Indonesia context, the PD 
designer needs to consider the specific needs of the participants, and the programme must be job-embedded, and preferably site-based. Other PD programmes that are designed for teachers to learn to research in some other countries - such the "Network of Research Project" in Australia (Ginns, Heirdsfield, Atweh \& Waters, 2001), the "INSET programme" in Turkey (Atay, 2008), and "Learning Cycle" in Singapore (Hairon, 2006) identify some similar features, specifically that the PD programme needs to run over a long time as well as be supervised intensively by mentors. Borg (2006) contends that promoting good quality teacher research will only occur if teachers have knowledge and skills. This finding is supported by the other studies which reveal that insufficient knowledge of CAR concepts became one of several constraining factors that are faced by teachers in doing their project (e.g., Borg, 2009; Burns \& Rochsantiningsih, 2006; Rayney, 2009; Volk, 2009).

The absence of mentoring became a dominant factor that hampered teachers when conducting their CAR projects. They were not provided with advice from the CAR experts involved in the workshop and these experts were not available to help them when encountering problems in doing their CAR project. Borg (2006) asserts that teachers seem not to engage with research or sustain their research practice if they do not find continued support from a mentor. Likewise, teachers are more likely to participate in the project if they are supported by a more expert mentor (Borg, 2009). Furthermore, the role of mentor becomes more 
central when the teachers feel isolated and do not possess adequate knowledge to do their research (Borg, 2006). This finding supports the statement of Burns (2009) who asserts that limitation of advice becomes one of the constraints to the action research teachers.

Another problem faced by the teachers in this study is the lack of support from designated collaborators who were the teachers' colleagues who taught the same subject at their own schools. Many collaborators did not intensively engage with others in the CAR process and as a result some teachers did their projects individually. Borg (2006) contends that this lack of collegial support is likely experienced by the vast majority of language teachers. In terms of benefit, the role of collaborators is vital as a venue for meaningful dialogue (Levin \& Rock, 2003) among the teachers who did the research.

Successful collaboration entails equity and mutual participation among the members (Burbank \& Kauchak, 2003). Sadly, these two tenets did not occur in the teachers' collaboration in this study. Furthermore, this finding contrasts with other studies conducted elsewhere that noted that teachers' collegially and learning grows from doing action research collaboratively (Atay, 2006; Gebhard, 2005; Wigglesworth \& Murray, 2007). The major difference between this collaborative study and other studies was that no monitoring took place by the supervisors (facilitators) to see the progress of the collaborative project done by teachers; while in the other studies, the facilitators played a significant role to ensure that all 
parties were involved in the process. However, this finding also supports the finding of Rayney's (2000) survey which notes that the absence of collaborative friends was one of the constraints to the teachers doing their research.

Some teachers in this study also noted that they experienced time as a problem. Time conflicts occurred when each member of a collaborative team had their own school tasks to do which took priority over the CAR project. In addition to time conflict, less time devoted to the CAR project was also the hindrance since most of the teachers had heavy workloads to do any tasks in their schools. Hancock (1997) asserts that teachers' working condition with the abundance of teaching activity and engaging with other tasks may hamper teachers to do research project in their own classroom. Other studies also identified lack of time due to teachers' heavy workload as a barrier to conducting action research (e.g., Borg, 2009; Burns and Rochsantiningsih, 2006; Rainey, 2000; Volk, 2009). To deal with this, Burnaford (1996) suggests that school principals could assist the teachers by providing time for teachers to do research. Reimer and Bruce (1994) suggest that for this time conflict to be resolved, the researcher and his/her collaborator needs to build a relationship to work on their project. Likewise, Borg (2010) asserts that teachers are more likely to engage with research if their workplace provides opportunities to be engaged with research. 
The role of support for teachers. In the efforts to grow professionally through doing CAR project, teachers highlighted the importance of support they gained from principals and their colleagues either inside or outside schools. They found that support from the school community was central to allow them to be able to do their CAR project in school. However, sadly, during the project implementation phase, no support from the pilot workshop supervisor nor monitoring appointed by the provincial DIKJAR office (the pilot provider).

In terms of principal support, teachers in this study noted that support ranged from an administrative type - such as allowing teachers to do research- to giving incentives such as rewards and recognition to teacher who did the project. The importance of the role of the principal to support the teachers' research has been voiced by several authors (e.g., Burnaford, 1996, Calhoun, 2002; Tinker Sach, 2000). In particular, Burnaford (1996) suggests that principals should provide a conducive atmosphere for teachers to do research, ensure teachers are able to collaborate and share their research with others, provide facilities needed by teachers to ensure that they are able to conduct research, and be attentive to teachers' research in school. In addition, Borg (2010) views that the incentive and recognition provision for teachers in their workplace is important to provide a possible condition for doing research and motivate teachers to become involve in research. A study by Gilles, Wilson, and Elias (2010) who also reveals that the role of principal to 
facilitate teachers to do the action research project in school is critical to support them successfully to undertake such projects.

Some teachers noted that their teacher colleagues helped them to discuss their problems with their projects. Hence, for certain teacher (Teacher E) whose collaborators did not fully engage in the project, teachers' colleagues outside the school also provided important support and assistance aligned with their CAR project. The role of colleagues as the important component to support teachers to do action research has been highlighted by other studies (e.g., Gilles, Wilson, and Elias, 2010). Burns (1999) suggests that building teachers' networks can facilitate teachers and sustain them to do research. Similarly, Tafel and Fisher (2001) and Burnaford (1996) note that building learning community among the teachers inside or outside school can facilitate them to share and discuss their project-related problems. A study by Chou (2010) found that discussion and sharing among the teachers who did action research project facilitates information exchange, knowledge construction, and clarification.

Teachers in this study mostly found the absence of supervision or monitoring from the CAR pilot provider as the greatest barrier to the success of their project. As a result, teachers expressed that they felt vulnerable and encountered problems that they did not know how to resolve and therefore assumed their CAR project was far from good research. Ediger (2003), Slater (2006), and Ha, et al. (2004) highlight the 
need for principals, trainers, and colleagues to support teachers implementing in the classroom what they have learned from training. For CAR teachers, receiving this support would ensure them to apply what they have learned into practice by doing action research (Hill, 1995). Similarly, monitoring is essential to do; as Ingvarson, et al. (2003) point out that teaching practice should be monitored during the implementation phase (in this case, doing CAR project phase) along with the offer of support and assistance to the teachers.

\section{B. Factors Influencing Teachers' Decision to Continue with CAR}

After their first experience of a CAR project, three teachers (Teacher A, $\mathrm{D}$, and $\mathrm{E}$ ) made a conscious decision to continue do CAR individually or collaboratively with self-funding or from other funding sources (e.g. school and university); Teacher $B$ and $C$ did not engaged in further CAR projects. Teacher $A$ and $D$, were each involved in one more CAR project following the first one and Teacher E did three more projects.

Teachers B and D, involved in their CAR projects in 2009 for the sake of completing their postgraduate study at a local university in Palu. However, in this current study their projects were not counted as the selfdirected CAR projects as they were conducted for the purpose of the study than were driven by the teachers' self motivation (Lankshear \& Knobel, 2004, cited in Borg, 2010). 
This section describes the motives influencing teachers' decision whether to continue to engage in CAR projects after the first CAR one.

\section{Teachers' motivation to do CAR projects}

CAR as professional growth. All teachers noted that continue to do CAR beyond the pilot project was a means for them to develop professionally as teachers. They learned from this CAR process to improve their competency which in turn impacted on their students' learning and achievement.

Teacher A, for instance, found that CAR was a venue for her to learn to conduct research and to develop her teaching skills. She said below.

For me, I have to keep improving my self in teaching for the sake of my students; from CAR I learned how to identify the students' problem as well as finding its solutions...CAR helped me to increase my ability to develop creative ideas in the classroom...In short, I learn a lot from doing CAR project (TA:I2).

Her CAR project taught her how to be a reflective action researcher.

Hence, when she found that her students' were having problems in their English language learning, she decided to use a CAR approach to deal with this. She said 'CAR taught me to be a problem solver of my students' learning issues" (TA:I2). For her, this was the main reason she decided to keep on practicing CAR - it was a venue to learn and to grow as a teacher. 
Similarly, Teacher D noted that involvement in CAR projects encouraged him to learn through using reference books and he became more creative and developed initiative to improve his teaching issues in the classroom. He commented, "Involving in CAR project enforced me to learn teaching techniques from books...I gained many ideas of how to involve all students in teaching and learning process" (TD:I2).

Two teachers ( $D$ and $E$ ) noted that CAR was a path for them to grow professionally as it helped them to improve their writing skills. Teacher D said, "By engaging in CAR, I can develop my writing skill". Teacher E claims that doing CAR constantly is preserving her writing habit "If I stop doing CAR projects, I will stop writing. I don't want to stop this activity as I feel it would be hard for me to commence again from scratch. Hence, I keep doing CAR regardless of whether any budget is available or not" (TE:I2).

In the Indonesian context, the current policy (MENPAN decree No.16/2009) mandates that teachers need to be able to perform professional tasks such as writing research reports or articles (WI:I). Teachers D and E's motivation to keep practicing CAR was related to that policy.

Support factor. Following their initial CAR projects, three of the teachers $(A, D$, and $E)$ went on to engage in further CAR. It is interesting that teachers made more effort to conduct CAR when they had support to 
facilitate them to do CAR projects, particularly when the support was from within their schools. There were three pertinent factors that supported the teachers to successfully do their project: the provision of support from principals, the availability of advice and funding. All three of these factors were experienced by Teacher $E$, while teachers (A and D) only experienced two factors, as they did not received the budget support.

Principals play an important role to support teachers doing research in their classrooms (Borg, 2009; Burnaford, 2009). Teachers in this study gained support from their school principals when involved CAR projects after their first project. This is reflected from in teachers' A, B and E statement "Before doing CAR, I met the principal to discuss my project; He, indeed, supported it by allowing me to do it in my classroom" (TA:I2); "My principal supported me to do CAR project but not in form of funds (TB:I2), and "In my school, all teachers are encouraged to CAR projects; the principal even provided incentive by allocating a budget for us" (TE:I2).

Support in the form of the availability of advice became one factor that facilitated and sustained teachers to do their projects. All teachers noted that when they needed it received help from their fellow teachers who were more experienced in doing CAR.

Teacher E, for instance, got advice from her fellow teachers in her school who were frequently involved in their own projects, as well as from her "critical friend" who became her collaborator in the last CAR project. 
Regarding feedback from her colleagues, she said "I got lots of support from my colleague teachers who actively do their CAR projects in the classroom; ...whenever I had a problem I would run to them". About her collaborator, she said "For my last project, I was involved in collaborative action research with a teacher educator from one university; my collaborator helped me a lot to run this project" (TE:I2).

From her CAR report, I found that Teacher E did her last CAR collaboratively with one of the teacher educators in the local university in Palu. This project was funded by the university which aimed at encouraging teaching staff at the university to do collaborative action research with teachers in schools. The team did the CAR projects - from designing the projects until the reporting phase - collaboratively. The CAR project had been published in a journal in the university. (TE:CR)

Teachers also received advice from their friends who were involved in a teachers' forum (or MGMP). Teachers $A$ and $D$ were active members of English teachers MGMP. These teachers received feedback from their friends who were more experienced in the topic that they investigated. This feedback came from direct communication with an individual and not from a result of discussion in the forum by MGMP's member. Both teachers stated as "I got many suggestions personally from other English teachers who are the members of MGMP. After the MGMP meeting, I approached them personally to discuss my CAR project" (TA:I2); and "I 
sometime gained feedbacks from my colleagues from MGMP forum; I asked their opinion personally about my project" (TD:I2).

Another important form of support influencing teachers to want to continue to do CAR was the availability of funding. In the case of Teacher E, funding was provided by her school. For her, the provision of a certain budget allocated by the school helped her to sustain the practice of conducting CAR every year: "Following the first CAR project in 2006, I continuously do my CAR projects both individually or collaboratively...I did my own project twice which was funded by my school" (TE:I2). In her school, the provision of funding for the teachers to do CAR project commenced some years ago and it is open to all teachers who wish to do CAR project. She said "Since 2007, my school has allocated a budget for all teachers in the schools to do their own project" (TE:I2).

Pursuing higher teaching career. In the Indonesian context, it is a common practice now that a teacher may use his/her CAR report as a requirement to attain one more level of his/her career as regulated by government (MENPAN decree No.16/2009). For teacher D, one of the motives to engage with more CAR projects was to be able to use his CAR report or article as a supplementary document needed for getting promotion in this teaching career. 
In this case, Teacher $\mathrm{D}$ used his CAR articles for gaining one more rank above (level IV/ $\mathrm{b}^{34}$ ) as a government teacher; for many Indonesian teachers, to achieve this level is somewhat difficult since they have to provide professional works such as a CAR report. The teacher stated, "I used my CAR report for the sake of career advancement by rewriting it into article forms and sending them to a Journal in Makassar...Previously, my career got stuck in level IV/a for long time, now I have attained level IV/b - a level that most teachers feel difficult to get to" (TD:I2).

Teacher D's statement was congruent with the effort of the Indonesian government to encourage more teachers to participate in CAR practice as marked by the issue of the MENPAN decree No.16/2009 ${ }^{35}$. This policy acknowledges that Indonesian teachers need to be provided with numerous opportunities to enhance their PD which at the end will impact on their teaching career too (Personal communication, LPMP staff, October, 2010).

Relevant to that above policy, the CAR pilot teachers in this study participated required teachers to submit a report on their CAR activity; this served as physical proof that they did the CAR project (DD) and they could also use the reports when applying for career advancement.

\footnotetext{
34 The explanation of how CAR reports can be used for the sake of advancing one's teaching career is on p. 29.

${ }^{35}$ Both are described in Chapter 1.
} 


\section{Why teachers decided not to do more CAR project: Stories}

from Teacher B and C. Not all teachers I interviewed attempted to keep conducting CAR in their effort to grow professionally as teachers.

Teachers $B$ and $C$ did not engage with any CAR projects after their first involvement. These teachers had different reasons for why they did not engage in CAR project: including: low self-motivation and limited knowledge of conducting CAR in English subject field.

Teacher B, a senior teacher, who had served in the teaching service for 22 years, noted that her main reason not to engage in CAR was due to her personal factor. She noted that she had low self-motivation to do CAR again individually. However, she indicated that she was more likely to engage in CAR collaboratively if she had a mentor to help her. She commented:

My problem with CAR doesn't come from lack of support that I will gain, but mostly from my within myself as I felt I am quite a lazy person when asked to do a CAR project...Maybe, if someone could help me to do it, I would be eager to do it again (TB:I2).

Teacher B's statement indicates that conducting a CAR project in a collaborative way would lead her to succeed in her project. In addition, in her last CAR project conducted for the sake of the completion of her postgraduate study, she reflected that the role of a collaborator to support her doing the CAR was of beneficial. She said "Just for my last CAR study, I asked one of my friends to assist me doing research in my classroom...the collaboration was really helpful" (TB:I2). 
Another reason why teachers did not engage in on-going CAR projects was their limited knowledge of CAR. Teacher C, in this case, admitted that she was not confident to do CAR individually as she thought that her knowledge and skill was still limited. Yet, she was keen to do a CAR project in the future, when she finds a mentor who can support her with it. She said, "My first experience with CAR did not provide me enough knowledge to do more CAR projects...I am not quite confident with my current knowledge of CAR...I need to learn more...I wish I could find someone who can guide me intensively to do this project. I believe I could do it again in the future" (TC:I2).

The above two teachers had similar intentions to continue their CAR practice with support both through collaboration and mentoring or critical friend. These teachers did not find this support as in their own schools CAR was not programmed as PD for teachers (TB,C:I2). In addition, Teacher $\mathrm{C}$, in particular, following her first CAR workshop, did not attend any CAR workshops (TC:SI). However, Teacher B, had a chance to do CAR project in 2009 as a requirement for her Masters study (TB:SI).

Discussion: (1) Teachers Continue to Do CAR: What motivated and supported them?

This section discusses the experiences of those teachers who continued with on-going CAR practice in their classroom after their first 
pilot project. It specifically discusses what motivated them to continue with CAR as a practice as well as the particular supporting factors that facilitated them to do that. Arguments from experts as well as findings from other studies are used to support this discussion.

CAR as a path to professionally. Teachers who continued to do CAR talked about how it helped them to learn and develop their professional growth. Teacher A for instance said that from CAR she learned to identify students' problems and action research increased her ability to develop creative ideas in teaching. Similarly, Teacher D said that CAR encouraged him to consult books/references in his teaching field. Teacher $E$ asserted that engaging with CAR over time flourished her interest in writing scientific research and decided to preserve this habit through doing CAR. For them, CAR is way of growing professionally which is congruent with Johnson's (2008) statement that action research facilitates teachers professional growth from their teaching practice; it also improves their problem solving and enhances their professional selfesteem (Parson \& Brown, 2002, cited in Mertler, 2009).

That teacher can learn from CAR practice has been noted by Strickland (1988, cited in McBee, 2004, p. 1) many years ago by saying that "teachers learn through systematic investigation on problems concerning them". This finding of the present study also supports the study of Watkins (2006) who found that teacher researchers see action research as a vehicle for professional learning. In addition, Massey, et al. 
(2009) found the teachers she investigated benefited in the areas of learning about research, their students, and improving classroom practice. Given this evidence, it is therefore easy to understand Burnaford's (1996) assertion that CAR provides practical possibilities for teachers to continue to learn and to grow.

Supporting teachers to continue do the CAR. Teachers noted that there were three main supporting factors that motivated them to do their next CAR project: (1) the principals' support, (2) the availability of different sources of advice, and (3) financial support. Two teachers (A and D) only experienced the first and two factors, while Teacher E had all of these combined with her higher motivation to do the CAR projects. For teacher E, in particular, whose school programmes CAR project as annual PD activity, this facilitates her to do a CAR project every year. This finding indicated that teachers cannot be expected to run their own project without adequate support from schools' community (Tinker Sachs, 2000), except for highly motivated teachers who are still able to run their own project individually without any support (Borg, 2006).

In terms of support, this finding supports Borg's (2010) assertion that these kinds of support - resources (such as funding, incentives), management support, and an expert mentor - will likely facilitate teachers to engage with more research in schools. Given that the support is essential for teacher research, in the Indonesian context, the role of 
schools are pivotal to support teachers when involve in CAR project (Burns \& Rochsantiningsih, 2006; Lim, Pagram \& Nastiti, 2009).

Pursuing career advancement. It is also interesting to note that in the Indonesian context engaging with CAR provides many opportunities for teachers to expand their teaching career and to take their rank to a higher level. One teacher (Teacher D) in this study revealed that he could use his CAR reports (mostly in form of articles) to gain one step in his rank after being stuck at a certain level. His motive to engage with more CAR projects was partly derived from his ambition to achieve a higher career level as a government teacher.

This finding is particularly relevant in the Indonesian context where the current policy (the decree of MENPAN No.16/2009) has regulated that Indonesian teachers are required to do CAR for the sake of enhancing their career and, in particular, for their professional growth. In the future, it is more likely this promise of promotion through getting involved in action research will drives Indonesian teachers to engage in CAR. Indonesia is alone in making this practice mandatory; whereas in other countries the reasons teachers are motivated to engage with CAR are due to strong personal, pedagogical, and professional focus (Borg, 2009).

Borg (2009) studied 500 teachers in 13 countries around the world and he noted that only very few teachers stated that promotion was the factor that motivated them to engage in research. However, in the 
Indonesian context, this policy is a good sign of the high concern of top level of policy makers to empower teachers to be more engaged with CAR. This is in line with Borg's (2006) claim that teachers will be likely to engage with research if management at the institution level gives positive messages about teacher research and highly values and acknowledges research activities as a part of institutional culture.

\section{(2) What Impeded Teachers not to Continue Doing CAR after their First Project?}

Two teachers in this study decided not to do any further CAR projects after their first project as they had not perceived the process to be helping them professionally. They shared reasons not to undertake further projects which were: low self-motivation (Teacher B) and not confidence to do a research project due to limited knowledge of CAR.

Low motivation has been acknowledged by some researchers (e.g., Borg, 2009; Rayney, 2000; Volk, 2009) as one of the factors that may inhibit teachers from doing their next projects. Therefore, Borg (2006) and Volk (2009) highlight the importance of motivation as the driving condition for teachers to commence doing research in the classroom. This finding supports the study of Volk (2009) which shows that low motivation is one of the factors that impedes the teachers to continue their project. As teachers' self-motivation does not stand alone and is potentially affected by external factors (Borg, 2006), in the Indonesia context, the new policy 
(the decree of MENPAN No.16/2009) that requires teachers to do CAR if they want to be recognised as professional teachers and paid as professionals, will potentially motivate them to engage with CAR.

Teacher $\mathrm{C}$, in particular, revealed that what impeded her to continue CAR was her limited knowledge of CAR. This finding supports studies that have revealed that limited knowledge of CAR concepts impedes teachers to engage more with a CAR project (e.g., Borg, 2009; Burns, 2009; Rayney, 2000). Borg (2006) contends that it is important for teachers to possess sufficient knowledge and skills of research since it will result in them producing better quality of research. To deal with this problem, Borg (2006) suggests that the role of mentor is central to "scaffold" teachers doing research projects in their classrooms.

\section{Teachers' Recommendation about CAR as a PD programme}

This section is to address the last questionof my research: how do teachers believe CAR as a PD programme should be comprehensively designed and implemented to accommodate the needs of teachers to grow professionally through CAR engagement?

It discusses the teachers' perception of how CAR as a professional development tool should be effectively implemented by the policy makers (in particular to local education office). The teachers' recommendations 
are based on their experiences of the first pilot project and any following CAR projects they have been involved in.

From the interview data, several recommendation points emerged as to how the CAR workshop/training should be run and organised, what party should take part in executing CAR program, how should teachers be facilitated and supported in order to meet the notion of sustainable practice and most importantly what tenets should teachers possess to enable them to grow through the application of CAR approach in their classroom.

\section{How should CAR workshop/training be designed?}

CAR content designed for specific subject teachers. There is unanimous agreement among all the study participants that any CAR workshop must be designed to cater to the specific needs of the teachers taking part. Teachers prefer that workshops are specifically designed for certain subject teachers. This recommendation was based on their experience of the CAR workshop at which the CAR material was presented in a very general way, focusing on explaining the procedures of doing CAR; it did not discuss specifically how CAR could be most effectively used in the English teaching classroom. Teacher B stated, "The previous workshop did not cater for our need as English teachers...the materials were too general. Besides, the participants came from a range of 
different subject teachers...I found it difficult to understand all the materials learned in the training" (TB:I2)

Teachers B and D suggested that the district DIKJAR (or local Education office) could conduct a CAR workshop specifically designed only for certain subject teachers. This model could involve other parties such as teacher educators in university as facilitators. Teacher D commented:

DIKJAR Palu could commence a programme of CAR workshops that is designed to cater the need of certain subject teachers such as all English teachers from some schools are invited to attend the workshop. District could provide instructors and tutors who come from language teachers background and know well CAR concept (TD:I2).

Teacher B argued that the effort to specify the content material of CAR for certain subject teachers will help the teachers to learn the concept of CAR well. As she said, "I would prefer the content of CAR training to be more specific to accommodate teachers' confusion as well as to facilitate teachers to know well how to conduct CAR based on their problems in the classroom" (TB:I2).

The statement of Teacher B above in relation to the general nature of the CAR material is congruent with the DIKJAR's workshop guideline report and the workshop materials sought from the instructor. Both documents showed that none of the materials presented were particularly designed for certain subject teachers (such as English teacher). 
Likewise, the above Teacher B's statement accorded with the statement of the workshop instructor who said the CAR materials for the workshop were not designed to specific subject teachers. According to him, the reasons were twofold: (1) the workshop participants came from different subject areas; and (2) the time allocation for explaining the concept of CAR was very limited (only 2 hours) ${ }^{36}$ (WI:I).

School-based workshop. Teachers also suggested that each school could play an important role in designing its own CAR workshop model to meet their teachers' specific needs. In addition, it could accommodate all teachers in the school to learn CAR knowledge. The workshop teacher that the teachers attended was not offered to all teachers in each school which participants see as a limitation. Teacher C states "Previous workshop was only attended by some teachers from my school" (TC:I2).

In line with the above recommendation, Teacher $\mathrm{C}$ suggested that DIKJAR Palu (local Education office) could support each school to run its own CAR workshop for its teachers by providing the sources needed such as facilitators. She said "DIKJAR Palu could support schools to do their own CAR workshop/training for teachers by providing the facilitators. This will potentially cater for all the teachers in each school to learn to do CAR" (TC:I2)

${ }^{36}$ See page 112 
Another teacher suggested that a school-based workshop could be successful, providing that the school principal motivates and encourages all teachers to be involved. This was based on her reflection that not all teachers in her school were interested to participate in PD activity initiated by her school. She said, "I prefer the workshop is initiated in each school, but the principal must provide support to all teachers by encouraging them to participate. In practice, as I am concerned only certain teachers to participate in any PD programmes conducted in my school" (TA:I2).

Teacher E, similarly, supports the idea of the CAR programme being initiated within the school as in her school. It was based on her experience in her school that has been programming such school-based workshops and provides the chance for teachers to do the CAR projects afterwards. She said, "Every year my school conducts a CAR workshop for teachers. This programme provides a large opportunity for all teachers in school to learn CAR" (TE:I2).

The school-based workshop recommendation was relevant with the current policy being implemented in Indonesian schools - school-based management- that was introduced in 1999. Congruent with this the DIKJAR staff that said in line with the above policy, schools are today encouraged to run their own PD programme and to include a CAR workshop programme (DS:I). 
In the context of Palu city, this recommendation could potentially be realised and put into practice. The workshop instructor revealed that he has been involved in the training programme since 2010 under BERMUTU ${ }^{37}$ project that is specifically designed for all school principals and school supervisors to support teachers to do CAR projects in Palu city. One of the aims of this training is to initiate the CAR programme within schools thereby providing more chances for teachers to learn and engage with CAR (Source: WI:I).

\section{Empowering MGMP (Teacher Network Group of Subject}

Teacher). There is also a strong demand from some teachers (Teacher A, $B$ and $C$ ), to empower the teacher network group or MGMP as the best venue to learn CAR concept to accommodate its members. In the Indonesian context, $\mathrm{MGMP}^{38}$ has a weekly meeting programme to discuss pedagogy matters (Hendayana, 2007). However, teacher claimed that in Palu city, particularly, the senior secondary English teacher's MGMP, only focus its programme on teachers' administration tasks such as designing lesson plans and developing test items rather than on PD programme such as CAR. This view was offered by Teacher B, the secretary of the senior secondary English teacher's MGMP of Palu City:

As far as I am concerned, there has not been one single CAR workshop or training conducted by MGMP that aims to facilitate teachers to do CAR projects in their classroom... we used to get an operational budget (fifteen million) but this was only allocated for

\footnotetext{
${ }^{37}$ BERMUTU Programme is described in Chapter 1.

${ }^{38}$ MGMP for secondary teacher was described in p. 27 of Chapter 1.
} 
training teachers to make syllabus, lesson plans, and develop test items...We certainly intend to shift our focus to teachers' professional growth by programming CAR projects in the future (TB:I2).

Teachers $\mathrm{A}$ and $\mathrm{C}$ recommended that the MGMP forum could involve other parties such as the local education office staff and university teacher educators to facilitate teachers to learn CAR:

The MGMP administrator should design a programme which accommodates its member to learn CAR through workshops. Some related parties could be involved in this project, such as the district education office that provides funds and instructors from university or master teachers from LPMP could deliver workshop materials (TA:I2).

Our MGMP solely pays attention to programming administration matters for teachers. I think it would be more effective if MGMP should commence to enhance its member's continuous professional learning through CAR workshops for instance (TC:I2).

Likewise, Teacher A considered learning CAR skills in the MGMP forum could also provide a good opportunity for teachers to gain more intensive guidance from workshop instructors as the forum has few members compared with previous workshops where large numbers of participants attended and not all got full attention from the trainers. She said, "Last time the workshop was so crowded (about 80 participants in the class). As a result, we did not get enough opportunity to practice what we learned or get intensive attention from instructors; learning CAR in the 
MGMP forum, I think, could be more effective as we have fewer members" (TA:I2).

In summary, then, study participants believe that learning CAR at a MGMP forum could be effective because MGMP members are mostly teachers who teach similar subjects. It is clear that the previous CAR workshop these teachers attended did not cater for their specialised needs.

CAR project programme. It is interesting to note in this study that teachers viewed that, regardless of which parties (local DIKJAR or schools) facilitate and sustain teachers to do CAR projects, that CAR as a PD programme should be planned and implemented comprehensively. In this sense, they demanded that the CAR programme must be supervised and supported. In terms of supervision, teachers suggested that guidance, mentoring, or supervision need to be conducted by the pilot provider. It is recommended that support from school communities such as principals and colleagues coupled with the provision of funding and rewards could be central factors to support and facilitate teachers to engage with CAR projects.

Supervision. In terms of supervision, teachers suggested that during the process of conducting the CAR project, they needed to be supervision in the form of both guidance and advice on their projects. The supervisor might be an instructor, tutor, or mentor. This point of recommendation is based on participants' reflections on the initial CAR 
pilot where teachers did not receive intensive mentoring; for example, "We, teachers, did not get any guidance or supervision during doing our CAR projects. Perhaps, we could do better CAR projects with follow-up by guidance, feedback or supervision" (TA:I2).

In conjunction with the above recommendation, three teachers provided their suggestions. Teacher D said that "If teachers are expected to produce a good quality of CAR projects, we should get a chance to be well supervised so we are not in a vulnerable situation if we have a problem with our project" (TD:I2). Similarly, Teacher C added "Whatever parties held the CAR pilot as PD for teachers should consider the role of tutors or mentors who could facilitate teachers to do CAR projects on the right track" (TA:I2). Teacher C voiced similar intention as follows:

In the previous pilot, many teachers did not apply CAR project in the classroom due to the lack of supervision and guidance...to report their projects, they just copied their friends' work. In the future, supervision venues for consultation should get main priority (TC:12).

Referring back to the information about the initial project, in the phase of teachers doing their CAR projects, no guidance or mentoring took place. During this phase - from the process of conducting project up to the reporting stage- teachers themselves with their collaborators were left to do their own projects (DD).

School community support. Support from the school community has also become a centre of attention for the teachers. They expressed 
the hope that principals could provide more support to motivate teachers to do their projects. Colleagues in the school are also regarded as having pertinent roles as well.

One of the participants suggested that principals should encourage all teachers to be involved in CAR projects to avoid any atmosphere of disharmony among the teachers. She suggested:

Principals should encourage all teachers to do CAR projects, not only certain teachers. Very often teachers who do PD projects get cynical responses from other teachers who do not...Principal should ease this condition by involving all teachers in more collegial learning particularly in CAR project (TC:I2).

Participants suggested that colleagues could serve as critical friends or join teams in the CAR projects. Teacher E, who experienced the reluctance of her collaborators to participate in the CAR project, suggested that it is central for colleagues to support the other teachers who do CAR. She said:

Those teachers who do not do their CAR project should support teachers who do it...they could function as critical friends for us who could provide critique as well as suggesting solutions for our obstacles...I did not find this condition in my first project" (TE:I2).

Furthermore, Teacher A noted that it is good for teachers who teach the same subject in one school to collaborate in CAR in order to gain mutual benefits in terms of ideas, knowledge, and experiences. She said "I wish my friends could be involved in the CAR project collaboratively, 
so there would be sharing of ideas and knowledge as well as providing feedback to each other" (TA:I2).

Funding and Reward. Another source of support that teachers in this study considered important, if not crucial even, is the provision of funding to facilitate and sustain them to do CAR projects. Teacher A, for instance, said funding will motivate teachers to keep doing CAR, "I would feel motivated to do CAR if the school could supply teachers with adequate fund to do their project" (TA:I2). Similarly, Teacher D said that "School should support teachers to do CAR by providing sufficient budgets" ( $T: I 2)$. These both teachers mentioned that when they did their second project, school did not provide them funding. Further, Teacher A said "I used my own and students' money to copy the materials used in the classroom;...school did not have budget allocation for teachers to do CAR project" (TA:I2); and Teacher D stated "My principal supported me to do CAR but not in form of funds; I used my own and students' money for buying things that I needed" (TD:I2).

Teacher B suggested that whoever runs the CAR pilot should provide funding to support teachers to conduct their projects. She said, "We want that when involved in any CAR, the PD providers should provide us funding" (TB:I2).

In addition to funding support, participants of the study viewed rewards as a supplementary factor that motivates teachers to continue to 
apply CAR in their practice. Teachers suggested rewards come in two modes: bonus and the large chance to publish their works:

It would be wonderful if DIKJAR office or schools could provide incentives such as bonuses for teachers who wish to conduct CAR projects...This bonus could be meaningful to sustain us to do more CAR projects" (TD:I2).

I hope my CAR works could be published in a journal...I wish schools or DIKJAR office could facilitate this: publishing my works. This will stimulate us to produce more CAR works" (TA:I2).

Teacher $E$ who received funding support from her school to keep her doing CAR, suggested that the reward provision will enhance teachers' motivation as well as recognise their hard work:

School support is inevitably pertinent for teachers who conduct CAR projects... This could be in the form of the provision of facilities needed by the teachers and provide more incentives to boost teachers' motivation to do CAR projects. Doing CAR needs extra time; hence, teachers indeed need an incentive (TE:I2).

\section{Discussion: Facilitating Teachers Learning CAR and Sustaining CAR Projects}

This section discusses the teachers' perception of how CAR workshop/training should be facilitated to cater to teachers' specific needs. In addition, it also discusses the case study teachers' perceptions of how CAR projects should be ideally conducted by the PD provider in order to encourage them to sustain their practice. 
Facilitating teacher learning CAR. Some teachers in this study highlighted the importance of selecting appropriate materials for delivery in the CAR workshop to facilitate them to learn CAR concepts and apply them in the classroom. They thought CAR material should accommodate the teachers' needs and questions. Richards and Farrel (2005) say that for a workshop to be effective it is important for an instructor to choose an appropriate topic that relates to the background of the workshop participants as well as their interests. In addition, this idea is aligned with the theory of transfer of training which denotes that training participants will maximally apply what they learn from the training/workshop if the content and task of the workshop are matched and similar to the transfer setting, in this case classroom (Baldwin \& Ford, 1988).

Driven by the notion of accommodating the need of teachers, the teachers of this study suggested that a workshop could be initiated in a small-scale venue such as school or MGMP. They noted that conducting workshops in school will allow more teachers to learn CAR knowledge as well as being able to apply it in the classroom. For a school-based workshop to achieve maximum results, teachers suggested it is critical that principals encourage teachers to fully participate in the workshop. The literature has highlighted that school-based professional development as opposed to off-site workshops gives maximum opportunity for teachers to get guidance and assistance from the wider school communities as well as support from principals and top management (Darling-Hammond, 1998; 
Lieberman, 1996; Veenman \& Denessen, 2001). In the Indonesian context, Lim, Pagram, and Nastiti (2009) suggest it is more likely that PD programmes will be successful when they are job-embedded, site-based and needs-based coupled with on-going support from school leader. A study from Cromwell and Kolb (2004) also reports that trainees who received a high level of support from their supervisor (principals in school context) demonstrated more application of knowledge and skill from their training on the job (for teachers in the classroom).

Similarly, there has been increasing need expressed by teachers to strengthen their teacher network group and thus make it more powerful and influential (in this case MGMP) as a venue for PD activity such as learning CAR knowledge and skills. Teachers in this study noted that the senior secondary English teacher $\mathrm{MGMP}^{39}$ in Palu for a long time only served as a place for discussing administrative issues such as creating lesson plans and annual teaching programmes and that this network group has not become a place for teacher learning (Hendayana, 2007). Empowering this teacher network for promoting teachers to engage with research is consistent with Lieberman and Groldnick's (1998, cited in Richards \& Farrel, 2005, p. 51) statement that teacher networks play a vital role in "providing opportunities for teachers to validate both teachers' knowledge and teacher inquiry". Burns (1999) suggests that building

\footnotetext{
${ }^{39}$ MGMP for senior secondary English teachers in Palu that meet once a week chaired by senior teachers. This independent network group is attended by English teachers who voluntarily join in the senior secondary level education. This type of teacher network is the only network recognised by government for a long time.
} 
teachers' network can facilitate teachers and sustain teachers to do research. In term of its function, a teacher network may serve a variety of purposes as suggested by Richard and Farrel (2005) such as: reviewing and reflecting teaching, developing materials, trying out new teaching strategies, applying peer observation technique, observing video tapes, writing articles, inviting outside speaker, developing research projects, and planning seminars.

Moreover, In terms of the effectiveness of PD, Burnaford (1996) says that "PD activities are far more effective if they are organized, implemented and evaluated by teachers", (p. 148). Likewise, inspiring teachers to reflect on their practice through this group network will enhance the status of their network group as it evolves into professional learning community (PLC) - a venue where teachers inside or outside schools can enhance each other's and students' learning as well as school development (Stoll et al., 2006). Stoll et al. (2006) describe PLC as "an on-going, reflective, collaborative, inclusive, learning-oriented, growthpromoting way operating as a collective enterprise" (p. 223). Teachers who engage in PLC find this impact on their teaching practice, their professional knowledge, and students' achievement (Vescio, Ross, \& Adams, 2008).

Facilitating teachers doing the CAR project. There is a common perception among all teachers that to sustain the CAR practice in the classroom, CAR as a PD programme needs to be supervised (such as the 
provision of mentoring), supported (by principals, colleagues and education stakeholders), and supported financially and by recognition (in form of incentives, acknowledgement of their CAR projects, or access to publishing projects). In this sense, all teachers agreed that their successfulness in their CAR project and their high willingness to sustain the practice are more likely affected by the enormous support both externally (parties are outside schools) and internally (school communities).

This is consistent with the finding of Westwell (2006) who reported that teachers are more likely to be successful and motivated to continue their project if they gain external support such as one-to-one support (critical friend), seminar provisions, and internal support (such as interest and encouragement from colleagues and heads of schools).

Teachers noted that the role of mentoring from external agencies such as the local university teacher educators and teacher trainers from LPMP- is critical to guide teachers to successfully conduct their CAR project. Borg $(2006,2009)$ highlights the significant role of mentors to facilitate the teachers to conduct action research in their classroom. Numerous studies reveal that teachers who successfully reflect on their practice through engaging with CAR are supported by teacher educators in the form of in-services programmes (e.g., Atay, 2008; Chou, 2010), pilot project (e.g., Burns, 2000; Wiggleworth \& Murray, 2007), critical friends (Westwell, 2006) and research partnership (e.g., Atay, 2006; Burbank \& Kauchak, 2003; Ponte, Ax, Beijaard \& Wubbles, 2004). 
In addition to the role of external mentors, internal support such as from colleagues inside schools and principals is also a critical factor which teachers believed can facilitate them to conduct CAR project in school. In particular, teachers viewed the colleagues' role as collaborators is central to support them doing CAR projects. Likewise, they considered principals play an important role in encouraging all teachers to be involved in PD programmes of CAR in schools to reduce disharmony between teachers who conduct CAR and those who do not.

Various international studies have noted that support from the school community such as colleagues and principals is immensely important to encourage teachers to engage with CAR in their own classrooms (e.g., Burnaford, 1996; Gilles, Wilson, \& Elias 2010; Hancock, 1997; Senese, 2000; Tinker Sachs, 2000). Senese's (2000) study of teachers who carry on doing action research projects notes that collaboration with a colleague during CAR became a crucial factor for teachers in sustaining their research efforts.

Finally, some of the participants of this study recommended that it is important to facilitate and help teachers engage with CAR through the provision of financial support and other recognition (such as provide access to publish their works). Borg (2010) asserts that the provision of funding and incentive for teachers to research is likely to support them to engage more with research in schools. Senese (2000) reports that teachers who were given broad access for publishing their works in local 
and national publications and also to present them at local or even international conferences kept on with their practice as classroom researchers. Senese (2000) further points out that those teachers felt proud of their efforts since their works were not only worthwhile for themselves and their students but also to the larger community. In the Indonesian context, providing access to teacher to publish their CAR works is not only useful for their professional growth but also provides incentives for their teaching career status as mandated by the policy of MENPAN 16/2009.

\section{Chapter Summary}

This chapter has described the findings from the interviews with the teachers of the present study and considered some of the statements of the workshop's aims and evaluations. It also provides a discussion of how the findings from the current study are supported by international literature and studies specifically in the area of action research and professional development. The section $A$ of the chapter examines the experiences of teachers engaged with CAR projects and discusses the benefits, challenges, and support provided by school communities and supervisors when doing CAR projects. All teachers benefited from doing CAR which impacted on their teaching practice, self-awareness of students' needs and their own teaching profession, as well as on their personal learning. This current study supports the other studies which noted the involving 
with CAR impacted on teachers' teaching practice, awareness of their profession and students and their professional development.

Section B provides the teachers' experiences of engaging in ongoing CAR after their first project. This section reveals that teachers were motivated to continue with CAR as a professional development tool and for enhancing and advancing teaching careers. Those who did not remain involved in any project attributed this to their limited knowledge of CAR and low motivation. These challenges that potentially impede teachers have been also identified by several other studies. However, teachers found that support from principals and other teachers was critical to support them to engage with CAR. Next, teachers who decided to engage more with CAR were prompted by their belief that CAR is a path that leads to their own professional development. For those teachers who did not intend to engage more with CAR, low motivation and limited knowledge became the reasons as have been highlighted by numerous studies.

The final section provides the teachers' recommendation about how to facilitate and sustain teachers to engage with CAR, suggesting that CAR as a tool PD needs to be well supervised and supported. one common recommendation provided by teachers in this study that CAR as a PD tool needs to be comprehensively imposed at the level of school or teachers' network groups by involving external support (such as expert mentors from university) and internal support (such as from principals and 
colleagues). Moreover, this also should be supported with adequate funding and recognition of teachers' work from the policy makers. 


\section{CHAPTER 7}

\section{Conclusion and implications}

This concluding chapter considers the implications of the study for policy makers and related parties promoting CAR as a tool of professional development for teachers, and makes some recommendations for the planning and delivery of future such projects in the Indonesian context.

\section{Conclusion of the Study}

This study which was conducted in Palu city, Central Sulawesi, Indonesia aimed at exploring the experiences of five teachers who participated in a CAR pilot (workshop and CAR project) in 2005-2006. Specifically, this study investigated the teachers' experiences of engaging with CAR in the following areas: the benefit of CAR for teachers; the problems or challenges that they encountered while engaging with CAR projects; the kinds of support provided by principals, colleagues, and supervisors, factors motivating some teachers to undertake additional projects; and the teachers' perceptions of CAR as a PD tool. In the preceding chapters, the findings of this qualitative case study have been considered in detail and the research questions around which study was designed have been discussed and responded to in depth. 
In brief, this study found that teachers did benefit from engaging with a CAR project in their schools. There were three main benefits they gained from this practice: CAR impacted on their teaching practice, enhanced their awareness of their teaching profession and students' learning problems, and helped them to learn and to grow personally. The findings from this study support those of other studies (e.g., Falk \& Blumenreich 2005; Gebhard, 2005; Rochsantiningsih \& Burn, 2006). However, doing a CAR project was not a straightforward process for the teachers in this study as they experienced a number of challenges that impeded the progress of their projects. Insufficient knowledge of CAR concepts, lack of mentoring, no assistance from collaborators and time constraints emerged as the key factors that hampered them in doing action research. These problems have been also identified by several other studies (e.g., Borg, 2009; Rayney, 2000; Volk, 2009). Teachers of this study highlighted the importance of support in enabling them to successfully complete their projects. In this case, they found support from principals and colleagues to be critical to encourage them to remind engage with CAR and requested that, in future programmes, workshop supervisors also need to provide support.

Of the five teachers participating in this study, three were involved in more than one CAR project and were motivated to do so by the belief that CAR contributes to their professional development; their experience was that support from friends and the principal was the key to their 
success. Indeed, the literature suggests the importance of support from top administration and colleagues (Borg, 2006, 2009; Burnaford, 1996). Meanwhile, the two remaining teachers who conducted only the first pilot project attributed this to low self motivation and insufficient understanding of how to do research.

\section{Recommendations}

The recommendations from this study are based on all these above experiences of the five participating teachers. These recommendations are relevant to all parties involved in facilitating teachers to learn and grow through CAR projects in the Indonesian context. In terms of training, the recommendation is that material should align with the teachers' needs and problems; this recommendation is also suggested by the literature of transfer of training (Baldwin and Ford, 1988).

A further recommendation is to initiate small scale, school-based workshops, or for MGMP to accommodate the needs of all teachers to learn and grow through CAR. This recommendation is in line with the internationally accepted notion that doing school-based PD will provide more chances for teachers to get support from principals and colleagues (Darling-Hammond, 1998; Lieberman, 1996; Veenman \& Denessen, 2001).

The next set of recommendations is how best to support and assist teachers doing research in their own classrooms. The major 
recommendation is for the PD providers themselves (regardless of whatever party is delivering it) to provide supervision and support. Teachers felt they needed external support from expert mentors along with the internal support they received from school principals and colleagues. A further recommendation is to reward teachers for completing CAR projects, preferably, in the form of incentives and broad access for publishing teachers' works. The teachers' experience is that - particularly financial assistance and recourses - from policy makers (in this case, local DIKJAR) is highly important for the sake of ensuring the success of PD programmes at all levels of schooling.

\section{Implication of the Study}

Given the findings of this study, there are some implications that are applicable for any programme intended to enhance teacher's professional development through action research in the Indonesian context, more specifically in Central Sulawesi province:

a. Engaging with action research, clearly, benefited teachers to grow as professionals. Hence, efforts to facilitate teachers to learn to use CAR approach as well as supporting them to implement that approach in their own classroom need to be fostered, particularly at the level of schools. Hence, the local DIKJAR office, as the district 
policy maker, should encourage and support schools to initiate school-based PD by providing recourses and financial support.

b. Teachers experienced difficulties learning CAR through a shortterm training workshop that was attended by a large number of participants with very different subject backgrounds. Therefore, small-scale workshops which accommodate specific subject teachers to learn CAR concepts more comprehensively need to be conducted at the school level, or in MGMP network group. This would be more effective for equipping teachers with the knowledge and skills required for conducting CAR, and therefore, be more likely to produce good quality research.

c. During the phase of doing CAR projects, teachers did not find any mentors or supervisors who could provide them feedback regarding their projects and this resulted in them isolated and vulnerable. In the future, any efforts to facilitate teachers to engage with a CAR project should be accompanied by the provision of mentoring that may come from teacher educators( such as myself) from university, teacher trainers from LPMP, or experienced teachers from MGMP. Such mentors role would be to supervise as well as guide teachers to successfully involve in CAR projects.

d. One notable finding is that teachers who do CAR projects face challenges in their efforts to grow professionally at schools. Hence, support from school communities (school principals, teachers and 
administration staffs) is extremely important to enable teachers to sustain the practice of CAR in the classroom. Schools need to provide a range of support such as administrative help, mentors, a venue for discussion, financial incentives, and recognition.

e. As evidence by the decree of MENPAN No.16/2009), which requires all teachers to engage with CAR in their classroom, the Indonesian government has placed enormous emphasis on developing teachers' growth through using CAR. This policy effectively commenced on April 2011. To maximise the effectiveness of this new requirement, should be accompanied by extensive support from external school and internal school parties as mentioned above to both within and beyond the schools.

f. The finding of this study provides considerable inputs for district education offices, schools, and MGMPs that are involved in providing PD training and workshops in Central Sulawesi context, particularly in Palu city. These parties should conduct a need analysis of the participants, monitor and evaluate the programme, and provide extensive support after the program. Moreover, in the interest of conducting better PD programmes as suggested by literature and studies, PD providers should collaborate with relevant parties from university and teachers training institution such as LPMP in designing, planning, and implementing PD programmes. 
g. Finally, this study provides reassurances to all teachers that practice research is of high value. In particular, it provides persuasive evidence to English teachers in Palu city, that engaging in CAR facilitates professional growth; via CAR they can reflect upon, examine, and change their practice which ultimately impacts on their students learning achievement as well as their own professional status.

\section{Issues for Further Research}

Given this study was exploratory and limited in scope, it is important that further research investigates teachers' practices of CAR particularly in the context of Central Sulawesi. The study has highlighted the need for further related research in other school contexts, subject areas, and over a longer time frame as follows.

a. Research into the effectiveness of CAR training that better accommodates teachers' needs and interests and its impact on participants' implementation and application in terms of the quality of subsequent CAR project.

b. Research that investigates what kinds of support make a significant difference for teacher learning from their ongoing CAR practice.

c. Research on how to introduce CAR practice at all levels of school and how to use the teachers' network forum such as MGMP to 
inform the best practice of CAR as PD programme that could be implemented in Palu city.

d. Research to understand more about the role of teacher educators in the university as critical friends or collaborators for teachers who engage with CAR. Such study would enhance understandings of how schools collaborate with the university and teacher educators.

Given the findings of this research study, it is of vital importance to do more research in facilitating teachers' professional growth through reflective practices. This preliminary study provides valuable information about the use of CAR as a tool for teachers' professional development. To best facilitate teachers to achieve professional status through engaging in CAR, considerable support both from within and beyond schools is needed. 


\section{REFERENCES}

Atay, D. (2008). Teacher research for professional development. ELT Journal, 62(2), 139-147.

Atay, D. 2006. Teacher's professional development: partnerships in research. TESL-EJ , 10(2), 1-14.

Baldwin, T.T., \& Ford, J.K. (1988). Transfer of training: A review and directions for future research. Personnel Psychology, 41, 63-105.

Bandur, A. ( 2008). The implementation of school-based management in Indonesia: creating conflicts in regional levels. Journal of NTT studies, 1(1), 16-27.

Bappeda Sulteng. (2010). Profil Daerah Provinsi Sulawesi Tengah (the profile of Central Sulawesi Region). Palu: Indonesia .

Barlett, S., \& Button, D. (2006). Practitioner research or descriptions of classroom practice? A discussion of teachers investigating their classrooms. Educational Action Research,14( 3), 395-405.

Begoray, D. L., \& Banister, E.M. (2010). Reflexivity. In Mills, A. J., Durepos, J., \& Wiebe, L (Eds). Encyclopedia of case study research. Long Angles: A Sage Reference Publication.

Best, J.W., \& Kahn, J.V. (1998). Research in education. Boston: Allyn and Bacon.

Birman, B.F., Desimone, L., Porter, A.C., \& Garret, M.S. (2000). Designing professional development that works. Educational Leadership, (5), (28-33).

Boeije, H. (2010). Analysis in qualitative research. Los Angles: Sage Publication Ltd. 
Bogdan, R.C., \& Biklen, S.K. (2003). Research for education: An introduction to theories and methods (4th Ed). Boston: Pearson Education.

Bolam, R. (1982). In-service education and training of teachers: $A$ condition of educational change. Final Report of CERI Project on INSET. Paris: OECD.

Borg, S. (2006). Conditions for teacher research. English teacher Forum, (4), 22-27.

Borg, S. (2009). English language teachers' conception of research. Applied Linguistics, 30(3), 355-388.

Borg, S. (2010). Language teacher research engagement. Language teaching, 43(4), 391-429.

Burbank, M.D., \& Kauchak, D. 2003. An alternative model for professional development: investigation into effective collaboration. Teaching and teacher education (19), 499-514.

Burnaford, G. (1996). Supporting teacher research: professional development an the reality of schools. In Burnaford, G., Fischer, J., \& Hobson, D., (Eds). Teachers doing research; practical possibilities. Mahwah, New Jersey: Lawrence Erlbaum.

Burns, A. (2009). Action research in second language teacher education. In Burns, A., \& Richard, J. C., (Eds). A Cambridge guide to second language teacher education. Cambridge: Cambridge University Press.

Burns, A. (2010). Doing action research in English language teaching: $A$ guide for practitioners. New York: Routledge. 
Burns, A. \& Rochsantiningsih, D. (2006). Conducting action research in Indonesia: Illustrations and implications. Indonesian Journal of Language Teaching, 2(1), 21-35.

Burns, A. (2000). Facilitating collaborative action research: Some insights from the AMEP. Prospect, 15( 3) , 23-3

Burns, A. (1999). Collaborative action research for English language teachers. Cambridge: Cambridge University Press.

Burton, D., \& Barlett, S. (2005). Practitioner Research for Research. Great Britain: Paul Chapman Publishing.

Burton,J. (2000). Sustaining language teachers as researchers of their own practice. The Canadian modern language review, 54(1), 84102

Caldwell, B. J. (2005). School-based management. Retrieved May 30, 2010, from http://www.unesco.org/iiep

Calhoun, E.F. 2002. Action research for school improvement. Educational Leadership (3), (18-24)

Cardno, C. (2003). Action research: A developmental approach. Wellington: New Zealand Council for Education Research.

Carr, W. \& Kemmis, S. (1986). Becoming critical: knowing through action research. London: The Falmer Press.

Chou, C. (2010). Investigating the effects of incorporating collaborative action research into an in-service teacher training program. Procedia social and behavioural science, (2), 2728-2734

Cohen, L., Manion, L., \& Morrison, K. (2002). Research methods in education $\left(5^{\text {th }} \mathrm{Ed}\right)$. London: Routledge Falmer. 
Cole, A.L., and J.G. Knowles. (1993). Teacher development partnership research: A focus on methods and issues. American Educational Research Journal,30(3), 473-95.

Creswell, J. W. (1994). Research design: qualitative \& quantitative approaches. Thousand Oaks: Sage Publication, Inc.

Creswell, J. W. (2007). Qualitative inquiry and research design: choosing among five traditions. Thousand Oaks, CA: Sage.

Curtis, A. (2001). Hongkong secondary school teacher' first experiences of action research. PAC Journal (1), 65-78.

Denzin, N. K., \& Lincoln, Y. S. (Eds.). (1995). The handbook of qualitative research. London: Sage.

Diaz-Margiolli, G. H. (2003). Professional development for language teacher. Eric Digest. Retrieved March 25, 2010 from http://www.cal.org/resources/Digest/digest pdfs/0303diaz.pdf

Dispendik Palu. 2010. Data pokok pendidikan wilayah (Main data of district education). Retrieved February 21, 2011 from http://palu.dapodik.org/index.php.

Dowling, M. (2008). Reflexivity. In Given, L.M (Eds). The SAGE Encyclopedia of Qualitative Research Method. Long Angles: A Sage Reference Publication.

Ediger, M. (2003). Data driven decision-making. College Student Journal, 37(1), 1-9.

Falk, B. \& Blumenreich, M. (2005). The power of questions: A guide to teachers and student research . Portsmouth, NH: Heinemann. 
Farrell, T.S.C. (2007). Reflective Language Teaching: from research to practice. London: Continuum.

Flinders, D.J. (1992). In search of ethical guidance: Constructing a basis for dialogue. Qualitative Studies in Education 5(2), 101-115.

Fueyo, V., \& Koorland, M.A. (1997). Teacher as researcher: a synonym of professionalism. Journal of teacher education, 48(5), 336-344.

Fullan, M. (2001). The New meaning of educational change ( ${ }^{\text {rd }}$ Ed). USA: Routledge Falmer.

Garet, M., Porter, A., Desimone, L., Birman, B., \& Yoon, K. (2001). What makes professional development effective? Results from a National Sample of Teachers. American Educational Research Journal, 38(4), 915-945.

Gebhard, J.G. (2005). Awareness of Teaching through action research: examples, benefits, limitations. JALT Journal, 27(1), 53-69.

Gilles, C., Wilson, J., \& Elias, M. (2010). Sustaining teachers' growth and renewal through action research, induction programs, and collaboration. Teacher education quarterly, 91-108.

Ginns, I., Heirdsfield, A., Atweh, B., \& Watters, J. J .2001. Beginning Teachers becoming professionals through action research. Educational Action Research, 9(1),(111-133).

Goldstein, L. S. (2002). Moving beyond collaboration: redescribing research relationships with classroom teachers. Teachers and Teaching: theory and practice, 8(2), 155-170. 
Gore, J. \& Zeichner, K. (1991). Action Research and Reflective Teaching in Preservice Teacher Education: A Case Study from the United States. Teaching and Teacher Education, 7(2), 119-136 Ha, A., Lee, J., Chan, D., \& Sum, R. (2004). Teacher perceptions of inservice Hong Kong experience. Sport, Education and Society, 9(3), 421-438.

Hairon, S. (2006). Action research in Singapore Education : constraints and sustainability. Educational Action Research, 14(4), 503-523.

Hancock, R. (1997). Why are class teachers reluctant to become researchers?. Professional development in Education, 23(1), 8599.

Hendayana, S. (2007). Development of INSET model for improving teacher professionalism in Indonesia. Nue Journal of International educational corporation, (2), 97-106.

Hendriks, C. (2006). Improving Schools through Action Research: a comprehensive guide for educators Boston,MA: Allyn and Bacon.

Hendriks, C. (2009). Improving Schools through Action Research: a comprehensive guide for educators $\left(2^{\text {nd }} E d\right)$. New Jersey: Pearson Education, Inc.

Hinchey, P.H. (2008). Action Research. New York: Peter Lang.

Hopkins, D. (2008). A teacher's guide to classroom research $\left(4^{\text {th }}\right.$ Ed). UK: Open University Press.

Ingvarson, L., Meiers, M., \& Beavis, A. (2003). Evaluating the quality and impact of professional development programs. In M. Meiers (Ed.), ACER Research Conference (pp.28-34), Melbourne: ACER. 
Jalal, et al. (2009). Teacher certification in Indonesia: a strategy for teacher quality improvement. Washington, DC: World Bank

Jensen, D. (2008). Transferability. In Given, L.M (Eds). The SAGE Encyclopedia of Qualitative Research Method. Los Angles: A Sage Reference Publication.

Johnson , A. P. (2008). A short guide to action research ( $3^{\text {rd }}$ Ed). Boston: Allyn \& Bacon.

Johnson, B., \& Christensen, L. (2008). Educational research: quantitative, qualitative, and mix approaches ( $3^{\text {rd }}$ ed). Los Angles: Sage.

Kartadinata, S. (2009). Strategies in improving teacher quality in Indonesia. Retrieved June 15, 2010, from http://file.upi.edu/Direktori/

Kitchen, M., \& Jeurissen, M. (2006). Teacher research as TESOL professional development. New Zealand Journal of Teachers' Work, 3(1), 33-41.

Kompas online (2010, March 19). Lemah, kemampuan guru menulis karya ilmiah (The ability of teachers in writing scientific work is weak). Retrieved February 14, 2011, from http://edukasi.kompas.com/read/2010/03/19/04191796/Lemah.Kema mpuan.Guru.Menulis.Karya.IImiah.

Koshy, V. (2005). Action research for improving practice: a practical guide. London: Paul Chapman Publishing.

Kvale, S, (1996). Interviews: an introduction to qualitative research interviewing. Thousand Oaks, CA: Sage. 
Lancy, D. F. (1993). Qualitative Research in Education: An introduction to the major traditions. New York: Longman Publishing groups.

Levin, B. B., \& Rock, T. C. (2003). The effects of collaborative action research on pre-service and experienced teacher partners in professional development schools. Journal of Teacher Education, 54(2), 135-150.

Licklider, B. L. (1997). Breaking ranks: Changing the in-service institution. NASSP Bulletin, 8(1), 9-22.

Lim C.P., Pagram, J., \& Nastiti, H. (2009). Professional development goes east: examining changes in teachers' beliefs in four Indonesian schools. Proceedings of the $2^{\text {nd }}$ international conference of teaching and learning (p. 1-9). INTI University College Malaysia: Malaysia.

Manfra, M.M. (2009). Action Research: exploring the theoretical divide between practical and critical approaches. Journal of curriculum and instruction, 3(1), 32-46.

Massey, D. D., Allred, M., Baber, P., Lowe, J., Ormond, A., \& Weatherly, J. (2009). Teacher research: who is it for and what is the point? Journal of curriculum and instruction, 3(1), 47-61.

Mathew, J., \& Price, C. (2010). Coding: open coding. In Mills, A. J., Durepos, J., \& Wiebe, L (Eds). Encyclopedia of case study research. Long Angles: A Sage Reference Publication.

Mathew, J., \& Price, C. (2010). Coding: selective coding. In Mills, A. J., Durepos, J., \& Wiebe, L (Eds). Encyclopedia of case study research. Long Angles: Sage.

McKernan, J. (1996). Curriculum action research. New York: Routledge. 
McMahon, T. (1999). Is reflective practice synonymous with action research?. Educational action research, 7(1), 163-169.

McNiff , J., \& Whitehead, J. (2006). All you need to know about action research. London: Sage Publication.

Merriam, S. B. (1988). Case study research in education: a qualitative approach. San Francisco, California: Jossey-Bass.

Merriam, S. B. (2009).Qualitative research: a guide to design and implementation. San Fransisco, California: Jossey-Bass.

Mertler, C. A. 2009. Action research: teacher as researchers in the classroom. USA: Sage.

Mettetal, G (2002). Improving Teaching through Classroom Action Research. Essays on Teaching Excellence: Toward the Best in the Academy, 14, retrieved April 02, 2010, from http://academic.udayton.edu/FacDev/Newsletters/EssaysforTeachi ngExcellence/PODvo I14/tevol14n7.html

Mettetal, G. (2001). The What, Why and How of Classroom Action Research. The Journal of Scholarship of Teaching and Learning, 2 (1). Indiana University. Retrieved April 022010 from http://www.iupui.edu/ josot//VOL 2/NO 1/mettetal v2 n1.pdf.

Miles, M.B., \& Huberman, A.M. (1994). Qualitative data analysis (2nd ed.). Thousand Oaks, CA: Sage.

Mills, G.E. 2007. Action Research: a guide for the teacher researcher $\left(3^{\text {rd }}\right.$ ed). USA: Pearson Merrill Prentice Hall. 
Mohandas, R. (2004). Overview of Education for Sustainable Development (ESD) in Indonesia. Retrieved February 02, 2010, from www.ias.unu.edu .

MoNE. (2005). Profil Pendidik dan Tenaga Kependidikan di Indonesia (the profile of teachers and teaching forces in Indonesia). Jakarta: Indonesia.

MoNE. (2007). EFA Mid Decade Assessment: Sustaining EFA performance in Indonesia. Jakarta, Indonesia.

Neopolitan J.E.. (2000). What do teacher believe about action research as a mechanism for change? Paper presented at the annual meeting of the association teacher educators. February 152000 , Orlando Florida.

Noffke, S. E. (1992). The work and workplace of teachers in action research. Teaching and Teacher Education, 8(1), 15-29.

O'Connor, K., Greene, C., \& Anderson, P. (2006, 7 April). Action research: A tool for improving teacher quality and classroom practice. Paper presented at the American Educational Research Association Annual Meeting, San Francisco, CA.

O'Sullivan, M.C. (2002). Action research and the transfer of reflective approaches to in-service education and training (INSET) for unqualified and underqualified primary teachers in Namibia. Teaching and Teacher Education, 18(5), 523-539.

Osterman, K.E and Kottkamp, R.B. (1997). Reflective Practice for educators: improving schooling through professional development. California: Sage Publication. 
Perkins, A. (2001). Here it is, rough it may be: Basic computer for ESL. In J. Edge (Ed.), Action research (pp.13-19). Alexandria, VA: TESOL.

Pine, G. J. (2009). Teacher Action Research: Building knowledge and democracies. USA: Sage Publication, Inc.

Plattel, T. Hulshol, H, Ponte, P, Driel J.V., \& Verloop, N. (2010). Forming a collaboration action research partnership. Educational action research, 18(4). 429-451.

Raihani, (2007). Education reforms in Indonesia in the twenty-first century. International Education Journal, 8(1), 172-183.

Rayney, I. (2000). Action research and the English as a foreign language practitioner: time to take stock. Educational Action Research, 8(1), 65-90.

Reimer, K.M., \& Bruce, B. (1994). Building teacher-researcher collaboration: dilemmas and strategies. Educational action research, 2(2), 211-221.

Richard, J. C. (2008). Second language teacher education today. RELC Journal, 39(2), 158-177.

Richard, J.C., \& Lockhart . C. (1994)._Reflective teaching in second language classrooms. New York: Cambridge University Press.

Richards, J. C., \& Farrell, T. S C. (2005). Professional development for language: Strategies for teacher learning. New York: Cambridge University Press.

Rodgers, C. (2002). Defining reflection: Another look at John Dewey and reflective thinking. Teachers college record, 104(4), 842-866. 
Rosaen, C., \& Schram, P. (1997). Professional development for beginning teachers through practical inquiry. Educational Action Research, 5(2), 255-281.

Roza, W. (2008, 11-14 August). Pembinaan dan Pengembangan Komponen Kompetensi Pengembangan Profesi Guru SMA Negeri Sumbar Sangat Memprihatinkan (the supervision and development of competency component of teachers profession in West Sumatera was very concerned). Paper presented in National Education Symposium. Jakarta: Indonesia.

Sagor, R. 2009. Collaborative action research and school improvement: We can't have one without the other. JoCl, 3(1), 7-14.

Senese, J.C. (2000, April 24-28.). What are the conditions that sustain teacher research?. Prepared for session 18.16 at the American Education Research Association Meeting in New Orleans.

Setiawan, R. (2009, 29-30 June). The effectiveness of Teacher Training in Indonesia: A practice by Sampoerna Foundation Teacher Institute (SFTI). Paper presented at the German Institute for Adult Education. Bergisch Gladbach, Germany.

Slater, J. (2006). The Times Educational Supplement, No 4694, p. 12.

Smith, J.K. (2008). Interpretation. In Given, L.M (Eds). The SAGE Encyclopaedia of Qualitative Research Method. Long Angles: A Sage Reference Publication.

Smith, L.C. (2005). The impact of action research on teacher collaboration and professional growth. In Tedick, D.J. (Eds). Second language teacher education: international perspectives. USA: Lawrence Erlbaum Associates. 
Soedijarto. (2009). Some notes on the ideas and goals of Indonesia's National education system and the inconsistency of its implementation. A comparative analysis. JISSH, 2, 1-11.

Sowa, P.A. (2009). Understanding our learners and developing reflective practice: Conducting action research with English language learners. Teaching and Teacher Education (25), 1026-1032.

Stoll, L., Bolam, R., McMahon, A., Wallace, M., \& Thomas, S. (2006) Professional learning communities : a review of the literature. Journal of Educational Change (7), 221-258.

Sukarni, E.I., Winarni, D \& Nirmayanti , Y.T. (2009). Improving teachers professionalism through material development, information technology and classroom action research. Teflin Journal, 20(2), 212-231.

Sumintono, B. (2006). Decentralized centralism: school based management and practices at state secondary schools in Mataram, Lombok, Indonesia, Unpublished Doctoral Dissertation, Victoria University of Wellington, New Zealand.

Tafel, L. S., \& Fischer, J. C. (2001). Teacher action research and professional development : foundation for educational renewal. In Burnaford, G., Fischer, J., \& Hobson, D. (Eds). Teacher doing research: the power of action research through inquiry ( $2^{\text {nd }}$ ed). Mahwah: New Jersey.

Thorne, C., \& Qiang, W. (1996). Action research in language teacher education. ELT Journal. 5(3), 254-262.

Tinker Sachs, G. (2000). Teacher and researcher autonomy in action research. Prospect, 15(3), 35-51. 
Toenlioe. (2006). KTSP: kurikulum yang tidak sistematis (School-based curriculum ( $S B C$ ): unsystematic curriculum). Retrieved June 12, 2010, from http://www2.kompas.com/kompascetak/0611/13/humaniora/3094950.htm)

Tomal, D. R. (2003). Action research for educators. Lanham, MD: Scarecrow Press.

Vescio, V., Ross, D, Adams, A. (2008). A review of research on the impact of professional learning communities on teaching practice and student learning. Teaching and teacher education, (24), 80-91.

Vogrinc, J., \& Zuljan, M.V. (2009). Action research in schools: an important factor in teachers' professional development. Educational Studies,35(1), 53-63.

Volk, K.S. (2010). Action research as a sustainable endeavour for teachers: does initial training lead to further action. Action research, 8(3), 315-332.

Watkins, A. (2006). Teachers as researchers: so what exactly do teacherresearchers think about doing research. Support for learning, 21(1), 12-18.

Westwell, J. (2006). Sustaining teacher research: what support really makes a difference?. National teacher research panel, engaging teacher expertise. Retrieved April 8, 2010, from www.standards.dfes.gov.uk/ntrp.

Wicks, D. (2010). Coding: axial coding. In Mills, A. J., Durepos, J., \& Wiebe, $L$ (Eds). Encyclopedia of case study research. Long Angles: A Sage Reference Publication. 
Widoyoko, E.P. (2008). Penelitian tindakan kelas dan pengembangan profesi guru (classroom action research and the development of teacher profession). Retrieved 3 February, 2011, from http://www.docstoc.com/docs/21178358/Penelitian-Tindakan-Kelasdan-Pengembangan-Profesi-Guru.

Wigglesworth, G., \& Murray, D.E. (2007). Opening doors: teachers learning through collaborative research. Prospect, 2(1), (19-36).

World Bank. (2010). Transforming Indonesia's teaching force: volume I executive summary. Jakarta: Indonesia.

York-Barr,J, Sommers, W.A., Ghere, G.S. \& Montie, J. (2006). Reflective Practice to improve school: A practical guide for educators. California: Corwin Press.

Yulaelawati, E. (2002). National education reform in Indonesia: Milestones and strategies for the reform process. Retrieved June 14, 2010, from http://www.worldedreform.com/intercon/kedre9.htm.

Yuwono, G. (2005). English language teaching in decentralized Indonesia: voices from the less privileged schools. Paper presented at AARE 2005 International education research conference. Sydney: Australia.

Zainurrahman (2009). Teachers' perception and problems and schoolbased curriculum implementation: a research on school based curriculum implementation. Retrieved June 15, 2010, from www.http://zainurrahmans.wordpress.com.

Zamorski, B., \& Bulmer M, (2002). Teacher engagement in research as professional development. Pedagogy, Culture, \& Society, 10(2), 279-291. 
Zeichner, K.M. (2003). Teacher research as professional development for P-12 educators in the USA. Educational Action Research, 11(2), 301-25.

Zeichner, K.M., \& Liston, D.P. (1996). Reflective Teaching : an Introduction. Mawah, NJ: Lawrence Erlbaum.

Zeichner, K. (2009). Educational Action Research. In Schmuck, R. A. (Ed). Practical action research. USA: Corwin Press. 


\section{Appendices}

Appendix 1: interview guide

\section{Interview Guide for teachers \\ Interview Guide for teachers}

\section{Opening statement:}

Thank you very much for taking part in this research and for agreeing to be interviewed. The interview will last approximately one hour. The purpose of this interview is to get your reflections on any classroom action research projects you have been involved in since you participated in the 2005 workshop conducted by provincial Education office in Palu at 4-8 December 2005. In particular I am interested in learning about any problems or difficulties you had to face when doing research in your own classroom but also the kinds of support from colleagues or supervisors or your school principal which you found helpful. I share your professional interest in in teaching and have a deep interest in teacher research myself. Your experiences will be most valuable for designing future professional development training. It is important that any policy decision to encourage action research in classrooms takes into account how classroom teachers experience doing it. Your responses will be used for research purposes only and will remain confidential. I would like to record the interview, with your consent. 
Before we proceed, is there anything you would like to ask me?

(allow time for any questions and begin recording)

List of basic questions (additional questions may be asked in relation to the teacher's answers to the basic questions)

1. First I have some questions about your participation in the CAR workshop in 2005 !

Why did you volunteer to attend?

What did you hope to gain from the experience?

What do you remember as being the most valuable part of the workshop?

$\square$ What did not work for you?

$\square$ What else did you learn from the CAR workshop?

2. Now I would like your reflections on that first CAR project immediately following workshop?

What was the focus of your research? How did you select your topic? Did you collaborate with anyone in writing the proposal?

How successful was your project? 
What did you learn from it and has it helped your classroom practice?

What were difficulties or problem (if any)?

Any supports from principals, supervisors and colleagues?

What kinds of support they provided?

Who provided assistance when faced problems?

What did your students think about being involved in research?

3. Now I would like to hear about any later projects you might have been involved in since that first one following the workshop? If you have attempted another project please describe it

$\square \quad$ What were difficulties or problem (if any)? Any supports from principals, supervisors and colleagues?

What kinds of support they provided?

Who provided assistances when found problems?

4. What are your reflections now after 5 years on the benefits of action research for your practices as a teacher?

Is this something that you will carry on doing in the future? 
$\square$ How does it compare to other kinds of professional development training?

$\square$ Which aspect of carrying out a CAR project is of most benefit?

5. What recommendations would you like to give trainers of future CAR workshops and supervisors of future CAR projects? Recommendation on how to support teachers doing them Ideas of how these PD activity fit with other PD techniques 


\section{Appendix 2: Questionnaire}

\section{QUESTIONNAIRE FOR TEACHERS}

The purpose of this questionnaire is to obtain information about your experience as a teachers of English, your involvement in professional development workshops/trainings and in particular your involvement in Action Research (AR) workshops or projects. It is NOT an evaluation of you as a teacher. It is NOT a test. I am interested in gaining a picture of your professional background and experience. There are no right or wrong answers. All your responses are confidential.

Please answer the following questions about yourself.

1) Name:

2. Age: (please tick one of age group that mostly fits you)

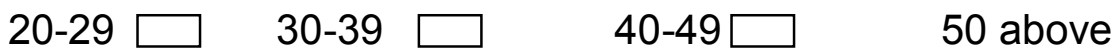

3) Gender: (please tick) $\square \quad$ Male $\square$ Female

4) Academic qualifications (please tick and complete):

A teachers' certificate in

A diploma in

A bachelor's degree in

A master's degree in 
A doctorate degree in

Other (please specify)

5) Number of years of teaching experience:

...years

6) School that you currently teach

in:

7) Please mentions any Professional Development (PD) workshops/training you have attended!

Year ......... :

Year

Year

8) Please write how many times have you attended CAR workshop/trainings? (times) and when did you attended? .... (year).

9) Can you write the titles of any AR projects you have done before? 


\section{Appendix 3: Guided Questions informal interview with the Education officer}

1. I would like you to think back to the pilot project of CAR for teachers conducted by Education office of Central Sulawesi in 2005-2006?

a. how the participants were recruited?

b. What parties were involved in this pilot (instructors, monitoring team)

c. What support was provided by the Education office to the teachers who did CAR project?

2. Have there been any follow-up programs specifically held by the Education office to sustain this CAR practice for teachers ? If yes, can you describe those programs?

Who designed them? Who ran them? Who participated in them? Where did they take place? Were they evaluated?

3. If there have not been any more CAR workshops, do you know if there were any specific reasons that this training has not been offered again?

4. What are the current programs that implemented by the Education office which facilitate teachers to grow professionally? What other kinds of PD have been developed or offered? 


\section{Appendix 4: Guided Questions Informal Interview with Workshop Instructor}

1. What is you professional interest in teacher training? Your background and experience in Education?

2. How did you structure the 2005 CAR workshop which was held by the Education office of Central Sulawesi? Do you still have an outline of the training day or copies of nay materials that you distributed to participants?

3. What were the key learning objectives of the workshop? Did you evaluate the workshop to ascertain what the teachers gain from the training? Would you have any copies of the workshop evaluation?

4. Would you also tell me, if you still remember, the selection process of teachers' proposal to get grants for conducting CAR project in their schools?

5. Are you still involved in training teachers to do classroom action research?

Can you elaborate any current workshop you have conducted? 
Appendix 5: Participant information sheets for teachers

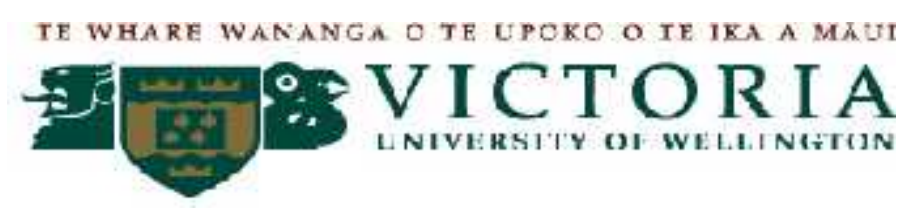

\section{Participant Information Sheets for Teachers}

Project title: : Investigation of problems, support, and benefits of conducting Classroom Action Research (CAR) with Secondary English Teachers at Palu city, Central Sulawesi, Indonesia

\section{Researcher: Mukrim Thamrin: School of Policy and Implementation, Victoria University of Wellington}

I am a student at Victoria University of Wellington, New Zealand, enrolled for a master degree at the School of Implementation and Policy, Education Faculty. I am conducting research for the purpose of my thesis. My research focuses on the potential of classroom action research (CAR) as a strategy for professional development. In particular, I am interested in discussing this issue with those English teachers who participated in the first CAR workshop which was held and funded by Central Sulawesi Education office in 2005-2005 and in particular wish to interview those teachers who went on to conduct a CAR project in their schools. The research questions address the perceived benefits of conducting CAR, what is required to sustain and support teachers in doing CAR and understanding the nature of any problems encountered while doing a CAR project.

I am contacting you as an English language teacher who took part in this first CAR workshop and would like to invite you to take part in my research. I would appreciate any assistance you can offer me and am most interested to learn more about your experiences of the workshop and doing classroom action research. This letter is an invitation to be part of my research and provides details of what the research involves. If you do agree to take part once you understand what your role would be , I will ask you to sign the attached consent form. 
Your participation would involve first a short semi-structured interview and questionnaire given by me about your teaching experience and involvement in a range of Professional Development programmes. It will take 15-20 minutes to complete.

Second, I would like to arrange a later time for an in-depth interview. At this interview, I would like to learn more about the workshop you attended and about any CAR projects you have been involved in. This interview will take no more than an hour and a half and will be recorded digitally if you consent. If you wish, you will be able to discontinue recording at any time during the interview. However, if you are not happy to be recorded, I will take notes to keep a record of our conversation. The complete transcript of the interview will be returned to you so that you make any necessary amendments to my record of the interview before I complete the analysis of all my data. I will conduct these interviews at a location convenient to you. We will discuss whether you prefer me to come to your work or home or if you would rather meet elsewhere.

This letter also is asking your permission to have access to relevant documents, if any, related to your participation in the workshop or your CAR pilot. I would like copies of any as workshop materials such as your action research proposal, and any reports you completed on your CAR projects. I would like to make a copy of them and I would then return the originals to you. I need to bring the copied version with me to Wellington where I will be conducting my data analysis and writing the thesis. All documents will be destroyed once the thesis is completed and deposited in the library. However, if you do not possess those documents anymore, I would like to ask your consent to access the copies that you submitted to the central Sulawesi Education Office. If you agree there is a consent form attached that you can sign which I can then take to the Education office.

I also offer you, if you wish, a summary report of this research after the thesis has been completed.

All your responses will be confidential. No one except myself and my thesis supervisor will have access to the information that you provide. All information that you provide will be stored in a locked cabinet for the duration of the project and will then be destroyed two years after the end of the project. Neither your name nor the name of your school will be used in any reporting of the research. Your participation is voluntary. You may withdraw information at any time without giving reasons or being disadvantaged. If you decide to withdraw, I would prefer that this decision 
is made before $31^{\text {st }}$ October 2010 , so that I can seek alternative participants.

Thank you very much for your time and for making this study possible. If you have any queries or wish to know more about the project, please contact me:

\author{
Mukrim Thamrin \\ JI.Padanjakaya Kel. Pengawu Palu Selatan, \\ Phone(0451) 462873
}

Email address: urhy_211@yahoo.com

or my supervisor:

Barbara Craig

School of Policy and Implementation

Faculty of Education Victoria University of Wellington,

Po Box. 17-310, Karori, Wellington 6147

New Zealand,

Phone +64 44635404

Email address: Barbara.Craig@vuw.ac.nz

The project has the approval of the Victoria University of Wellington Faculty of Education Ethic Committee. If you have any inquiries about ethical issues please contact Dr. Allison Kirkman, Victoria University of Wellington Human Ethic Committee (Allison.Kirkman@vuw.ac.nz).

Mukrim Thamrin

Signed: 


\section{Appendix 6: Sample of consent form}

Project title: : Investigation of problems, support, and benefits of conducting Classroom Action Research (CAR) with Secondary English Teachers at Palu city, Central Sulawesi, Indonesia

\section{Informed Consent Form for Teacher}

$\square$ I have had the project explained to me and I have read the ethics statements which I keep for my records.

I understand that agreeing to take part means that I am willing to be interviewed by the researcher.

I understand that I will have an opportunity to check the transcripts of the interviews before data analysis.

I agree to allow the researcher to access to documents relating to my CAR professional development and CAR projects.

I understand that any information that is collected or that I provide is confidential, and that no information that could lead to the identification of any individual will be disclosed in any reports on the project, or to any other party. All participants will be given pseudonyms. 
I also understand that my participation is voluntary, that I can choose not to participate in the project, and that I can withdraw at any stage of the project without being penalized or disadvantaged in any way.

I understand that the data I provide will not be used for any other purposes or released to others without my written consent and only used solely for the purpose of the writing the researcher's thesis, publication in academic or professional journals and dissemination at academic or professional conferences.

I understand that when this research is completed the information obtained will be destroyed two years after the end of the project.

I would like to receive a summary of this research when it is completed.

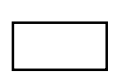

Yes No (please tick)

I agree to take part of in this research.

Signed:

Date:

Name of participant 
Appendix 7: Consent form of gaining document

Project title: : Investigation of problems, support, and benefits of conducting Classroom Action Research (CAR) with Secondary English Teachers at Palu city, Central Sulawesi, Indonesia

\section{Consent Form for Gaining the CAR Documents for Teachers}

I,$\ldots \ldots \ldots \ldots \ldots \ldots$, the undersigned below, allow Mr. Mukrim Thamrin (the researcher of this project) to access all my CAR documents relating to the 2005 workshop which I deposited in the Education Office of Central Sulawesi.

Signed

Name of Participant Date: 


\section{Appendix 8: Research inform to school principal}

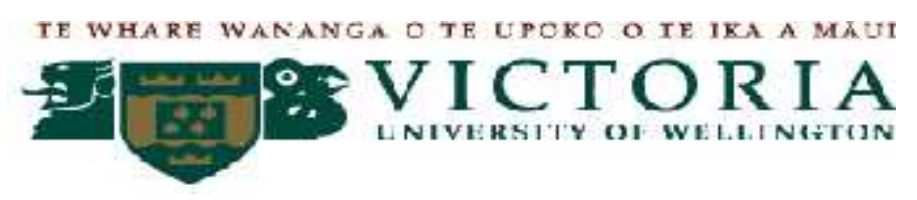

Research Inform to School Principal

To Whom It May Concern:

I am a student at Victoria University of Wellington, New Zealand, enrolled for a master degree at the School of Implementation and Policy, Education Faculty. I am conducting research for the purpose of my thesis. My research focuses on the potential of classroom action research (CAR) as a strategy for professional development. In particular, I am interested in discussing this issue the English teachers who participated in the first CAR workshop which was held and funded by Central Sulawesi Education office in 2005-2005 and went on to conduct CAR project in their schools. The research question address the perceived benefits of conducting CAR, what is required to sustain and support teachers in doing CAR and understanding the nature of any problems encountered while doing a CAR project. It is expected that the investigation will in particular benefit for teachers, schools and Education Office in facilitating and sustaining professional development through classroom action research for teachers.

In relation to this, I would like your consent to make contact with one of your teachers in your school. I will invite the teacher (s) to participate in my study by filling in a short questionnaire at our first meeting and then I will set up an in-depth interview with the teacher (s). To participate in this project, the teacher (s) will have to give his/her (their) consents by signing the consent form provided.

Your consent will valuable to make this project possible to do. Thank you for allow me to do study with your teacher (s) at your school. Should you have any queries or wish to know more about the project, please contact me 


\author{
Mukrim Thamrin \\ JI.Padanjakaya Kel. Pengawu Palu Selatan, \\ Phone(0451) 462873 \\ Email address: urhy 211@yahoo.com
}

or my supervisors:

Barbara Craig

School of Policy and Implementation

Faculty of Education Victoria University of Wellington,

Po Box. 17-310, Karori, Wellington 6147

New Zealand,

Phone +64 44635404

Email address: Barbara.Craig@vuw.ac.nz

The project has the approval of the Victoria University of Wellington Faculty of Education Ethic Committee. If you have any inquiries about ethical issues please contact Dr. Allison Kirkman, Victoria University of Wellington Human Ethic Committee (Allison.Kirkman@vuw.ac.nz). 


\section{Appendix 9: Letter of Information to the District Education Office}

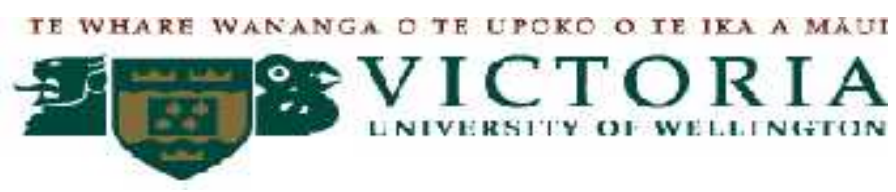

Letter of Information to the District Education Office

To Whom It May Concern:

I am a student at Victoria University of Wellington, New Zealand, enrolled for a master degree at the School of Implementation and Policy, Education Faculty. I am conducting research for the purpose of my thesis. My research focuses on the potential of classroom action research (CAR) as a strategy for professional development. In particular, I am interested in discussing this issue with the English teachers who participated in the first CAR workshop which was held and funded by Central Sulawesi Education office in 2005-2005 and who then went on to conduct CAR projects in their schools. The research questions address the perceived benefits of conducting CAR, what is required to sustain and support teachers in doing $C A R$ and understanding the nature of any problems encountered while doing a CAR project. It is expected that the investigation will in particular benefit teachers, schools and the Education Office in facilitating and sustaining professional development through classroom action research for teachers.

This study will involve interviewing several English teachers who are teaching in different schools in your area (names of the teachers are attached). I am seeking information about where those teachers are now teaching so that I can contact the school principals and ask their consent to approach a teacher in their school to ask them to participate in this study. I will of course require informed consent from those teachers before interviewing any of them. Their participation is entirely voluntarily and to indicate that they agree to participate, I have a consent form for them to sign. 
In relation to this, I would like to ask help from you to provide me the current place of employment of the above teachers who attended the pilot workshop as confirmed by the Central Sulawesi Education office. In addition to helping me locate these teachers, this letter is also asking your permission to visit schools in your area where the identified teachers as mentioned above who are now teaching.

Your consent will enable for me to conduct this study successfully. If you do grant me this permission I want to thank you very much for letting me conduct my research for my thesis with some English teachers in Palu city schools. If you have any queries or wish to know more about the project, please contact me:

\author{
Mukrim Thamrin \\ Jl.Padanjakaya Kel. Pengawu Palu Selatan, \\ Phone(0451) 462873 \\ Email address: urhy 211@yahoo.com
}

or my supervisor:

\title{
Barbara Craig
}

School of Policy and Implementation

Faculty of Education Victoria University of Wellington,

Po Box. 17-310, Karori, Wellington 6147

New Zealand,

Phone +64 44635404

Email address: Barbara.Craig@vuw.ac.nz

The project has the approval of the Victoria University of Wellington Faculty of Education Ethic Committee. If you have any inquiries about ethical issues please contact Dr. Allison Kirkman, Victoria University of Wellington Human Ethic Committee (Allison.Kirkman@vuw.ac.nz). 
Appendix 10: Letter to participate for educational officer

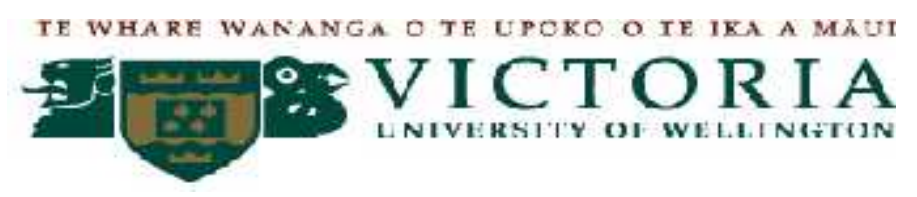

Invitation Letter to participate for Educational Officer

Project title: : Investigation of problems, supports, and benefits of conducting Classroom Action Research (CAR) of Secondary English Teachers at Palu city, Central Sulawesi, Indonesia

\section{Researcher: Mukrim Thamrin: School of Policy and Implementation, Victoria University of Wellington}

I am a student at Victoria University of Wellington, New Zealand, enrolled for a master degree at the School of Implementation and Policy, Education Faculty. I am conducting research for the purpose of my thesis. My research focuses on the potential of classroom action research (CAR) as a strategy for professional development. In particular, I am interested in discussing this issue the English teachers who participated in the first CAR workshop which was held and funded by Central Sulawesi Education office in 2005-2005 and went on to conduct CAR project in their schools. The research question address the perceived benefits of conducting CAR, what is required to sustain and support teachers in doing CAR and understanding the nature of any problems encountered while doing a CAR project.

I am contacting you as the one who in charge of conducting the first workshop and CAR project for the above English teachers and would like to invite you to take part in my research. I would appreciate any assistance you can offer me. I am most interested to find out the background information in relation to the execution of the pilot such as who involved in this pilot (participants, instructors, monitoring team) and the objective of this pilot in relation to the teachers' professional development. The university requires that all participants give the informed consent to take part in any research project. 
Your participation would be informal interview. This interview will be conducted once and will last not more than an hour and a half and be recorded digitally if you consent. If you wish, you will be able to discontinue recording at any time during the interview. The transcript of summary of the interview will be returned to you so that you make any necessary amendments to them before they are used in my thesis.

I also offer you, if you wish, a summary analysis of this research after the data analysis has been completed.

All your responses will be confidential. No one except myself will have access to the information that you provide. All information that you provide will be stored in a locked cabinet for the duration of the project and will then be destroyed two years after the end of the project. I would ensure that your name will not be used in any reporting of the research. Your participation is voluntary. You may withdraw information at any time without giving reasons or being disadvantaged. I would more prefer if you could withdraw from my study before $30^{\text {th }}$ September 2010 to allow me some time to find other prospective participants for this study.

Thank you very much for your time and for making this study possible. If you have any queries or wish to know more about the project, please contact me at: JI.Padanjakaya Kel. Pengawu Palu Selatan, Phone(0451) 462873, email: urhy 211@yahoo.com, or my supervisors, Barbara Craig, at School of Policy and Implementation Faculty of Education Victoria University of Wellington, Po Box. 17-310, Karori, Wellington 6147 New Zealand, Phone +64 44635404 . 
Appendix 11: Invitation letter to participate for workshop instructor

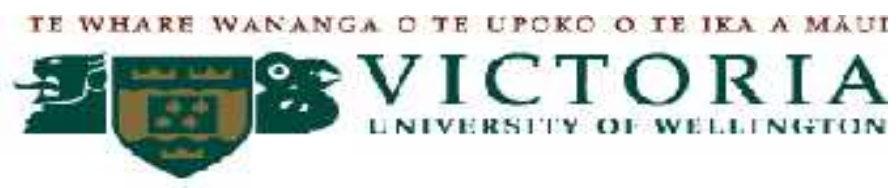

Invitation Letter to participate for Workshop Instructor

Project title: : Investigation of problems, supports, and benefits of conducting Classroom Action Research (CAR) of Secondary English Teachers at Palu city, Central Sulawesi, Indonesia

\section{Researcher: Mukrim Thamrin: School of Policy and Implementation, Victoria University of Wellington}

I am a student at Victoria University of Wellington, New Zealand, enrolled for a master degree at the School of Implementation and Policy, Education Faculty. I am conducting research for the purpose of my thesis. My research focuses on the potential of classroom action research (CAR) as a strategy for professional development. In particular, I am interested in discussing this issue the English teachers who participated in the first CAR workshop which was held and funded by Central Sulawesi Education office in 2005-2005 and went on to conduct CAR project in their schools. The research question address the perceived benefits of conducting CAR, what is required to sustain and support teachers in doing CAR and understanding the nature of any problems encountered while doing a CAR project.

I am contacting you as the one who involved in the pilot mentioned as above both as workshop instructor and evaluation team of those English teachers' proposal and report of CAR and would like to invite you to take part in my research. I would appreciate any assistance you can offer me and I am most interested to learn from you the background information in relation to CAR course materials that you have presented to the workshop participants. I am also interested to know from you the process of evaluating participants' action research proposal and CAR 
reports. The university requires that all participants give the informed consent to take part in any research project.

Your participation will involve informal interview with me. This interview will be conducted once and will last not more than an hour and a half and be recorded digitally if you consent. If you wish, you will be able to discontinue recording at any time during the interview. The transcript of summary of the interview will be returned to you so that you make any necessary amendments to them before they are used in my thesis.

This letter also is asking your permission to have access to relevant documents, if any, related to the materials of CAR course you have presented in this CAR workshop.

I also offer you, if you wish, a summary analysis of this research after the data analysis has been completed.

All your responses will be confidential. No one except myself will have access to the information that you provide. All information that you provide will be stored in a locked cabinet for the duration of the project and will then be destroyed two years after the end of the project. I will use pseudonym in any reporting of the research. Your participation is voluntary. You may withdraw information at any time without giving reasons or being disadvantaged. I would more prefer if you could withdraw from my study before $30^{\text {th }}$ September 2010 to allow me some time to find other prospective participants for this study.

Thank you very much for your time and for making this study possible. If you have any queries or wish to know more about the project, please contact me at: Jl.Padanjakaya Kel. Pengawu Palu Selatan, Phone(0451) 462873, email: urhy 211@yahoo.com, or my supervisors, Barbara Craig, at School of Policy and Implementation Faculty of Education Victoria University of Wellington, Po Box. 17-310, Karori, Wellington 6147 New Zealand, Phone +64 44635404. 
Appendix 12: Informed consent form for educational officers and workshop instructors

\section{INFORMED CONSENT FORM}

I have had the project explained to me and I have read the ethics statements which I keep for my records.

$\square$ I understand that agreeing to take part means that I am willing to be interviewed by the researcher.

I understand that I will have an opportunity to check the transcripts of the interviews before publication.

I understand that any information that is collected or I provide is confidential, and that no information that could lead to the identification of any individual will be disclosed in any reports on the project, or to any other party. All participants will be pseudonyms.

I also understand that my participation is voluntary, that I can choose not to participate in the project, and that I can withdraw at any stage of the project without being penalized or disadvantaged in any way.

I understand that the data I provide will not be for any other purpose or released to others without my written consent and only used solely for the purpose of the writing the researcher's thesis. 
I understand that when this research is completed the information obtained will be destroyed two years after the end of the project.

I understand that I will also receive a summary of interview transcription so I can review and make any necessary amendments before it will be used for thesis purpose.

I would like to receive a summary of this research when it is completed.

Yes No (please circle)

I agree to take part of in this research.

Signed:

Date:

Name of participant 
Appendix 13: Participant Information Sheets for Teachers (in Indonesian)

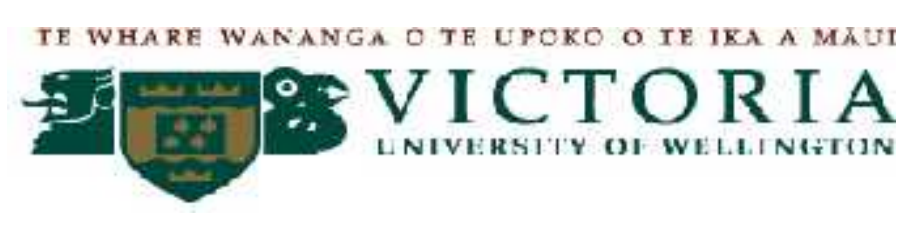

\section{Lembar Informasi Berpartisipasi dalam Studi}

Judul Project: : Investigation of problems, supports, and benefits of conducting Classroom Action Research (CAR) of Secondary English Teachers at Palu city, Central Sulawesi, Indonesia

\section{Peneliti: Mukrim Thamrin: School of Policy and Implementation, Victoria}

University of Wellington

Saya Mahasiswa Pasca Sarjana (S2) di Universitas Victoria, Wellington, New Zealand pada Fakultas Pendidikan di School of Implementation and policy. Saat ini saya sedang melakukan studi (penelitian) untuk penyelesaian pendidikan saya. Fokus studi saya adalah potensi Penelitian Tindakan Kelas (PTK) sebagai strategi untuk pengembangan profesionalime guru. Secara khusus, saya tertarik untuk meneliti guru-guru bahasa Inggris yang pernah berpartisipasi dalam workshop PTK dan melakukan proyek PTK yang diselenggarakan oleh Dinas Pendidikan Provinsi Sulawesi Tengah, 2005-2006. Masalah ingin diteliti adalah manfaat melakukan PTK, dukungan yang didapatkan guru, kelanjutan dari praktik PTK dan ingin memahami masalah yang dihadapi oleh guru-guru tersebut dalam melakukan PTK.

Saya menghubungi Anda karena sebelumnya Anda pernah mengikuti workshop PTK dan melakukan projek PTK seperti tersebut diatas, dan 
ingin mengundang Anda berpartisipasi dalam studi saya. Saya sangat menghargai segala bentuk bantuan Anda dan tertarik ingin mengetahui lebih dalam pengalaman Anda ketika melakukan PTK.

Partisipasi Anda meliputi wawancara pendek semi-terstruktur dimana saya akan menanyakan pertanyaan dalam kuesioner mengenai pengalaman mengajar dan keterlibatan dalam program pengembangan

profesionalisme. Wawancara ini hanya berlangsung sekitar 20 menit. Selanjutnya, saya juga ingin mengatur jadwal wawancara mendalam dengan Anda. Secara khusus, saya ingin mengetahui dan mempelajari dari Anda tentang workshop PTK dan proyek PTK yang pernah Anda ikuti dan lakukan.

Wawancara ini hanya sekali saja dan berlangsung tidak lebih dari 1.5 jam dan direkam atas izin Anda. Anda boleh menghentikan wawancara kapanpun Anda mau. Saya akan mengembalikan resume dari transkrip wawancara kita untuk Anda koreksi sebelum saya gunakan dalam thesis saya.

Surat ini juga meminta izin kepada Anda untuk mengakses dokumen yang berkenaan dengan PTK diatas. Jika ada, saya ingin memperoleh materi workshop dan proposal PTK dari Anda. Namun, jika Anda sudah tidak memilikinya, saya akan meminjamnya di kantor Dinas Pendidikan dan Pengajaran Prov.Sulawesi Tengah atas izin Anda.

Saya juga menawarkan pada Anda, resume dari analisis penelitian saya setelah semua data selesai dianalisa.

Semua jawaban/respon Anda dijamin kerahasiaannya. Tak seorangpun yang mempunyai akses untuk mendapatkan informasi yang Anda berikan kecuali saya sendiri. Semua informasi akan disimpan dilemari terkunci dan akan dimusnahkan 2 tahun setelah thesis ini selesai. Baik nama dan nama sekolah Anda tidak akan tercantum dalam laporan penelitian ini. Olehnya partisipasi Anda juga sukarela dan Anda dapat mengundurkan diri kapanpun Anda mau tanpa alasan ataupun dirugikan. Saya sangat menghargai jika Anda memberitahukan sebelumnya pada saya sebelum 
tanggal 30 september 2010 untuk memberikan waktu pada saya mencari narasumber lain.

Sebagai penghargaan saya kepada Anda, Saya ingin memberikan Anda hadiah berupa suvenir dari New Zealand dan juga koleksi e-book dengan topic pengajaran Bahasa Inggris dan PTK dalam bahasa Inggris.

Saya ingin menyampaikan banyak terima kasih atas waktu Anda sehingga penelitian ini bisa terlaksana. Jika Anda ingin lebih tahu lagi penelitian ini, silahkan menghubungi saya di alamat ini:

JI.Padanjakaya Kel. Pengawu Palu Selatan, TIp(0451) 462873, email: urhy 211@yahoo.com, atau pada supervisor saya, Barbara Craig, pada School of Policy and Implementation, Faculty of Education Victoria University of Wellington, Po Box. 17-310, Karori, Wellington 6147 New Zealand, Phone +64 44635404 .

Mukrim Thamrin

Tanda Tangan: 
Appendix 14: Consent form for participants (In Indonesian)

\section{Formulir Pernyataan Setuju Berpartisipasi dalam Studi}

Instruksi: Silahkan membubuhi tanda Vdalam kotak di bawah ini jika Anda setuju

dengan pernyataan-pernyataan di bawah ini.

Saya mengerti penelitian ini seperti yang dijelaskan dan telah membaca pernyataan yang berkenaan dengan etik untuk menjaga kerahasiaan saya.

Saya mengerti bahwa menyetujui berpartisipasi dalam studi ini berarti bahwa saya bersedia diwawancarai oleh peneliti, menjawab pertanyaan dari kuesioner dan menyediakan dokumen yang dibutuhkan oleh peneliti.

Saya mengerti bahwa saya mempunyai hak untuk mengecek transkripsi wawancara sebelum diterbitkan.

Saya mengerti bahwa segala informasi yang saya berikan adalah rahasia, dan tidak akan ada informasi yang diberikan atau dibuka ke pihak lain untuk kepentingan laporan ataupun penelitian lain. Semua nama peserta studi akan ditulis dengan nama samaran.

Saya juga mengerti bahwa keikutsertaan saya adalah sukarela, dan olehnya saya bisa mengundurkan diri dari penelitian ini tanpa dirugikan dalam bentuk apapun. 
Saya mengerti bahwa data yang berikan tidak akan digunakan untuk kepentingan lain ataupun diserahkan ke pihak lain tanpa persetujuan saya dan hanya digunakan semata-mata untuk kepentingan penelitian ini.

Saya mengerti pula informasi yang saya berikan akan dimusnahkan 2 tahun setelah penelitian ini berakhir.

Saya mengerti saya akan menerima resume dari trankripsi wawancara sehingga saya bisa meninjau kembali dan mengubahnya jika diperlukan sebelum digunakan dalam penulisan thesis.

Ya

Tidak (pilih salah satu)

Saya bersedia mengambil bagian dari penelitian ini.

Tanda Tangan

Tanggal:

Nama Peserta: 


\section{Appendix 15: Information letter for principals (in Indonesian)}

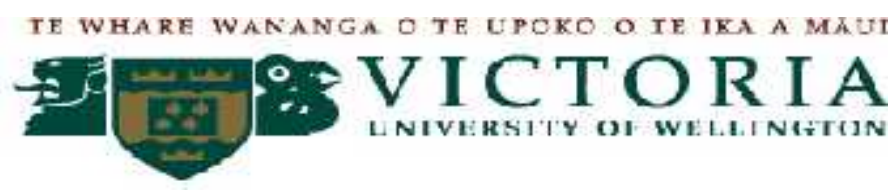

No

Perihal : Pemberitahuan penelitian

Lamp

Kepada Yth. Kepala SMU

$\mathrm{Di}$

Tempat.

Saya Mahasiswa Pasca Sarjana (S2) di Universitas Victoria, Wellington, New Zealand pada fakultas Pendidikan, School of Implementation and policy. Saat ini saya sedang melakukan studi (penelitian) untuk penyelesaian pendidikan saya. Fokus studi saya adalah potensi Penelitian Tindakan Kelas (PTK) sebagai strategi untuk pengembangan profesionalime guru. Secara khusus, saya tertarik untuk meneliti guru-guru bahasa Inggris yang pernah berpartisipasi dalam workshop PTK dan melakukan proyek PTK yg diselenggarakan oleh Dinas Pendidikan Provinsi Sulawesi Tengah, 2005-2010. Masalah ingin diteliti adalah manfaat melakukan PTK, dukungan yang didapatkan guru, kelanjutan dari praktik PTK dan ingin memahami masalah yang dihadapi oleh guru-guru tersebut dalam melakukan PTK. Di harapkan penelitian ini akan bermanfaat untuk guru, sekolah dan semua pihak yang terlibat dalam pengembangan guru dalam mendukung dan menunjang pengembangan profesionalisme guru melalui PTK. 
Sehubungan dengan hal ini, saya bermaksud meminta izin Bapak/lbu untuk melakukan penelitian dengan salah satu guru tersebut namanya :

Dengan guru tersebut saya akan melakukan wawancara singkat pada pertemuan pertama kami. Saya juga akan melakukan wawancara mendalam dengan beliau tidak lebih 1.5 jam mengenai pengalaman ketika melakukan PTK. Dalam hal ini, guru tersebut diatas bersedia berpartisipasi dalam penelitian ini dengan menandatangani surat persetujuan.

ljin Bapak/lbu sangat berharga sekali guna kelangsungan dari penelitian ini. Saya mengucapkan banyak terima kasih atas bantuan Bapak/lbu. Jika Bapak/lbu ingin lebih tahu lagi penelitian ini, silahkan menghubungi saya di alamat ini: JI.Padanjakaya Kel. Pengawu Palu Selatan, TIp(0451) 462873, email: urhy 211@yahoo.com, atau pada supervisor saya, Barbara Craig, pada School of Policy and Implementation, Faculty of Education Victoria University of Wellington, Po Box. 17-310, Karori, Wellington 6147 New Zealand, Phone +64 44635404

Mukrim Thamrin

Tanda Tangan: 
Appendix 16: Information letter for Palu city DIKJAR (in Indonesian)

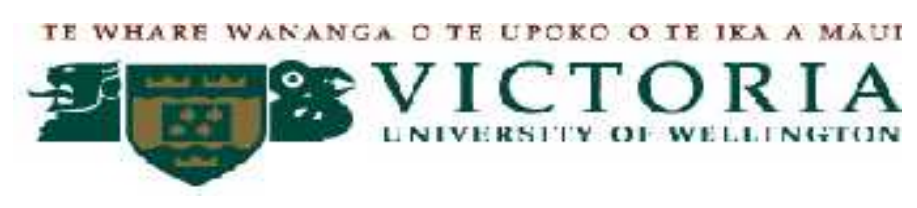

No

Perihal : Pemberitahuan penelitian

Lamp : :

Kepada Yth. Kepala Dikjar Kota Palu

$\mathrm{Di}$

Tempat.

Saya Mahasiswa Pasca Sarjana (S2) di Universitas Victoria, Wellington, New Zealand pada fakultas Pendidikan, School of Implementation and policy. Saat ini saya sedang melakukan studi (penelitian) untuk penyelesaian pendidikan saya. Fokus studi saya adalah potensi Penelitian Tindakan Kelas (PTK) sebagai strategi untuk pengembangan profesionalime guru. Secara khusus, saya tertarik untuk meneliti guru-guru bahasa Inggris yang pernah berpartisipasi dalam workshop PTK dan melakukan proyek PTK yg diselenggarakan oleh Dinas Pendidikan Provinsi Sulawesi Tengah, 2005-2010. Masalah ingin diteliti adalah manfaat melakukan PTK, dukungan yang didapatkan guru, kelanjutan dari praktik PTK dan ingin memahami masalah yang dihadapi oleh guru-guru tersebut dalam melakukan PTK. Di harapkan penelitian ini akan bermanfaat untuk guru, sekolah dan semua pihak yang terlibat dalam pengembangan guru dalam mendukung dan menunjang pengembangan profesionalisme guru melalui PTK. 
Penelitian ini akan melibatkan beberapa guru-guru bahasa Inggris di SMU Kota Palu (nama guru terlampir). Mereka akan berpartisipasi melalui wawancara serta memberikan beberapa dokumen yang relevan. Sebelum bertemu mereka, saya akan meminta izin dengan kepala sekolah.

Demikian halnya dengan guru-guru tersebut, mereka akan menandatangani surat persetujuan terlibat dalam penelitian sebelumnya jika berpartisipasi dalam penelitian ini.

Sehubungan dengan ini saya bermaksud meminta izin Bapak untuk melakukan penelitian dengan beberapa guru tersebut di atas. Izin Bapak sangat berharga sekali guna kelangsungan penelitian ini. Saya mengucapkan banyak terima kasih atas bantuan Bapak. Jika Bapak ingin lebih tahu lagi penelitian ini, silahkan menghubungi saya di alamat ini: JI.Padanjakaya Kel. Pengawu Palu Selatan, TIp(0451) 462873, email: urhy 211@yahoo.com, atau pada supervisor saya, Barbara Craig, pada School of Policy and Implementation, Faculty of Education Victoria University of Wellington, Po Box. 17-310, Karori, Wellington 6147 New Zealand, Telepon +64 44635404 .

Mukrim Thamrin

Tanda Tangan: 


\section{Appendix 16: Ethics approval letter}

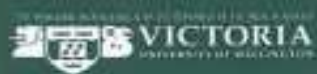

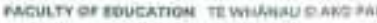

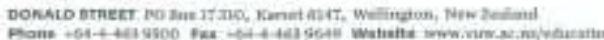

23 August 2010

Mukrim Thamrir

MEd Student

Victoria University of Wellington Faculty of Education

C.-School of Education Policy and Implementation

Donald Street

Wellington

Dear Mukrim

RE: Ethics application SEPI/2010/70: RM 17888

1 am pleased to advise you that your ethics application 'Enhancing Professional Development through Classroom Action Research (CAR) Projects: A case study of secondary English teachers in Palu city. Central Sulawesi, Indonesia", with the requested amendments, has been approved by the Victoria University of Westington Faculty of Education Ethics Committee. Please note that the approval for your research to commenoe is from the date of this letter

Best wishes for your research

Yours Sincerely

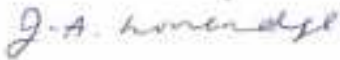

Dr Judith Loveridge

Co-Convenor

Victoria University of Weilington Faculty of Education Ethics Commattec 
